\title{
Morpho-molecular taxonomic studies reveal a high number of endophytic fungi from Magnolia candolli and M. garrettii in China and Thailand
}

\author{
de Silva NI ${ }^{1,2,6,7}$, Maharachchikumbura $\mathrm{SSN}^{4}$, Thambugala $\mathrm{KM}^{5,11}$, Bhat $\mathrm{DJ}^{8}$, \\ Karunarathna $\mathbf{S C}^{2,6,9,12,13}$, Tennakoon $\mathrm{DS}^{7,10}$, Phookamsak $\mathbf{R}^{2,6,9,12,13}$, \\ Jayawardena $\mathrm{RS}^{7,10}$, Lumyong $\mathrm{S}^{1,2,3}$, Hyde $\mathrm{KD}^{1,6,7,9,10}$
}

\author{
${ }^{1}$ Department of Biology, Faculty of Science, Chiang Mai University, Chiang Mai 50200 Thailand \\ ${ }^{2}$ Research Center of Microbial Diversity and Sustainable Utilization, Faculty of Science, Chiang Mai University, \\ Chiang Mai 50200 Thailand \\ ${ }^{3}$ Academy of Science, Royal Society of Thailand, Bangkok 10300, Thailand \\ ${ }^{4}$ School of Life Science and Technology, University of Electronic Science and Technology of China, Chengdu 611731, \\ People's Republic of China \\ ${ }^{5}$ Department of Plant and Molecular Biology, Faculty of Science, University of Kelaniya, Kelaniya, Sri Lanka \\ ${ }^{6}$ CAS Key Laboratory for Plant Biodiversity and Biogeography of East Asia (KLPB), Kunming Institute of Botany, \\ Chinese Academy of Science, Kunming 650201, Yunnan, People's Republic of China \\ ${ }^{7}$ Center of Excellence in Fungal Research, Mae Fah Luang University, Chiang Rai, 57100, Thailand \\ ${ }^{8}$ Formerly, Department of Botany, Goa University, Goa, India; No. 128/1-J, Azad Housing Society, Curca, P.O. Goa \\ Velha, 403108, India \\ ${ }^{9}$ East and Central Asia Regional Office, World Agroforestry Centre (ICRAF), Kunming 650201, Yunnan, P.R. China \\ ${ }^{10}$ School of Science, Mae Fah Luang University, Chiang Rai, 57100, Thailand \\ ${ }^{11}$ Genetics and Molecular Biology Unit, Faculty of Applied Sciences, University of Sri Jayewardenepura, \\ Gangodawila, Nugegoda, Sri Lanka \\ ${ }^{12}$ Honghe Center for Mountain Futures, Kunming Institute of Botany, Chinese Academy of Sciences, Honghe County, \\ Yunnan, People's Republic of China \\ ${ }^{13}$ Centre for Mountain Futures (CMF), Kunming Institute of Botany, Kunming 650201, Yunnan, People's Republic of \\ China
}

de Silva NI, Maharachchikumbura SSN, Thambugala KM, Bhat DJ, Karunarathna SC, Tennakoon DS, Phookamsak R, Jayawardena RS, Lumyong S, Hyde KD 2021 - Morphomolecular taxonomic studies reveal a high number of endophytic fungi from Magnolia candolli and M. garrettii in China and Thailand. Mycosphere 11(1), 163-237, Doi 10.5943/mycosphere/12/1/3

\begin{abstract}
Endophytic fungi are internal inhabitants of plant tissues that do not apparently cause harm to the host. Ecologically they provide a number of benefits to the plants by decreasing herbivory, increasing drought and disease resistance and enhancing the growth of plants. Endophytes have emerged as an exciting research topic as they have the potential to provide numerous metabolites with different biological activities. This study is focused on taxonomic novelties and new host or geographical records of endophytic fungi associated with Magnolia candolli collected from Yunnan Province, China and M. garrettii from Chiang Mai Province, Thailand. Magnolia plants are economically important and used in furniture, ornamental plants in gardens, temple trees, flowers for decorations and valuable medicine in China. In this study, 56 fungal endophytic isolates were obtained from Magnolia species, of which 54 belong to ascomycetes and two to basidiomycetes. The 56 endophytic fungal isolates were identified in 31 taxa that are distributed in eight orders, ten
\end{abstract}


families, 13 genera, including eight new species (Colletotrichum chiangmaiense, C. xishuangbannaense, Coprinellus magnolia, Diaporthe chinensis, Epicoccum endophyticum, Letendraea magnoliae, Nigrospora magnoliae and Pestalotiopsis endophytica) and 23 new host and or geographical records. The results indicate that members of Sordariomycetes are dominant groups of endophytic fungi in Magnolia candolli and M. garrettii. Considering the total fungal endophytic isolates from Magnolia candolli and M. garrettii, Sordariomycetes comprises the the highest number of isolates of 82\%, following Dothideomycetes 14\% and Agaricomycetes $4 \%$. Detailed morphological descriptions, micrographs and phylogenetic analyses are provided to show the placement of the novel taxa.

Key words - Ascomycota - Basidiomycota - Dothideomycetes - Multi-locus sequence analysis Sordariomycetes - Taxonomy

\section{Table of content}

Phylum Ascomycota Caval. Sm.

Class Dothideomycetes O.E. Erikss. \& Winka

Subclass Dothideomycetidae P.M. Kirk

Cladosporiales Abdollahz. \& Crous

Cladosporiaceae Nann.

Cladosporium Link

1. Cladosporium anthropophilum Sand. Den., Gené \& Wiederh., Persoonia 36: 290 (2016)

2. Cladosporium subuliforme Bensch, Crous \& U. Braun, Studies in Mycology 67: 77 (2010)

Subclass Pleosporomycetidae C.L. Schoch et al.

Pleosporales Luttr. ex M.E. Barr

Corynesporascaceae Sivan.

Corynespora Güssow

3. Corynespora cassiicola (Berk. \& M.A. Curtis) C.T. Wei, Mycological Papers 34: 5 (1950)

Didymellaceae Gruyter et al.

Epicoccum Link

4. Epicoccum endophyticum N.I. de Silva, Lumyong \& K.D. Hyde, sp. nov.

Leptosphaerulina McAlpine

5. Leptosphaerulina longiflori D.S. Tennakoon, C.H. Kuo \& K.D Hyde, Asian Journal of Mycology 2(1): 93 (2019)

Didymosphaeriaceae Munk

Letendraea Sacc.

6. Letendraea helminthicola (Berk. \& Broome) Weese, Transactions of the British Mycological Society 21(3-4): 277 (1938) [1937]

7. Letendraea magnoliae N.I. de Silva, Lumyong \& K.D. Hyde, sp. nov.

Class Sordariomycetes O.E. Erikss. \& Winka

Subclass Diaporthomycetidae Senan. et al.

Diaporthales Nannf.

Diaporthaceae Höhn. ex Wehm.

Diaporthe Nitschke

8. Diaporthe apiculata Y.H. Gao \& L. Cai, Systematics and Biodiversity Journal 14: 106 (2016) 
9. Diaporthe biconispora F. Huang, K.D. Hyde \& Hong Y. Li, Fungal Biology 119(5): 338 (2015)

10. Diaporthe chinensis N.I. de Silva, Lumyong \& K.D. Hyde, sp. nov.

11. Diaporthe velutina Y.H. Gao \& L. Cai, IMA Fungus 8(1): 178 (2017)

Subclass Hypocreomycetidae O.E. Erikss. \& Winka

Glomerellales Chadef. ex Re'blova' et al.

Glomerellaceae Locq.

Colletotrichum Corda,

12. Colletotrichum chiangmaiense N.I. de Silva, Lumyong \& K.D. Hyde, sp. nov.

13. Colletotrichum fructicola Prihast., L. Cai \& K.D. Hyde, Fungal Diversity 39: 96 (2009)

14. Colletotrichum gloeosporioides (Penz.) Penz. \& Sacc., Atti Reale Ist. Veneto di Scienze, Lettere ed arti. Series 6, 2: 670. 1884

15. Colletotrichum xishuangbannaense N.I. de Silva, Lumyong \& K.D. Hyde, sp. nov.

16. Colletotrichum karsti You L. Yang, Zuo Y. Liu, K.D. Hyde \& L. Cai [as 'karstii'], Cryptogamie, Mycologie 32(3): 241 (2011)

Subclass Xylariomycetidae O.E. Erikss. \& Winka

Amphisphaeriales D. Hawksw. \& O.E. Erikss.

Sporocadaceae Corda

Neopestalotiopsis Maharachch. et al.

17. Neopestalotiopsis chiangmaiensis Tibpromma \& K.D. Hyde, Fungal Diversity: [139] (2018b)

18. Neopestalotiopsis egyptiaca A.M. Ismail, G. Perrone \& Crous, Persoonia 35: 271 (2015)

19. Neopestalotiopsis keteleeria Y. Song, K.D. Hyde \& Yong Wang, Chiang Mai Journal of Science 41(4), 888 (2014a)

Pestalotiopsis Steyaert, Bull.

20. Pestalotiopsis endophytica N.I. de Silva, Lumyong \& K.D. Hyde, sp. nov.

21. Pestalotiopsis kenyana Maharachch., K.D. Hyde \& Crous, Studies in Mycology 79: 166 (2014b)

22. Pestalotiopsis neolitseae Ariyawansa \& K.D. Hyde, Mycosphere 9 (5): 1005 (2018)

Pseudopestalotiopsis Maharachch. et al.

23. Pseudopestalotiopsis ampullacea F. Liu \& L. Cai, Scientific Reports 7 (no. 866): 12 (2017)

24. Pseudopestalotiopsis simitheae (Yu Song, Tangthir., K.D. Hyde \& Y. Wang) Maharachch. \& K.D. Hyde, Mycological Progress 15(no. 22): 5 (2016)

Xylariales Nannf.

Apiosporaceae K.D. Hyde et al.

Nigrospora Zimm.

25. Nigrospora camelliae-sinensis Mei Wang \& L. Cai, Persoonia 39: 127 (2017)

26. Nigrospora chinensis Mei Wang \& L. Cai, Persoonia 39: 129 (2017)

27. Nigrospora magnoliae N.I. de Silva, Lumyong \& K.D. Hyde, sp. nov.

28. Nigrospora musae McLennan \& Hoëtte, Australian Institute of Science and Industry Research Bulletin 75: 15 (1933)

29. Nigrospora sphaerica (Sacc.) E.W. Mason, Transactions of the British Mycological Society 12(2-3): 158 (1927)

Phylum Basidiomycota Whittaker ex R.T. Moore

Class Agaricomycetes Doweld

Agaricales Underw 
Psathyrellaceae Locq.

Coprinellus P. Karst.

30. Coprinellus magnolia N.I. de Silva, Lumyong \& K.D. Hyde, sp. nov.

\author{
Polyporales Gäum. \\ Phanerochaetaceae Jülich \\ Phanerina Miettinen
}

31. Phanerina mellea (Berk. \& Broome) Miettinen, MycoKeys 17: 22 (2016)

\title{
Introduction
}

Over the past decade, endophytes have emerged as a compelling research topic as they are considered as the hidden component of fungal diversity that have the potential to produce metabolites with different kinds of biological activities (Huang et al. 2009, Ek-Ramos et al. 2013, Zheng et al. 2016, de Silva et al. 2019a, Rashmi et al. 2019). De Bary (1886) introduced the term 'endophytes' as any organism inhabiting a living plant tissue. Petrini (1991) stated "endophytes" as "all organisms inhabiting plant organs at some time in their life that can colonize internal plant tissues without causing apparent harm to the host". The universal presence of endophytes in diverse flora is facilitated by their asymptomatic colonization of various above and below ground tissues of liverworts, mosses, ferns and spermatophytes (Potshangbam et al. 2017, de Silva et al. 2019a, Rashmi et al. 2019). Fungal endophytes are symbiont in natural flora (Rodriguez et al. 2009, Rashmi et al. 2019). These mycobionts ecologically benefit their host plants by increasing drought and disease resistance and enhancing growth (Rodriguez et al. 2009, de Silva et al. 2019a, Rashmi et al. 2019). Arnold et al. (2003) showed that endophytic fungi (Colletotrichum sp., Fusarium sp., Nectria sp. and Xylaria sp.) significantly decreased both leaf necrosis and leaf mortality caused by a major pathogen, Phytophthora in host plant Theobroma cacao. This could be due to creating a barrier by endophytes that prevents pathogenic microorganisms from colonizing the same host plant (Bamisile et al. 2018). In another study by Zhang et al. (2017), greenhouse experiments were conducted to assess the ability of drought tolerance of dark septate endophytes in sorghum seedlings (Sorghum bicolor). Endophytic Exophiala pisciphila isolated from the roots of sorghum was used as the inoculum. Exophiala pisciphila inoculated sorghum seedlings showed a greater growth performance, photosynthetic capacity and secondary metabolism as compared to noninoculated seedlings under drought-stressed conditions (Zhang et al. 2017). These critical findings can be beneficial to optimize the harvest of crops and utilize fungal endophytes for pest and disease management programs (Bamisile et al. 2018). Endophytes can also serve as storehouse of bioactive secondary metabolites, such as alkaloids, saponins, tannins, phenolic acids, steroids, quinones and terpenoids (Gouda et al. 2016, Bamisile et al. 2018) and consist of important properties such as insect antagonist, antimicrobial and anticancer properties (Bamisile et al. 2018). Endophytes can be referred to as biofertilizers because they serve as plant growth promoters that facilitate nutrient uptake through plant roots and also insect-derived transformation of nitrogen to plants (Bamisile et al. 2018).

The number of fungal endophytes has been estimated at $7 \%$ of the 1.5 million species of total fungi (Hawksworth 2000, Chowdhary \& Kaushik 2015, Tibpromma et al. 2018a). Hawksworth \& Lucking (2017) replaced previous estimates of global fungal species richness of 1.5 million to an updated range of 2.2 to 3.8 million. Hyde et al. (2020a) have stated that the estimated fungal species number can be ranging from 0.5 to 13.2 million. This recent estimate might increase the number of endophytic fungi associated with plants. It is suggested that a single tropical leaf may harbour approximately 90 endophytic species, and 50 distinct genera in a grassland species (PorrasAlfaro et al. 2008, Rashmi et al. 2019). The diversity of endophytes inhabiting approximately 300,000 plant species on earth is roughly estimated as about one million taxa based on 1:4 or 1:5 fungi per host (Rashmi et al. 2019). The diversity of endophytes can also be influenced by the sample size and geographical location (Walther \& Moore 2005, Rashmi et al. 2019). Sample size can be determined by the number of asymptomatic leaves (or twigs or any relevent substrate) 
selected for the isolation of endophytes. In general, sample size can be increased by selecting leaves from different individual plants from the same host in the same geographical location and or different geographical location. Endophytic fungal diversity in various geographical locations had revealed a correlation with environmental parameters (temperature and rainfall) (Zimmerman \& Vitousek 2012, Rashmi et al. 2019). Small sample size from a particular host plant species in one geographical location might result in low endophytic diversity compared to a larger sample size of the same host plant species from different geographical locations (Rashmi et al. 2019). A comprehensive study by López-González et al. (2017) evaluated the effect of leaf age on the colonization frequency, species richness and diversity of the endophytic community of foliar fungal endophytes associated with lima bean plants. They showed that the richness and diversity of the foliar endophytic fungal community increased with the age of the leaves of lima bean under natural conditions. These facts reported that the diversity of endophytic fungal communities could be varied with distinct geographic locations, hosts and different sampling strategies.

In general, this diverse and polyphyletic group of endophytic microorganisms are classified into two groups, the clavicipitaceous (C) and the non-clavicipitaceous (NC) based on different criteria including, evolutionary relatedness, taxonomy, host plant range and ecological functions of fungi (Rodriguez et al. 2009, Santangelo et al. 2015, de Silva et al. 2019a). Clavicipitaceous endophytes (family Clavicipitaceae), i.e. Atkinsonella, Balansia, Balansiopsis, Echinodothis, Epichloe, Myriogenospora, Neotyphodium and Parepichloe species are mutualists that rely on plants in family Poaceae throughout their fungal life cycle (Rodriguez et al. 2009, Hardoim et al. 2015, de Silva et al. 2016, 2019a). Non-clavicipitaceous endophytes, i.e. Colletotrichum sp., Fusarium sp., Phomopsis sp., and Xylaria sp. occur in most terrestrial plants and might not inhabit for their entire life cycle inside the host (Petrini et al. 1992, Promputtha et al. 2005, 2007, Rodriguez et al. 2009, Jayawardena et al. 2016, de Silva et al. 2016, 2019a). Non-clavicipitaceous endophytes might be able to switch their life mode between pathogenic and saprobic when environmental conditions become unfavourable to the host (Promputtha et al. 2005, 2007, Delaye et al. 2013, de Silva et al. 2016, 2019a).

Identification of endophytes is mainly based on cultural procedures through different in vitro techniques (Promputtha et al. 2005, Wang et al. 2005, Ko et al. 2011, de Silva et al. 2019a). Most of the studies have conducted surface sterilization of fresh, asymptomatic plant tissues using ethanol, $\mathrm{NaClO}$ solution and sterile distilled water. At the same time, isolation of fungi was done on different artificial media (water agar (WA), potato dextrose agar (PDA)) (Promputtha et al. 2005, de Silva et al. 2019a). Molecular techniques advance the identification and classification of endophytes that were initially based on the cultural approach (Lacap et al. 2003, Promputtha et al. 2005, Ko et al. 2011, Doilom et al. 2017). DNA sequence data is a reliable molecular tool to identify sporulating and non-sporulating endophytes up to species level (Lacap et al. 2003, Promputtha et al. 2005, 2007, Doilom et al. 2017, Tibpromma et al. 2018a).

Magnoliaceae is an ancient and important group of flowering plants that is widely distributed in temperate and tropical South East and East Asia and One of the largest genera in Magnoliaceae is Magnolia that has early divergent flowering plants, bearing a number of large odoriferous flowers with chamber blossoms (Nooteboom \& Chalermglin 2009, Wang et al. 2017a). Magnolia plant species are important for furniture making (e.g. wood of Magnolia champaca) and as a valuable drug in China (e.g. Magnolia officinalis) (Nooteboom \& Chalermglin 2009). Besides, many Magnolia species and their hybrids are cultivated as ornaments in gardens, as temple trees, and the flowers are used for decorations (Nooteboom \& Chalermglin 2009). Nevertheless, Magnolia habitats have been badly degraded and fragmented due to heavy habitat destruction in the past, resulting in most (sub) populations being isolated from each other (Wang et al. 2017a). Therefore, it is important to explore the diversity of endophytes from tropical floras that are facing deforestation before their values could be permanently disappeared from nature (Bamisile et al. 2018). Few previous studies have investigated the diversity of endophytic communities from fresh leaves of Magnolia garrettii in Thailand based on ITS sequence data (Promputtha et al. 2005, 2007, 
2010). In this study, we present taxonomic novelties of fungal endophytes on Magnolia candolli Yunnan Province, China and M. garrettii in Chiang Mai Province, Thailand.

\section{Materials \& Methods}

Fresh leaves of Magnolia candolli were collected in Xishuangbanna Tropical Botanical Garden, Yunnan Province, China in April 2017 while fresh leaves of M. garrettii were collected in Chiang Mai, Thailand in September 2017. The leaves were kept at $4^{\circ} \mathrm{C}$ in sterile polyethene bags until they are processed in the laboratory. Isolation of endophytes was done according to the methods described by Promputtha et al. (2007) with some modifications. Leaves were first washed using tap water and cut into small pieces $\left(5 \times 5 \mathrm{~mm}^{2}\right)$. The cut pieces were soaked in distilled water for 1 minute and surface sterilized by dipping in $70 \%$ alcohol, followed by $2 \% \mathrm{NaOCl}$ for $30 \mathrm{~s}$. The pieces of leaves were washed thoroughly with sterile distilled water, air dried and plated on PDA. The PDA plates were incubated in ambient light at $25^{\circ} \mathrm{C}$. Growing hyphal tips from the leaf pieces were aseptically transferred to fresh PDA plates and incubated in ambient light at $25^{\circ} \mathrm{C}$. Finally, the fungi were isolated into pure culture and grouped according to their culture morphology.

One month old cultures on PDA and or WA were used to prepare dry fungal cultures. A solution was prepared by adding $2 \mathrm{~g}$ of agar powder into $200 \mathrm{ml}$ of distilled water containing $10 \mathrm{ml}$ of Glycerol. The solution was heated until the agar melted and kept for 5 to 10 minutes to cool. The solution was then poured on the fungal culture (removed from the original Petri plate and placed on an aseptic surface) and kept to air dry at room temperature $\left(25^{\circ} \mathrm{C}\right)$.

The specimens (dried cultures) cited in this paper were deposited at the Mae Fah Luang University Herbarium (Herb. MFLU), Chiang Rai, Thailand. The living fungal cultures recovered in this study were deposited at Mae Fah Luang University Culture Collection (MFLUCC) and Kunming Institute of Botany Culture Collection (KUMCC). Faces of Fungi numbers and Index Fungorum numbers were registered as described in Jayasiri et al. (2015) and Index Fungorum (2021), respectively.

\section{DNA extraction and PCR amplification}

One-week old pure cultures on PDA were used for DNA extraction (Dissanayake et al. 2020). The mycelia was scraped off from pure cultures and genomic DNA was extracted using a Biospin fungus genomic DNA kit (BioFlux ${ }^{\circledR}$, P.R. China) following the manufacturer's protocol. DNA was kept at $4{ }^{\circ} \mathrm{C}$ for DNA amplification and maintained at $-20^{\circ} \mathrm{C}$ for long term storage.

Polymerase chain reaction (PCR) was used to amplify partial gene regions of Internal Transcribed Spacers (ITS) and 28S ribosomal RNA (LSU), 18S ribosomal RNA (SSU), RNA polymerase II second largest subunit (RPB2), $\beta$-tubulin (tub2), Actin (ACT), Glyceraldehyde-3Phosphate Dehydrogenase (GADPH), Chitin synthase 1 (CHS-1), Calmodulin (CAL) and Translation Elongation Factor 1-alpha (tef1) where appropriate using primers as shown in Table 1. The final volume of the PCR reaction was $25 \mu \mathrm{l}$, containing $1 \mu \mathrm{l}$ of DNA template, $1 \mu \mathrm{l}$ of each forward and reward primers, $12.5 \mu \mathrm{l}$ of $2 \times$ Easy Taq PCR SuperMix (a mixture of EasyTaq TM DNA Polymerase, dNTPs, and optimized buffer, Beijing TransGen Biotech Co., Ltd., Beijing, P.R. China) and $9.5 \mu \mathrm{l}$ of $\mathrm{ddH}_{2} \mathrm{O}$. Amplification of PCR reactions were performed following $\mathrm{Li}$ et al. (2020) for ITS, LSU, SSU, tef1, RPB2, tub2, Gomes et al. (2013) for CAL and Weir et al. (2012) for ACT, GADPH, CHS-1. PCR purification and sequencing of amplified PCR products were carried out at Shanghai Sangon Biological Engineering Technology \& Services Co., Ltd, P.R. China.

Table 1 Details of genes/loci with PCR primers and references

\begin{tabular}{|l|l|l|}
\hline Loci & Primer pairs (Forward/Reverse) & References \\
\hline LSU & $\begin{array}{l}\text { LROR 5'-ACCCGCTGAACTTAAGC-3' } \\
\text { LR5 5'-ATCCTGAGGGAAACTTC-3' }\end{array}$ & Vilgalys \& Hester (1990) \\
\hline ITS & $\begin{array}{l}\text { ITS5 5'-GGAAGTAAAAGTCGTAACAAGG-3' } \\
\text { ITS4 5'-TCCTCCGCTTATTGATATGC-3' }\end{array}$ & White et al. (1990) \\
\hline
\end{tabular}


Table 1 Continued.

\begin{tabular}{|c|c|c|}
\hline Loci & Primer pairs (Forward/Reverse) & References \\
\hline SSU & $\begin{array}{l}\text { NS1 5'-GTAGTCATATGCTTGTCTC-3' } \\
\text { NS4 5'-CTTCCGTCAATTCCTTTAAG-3' }\end{array}$ & White et al. (1990) \\
\hline tefl & $\begin{array}{l}\text { 983F 5'-GCY CCY GGH CAY CGT GAY TTY AT-3' } \\
\text { 2218R 5'-AT GAC ACC RAC RGC RAC RGT YTG-3' } \\
\text { 728F 5'-CAT CGA GAA GTT CGA GAA GG-3' } \\
\text { 986R 5'-TAC TTG AAG GAA CCC TTA C-3' } \\
\text { 526F 5'-GTCGTYGTYATY GGHCAYGT-3' } \\
\text { 1567R 5'-ACHGTRCCRATACCACCRATCTT-3' }\end{array}$ & $\begin{array}{l}\text { Rehner (2001) } \\
\text { Carbone \& Kohn (1999) } \\
\text { Rehner (2001) }\end{array}$ \\
\hline RPB2 & $\begin{array}{l}\text { fRPB2-5f 5'-GGG GWG AYC AGA AGA AGG C-3' } \\
\text { fRPB2-7cR 5'-GGG GWG AYC AGA AGA AGG C-3' }\end{array}$ & Liu et al. (1999) \\
\hline CAL & $\begin{array}{l}\text { 228F 5'-GAG TTC AAG GAG GCC TTC TCC C-3' } \\
\text { 737R 5'-CAT CTT TCT GGC CAT CAT GG-3' }\end{array}$ & Carbone \& Kohn (1999) \\
\hline tub2 & $\begin{array}{l}\text { BT2a 5'-GGTAACCAAATCGGTGCTGCTTTC-3' } \\
\text { BT2b 5'-ACCCTCAGTGTAGTGACCCTTGGC-3' } \\
\text { T1 5'-AAC ATG CGT GAG ATT GTA AGT-3' } \\
\text { T2 5'-TAG TGA CCC TTG GCC CAG TTG-3' }\end{array}$ & $\begin{array}{l}\text { Glass \& Donaldson (1995) } \\
\text { O’Donnell \& Cigelnik (1997) }\end{array}$ \\
\hline ACT & $\begin{array}{l}\text { 512F 5'-ATG TGC AAG GCC GGT TTC GC-3' } \\
\text { 783R 5'-TAC GAG TCC TTC TGG CCC AT-3' }\end{array}$ & Carbone \& Kohn (1999) \\
\hline CHS-1 & $\begin{array}{l}\text { 79F 5'-TGG GGC AAG GAT GCT TGG AAG AAG-3' } \\
\text { 354R 5'-TGG AAG AAC CAT CTG TGA GAG TTG-3' }\end{array}$ & Carbone \& Kohn (1999) \\
\hline GADPH & $\begin{array}{l}\text { Gpd1 5'-ATT GGC CGC ATC GTC TTC-3' } \\
\text { Gpd2 5'-CCC ACT CGT TGT CGT ACC-3' } \\
\text { GDF 5'-GCC GTC AAC GAC CCC TTC ATT GA-3' } \\
\text { GDR 5'-GGG TGG AGT CGT ACT TGA GCA TGT-3' }\end{array}$ & $\begin{array}{l}\text { Myllys et al. (2002) } \\
\text { Templeton et al. (1992) }\end{array}$ \\
\hline
\end{tabular}

Newly generated nucleotide sequences were deposited in GenBank and accession numbers were mentioned in relevant entries. Sequences of the individual loci were aligned with MAFFT v. 7 online version (Yamada et al. 2016) using default settings. BioEdit v. 7.0.5.2 (Hall 1999) software was used to refine the alignments manually where necessary and to exclude incomplete portions at the ends of the sequences before the analyses.

\section{Phylogenetic analyses}

Maximum likelihood analysis was performed with RAxML GUI v. 1.3 (Silvestro \& Michalak 2012) and maximum parsimony analysis was done with PAUP (Phylogenetic Analysis Using Parsimony) v. 4.0b10 (Swofford 2002). Evolutionary models for phylogenetic analyses were selected independently for each locus using MrModeltest v. 3.7 (Posada \& Crandall 1998) under the Akaike Information Criterion (AIC). Parameters for maximum likelihood were set to rapid bootstrapping and the analysis carried out using 1000 replicates using the GTR + GAMMA model of nucleotide substitution. Bayesian analysis was conducted with MrBayes v. 3.1.2 (Huelsenbeck \& Ronqvist 2001). Parameters of Bayesian analysis in MrBayes v. 3.2; markov chains were run for 1 000000 generations and trees were sampled every 100th generations (printfreq $=100$ ) and 10000 trees were obtained. Initial trees were discarded (20\% burn-in value) and remaining trees were used to evaluate posterior probabilities (PP) in the majority rule consensus tree. Parameters for maximum likelihood were set to rapid bootstrapping and the analysis carried out using 1000 replicates using the GTR + GAMMA model of nucleotide substitution. Maximum parsimony was run with the heuristic search option, random taxon addition, tree bisection-reconnection (TBR) for the branch swapping algorithm and 1000 random sequence additions, with maxtrees set at 1000 . Gaps were treated as missing data. Tree Length [TL], Consistency Index [CI], Retention Index [RI], Relative Consistency Index [RC] and Homoplasy Index [HI] were calculated for the most parsimonious tree. Phylograms were visualized with FigTree v1.4.0 (Rambaut 2012) and annotated in Microsoft PowerPoint (2010). We conducted above two or 3 different analyses to obtain phylogenetic support and discussed results in respective entries. 


\section{Genealogical concordance phylogenetic species recognition analysis}

Two new species of Colletotrichum and their most closely related species were analysed using the GCPSR model. A pairwise homoplasy index (PHI) (Philippe \& Bryant 2006) test was performed in SplitsTree4 (Huson 1998, Huson \& Bryant 2006) as described by Quaedvlieg et al. (2014), in order to determine the recombination level within phylogenetically closely related species using a five-locus concatenated dataset for Two new species of Colletotrichum. If the pairwise homoplasy index is below a 0.05 threshold $\left(\Phi_{\mathrm{W}}<0.05\right)$, it indicated that there is significant recombination present in the dataset. The relationships between closely related species were visualised by constructing a split graph, using both the LogDet transformation and splits decomposition options (Figs 23, 26).

\section{Results}

Phylum Ascomycota Caval. Sm.

Class Dothideomycetes O.E. Erikss. \& Winka

Subclass Dothideomycetidae P.M. Kirk

Cladosporiales Abdollahz. \& Crous

Cladosporiaceae Nann.

The family includes saprobic, pathogenic or endophytic and pathogenic species that are involved in plant, human and animal diseases (Hyde et al. 2013). Cladosporiaceae comprises nine genera (Hongsanan et al. 2020). The asexual morph of Cladosporium is characterized by solitary to fasciculate conidiophores containing unbranched or branched acropetal conidial chains (SandovalDenis et al. 2016). The sexual morph is characterized by pseudothecial ascomata, 8 -spored obovoid to subcylindrical asci, and hyaline, obovoid to ellipsoid ascospores (Schubert et al. 2007, SandovalDenis et al. 2016).

\section{Cladosporium Link}

Cladosporium consists 170 species that are recognized as true Cladosporium in a monographic treatment (Bensch et al. 2018), with a worldwide distribution and isolated from a wide range of substrates (Bensch et al. 2012, 2015, Crous et al. 2014, Sandoval-Denis et al. 2016). Index Fungorum (2021) lists 855 epithets of Cladosporium. Species of Cladosporium are saprobes, endophytes and pathogens causing leaf spots on Capsicum annuum, Populus tremuloides, Quercus robur, Yucca elephantipes, or leaf lesions on Iris sp. as well as they are hyperparasites on other fungi (Bensch et al. 2012, Sandoval-Denis et al. 2016). There are three species complexes in Cladosporium mainly based on morphology; Cladosporium cladosporioides, $C$. herbarum and $C$. sphaerospermum species complexes (Bensch et al. 2010, 2018, Sandoval-Denis et al. 2016). Schubert et al. (2007) have performed comprehensive molecular analyses for the C. herbarum complex based on five genes, viz., rDNA ITS, ACT, CAL, tefl and histone. However, recent studies have used multigene DNA analysis employing three gene regions (ITS, ACT, tefl) and morphological studies to establish the identity and clarify of the taxonomic status of Cladosporium (Bensch et al. 2010, Sandoval-Denis et al. 2016). The Cladosporium cladosporioides complex includes a large group of species characterized by unbranched or branched, almost cylindrical conidiophores, bearing ovoid to ellipsoidal intercalary and terminal conidia, smooth or rarely showing fine ornamentation (Bensch et al. 2012, Sandoval-Denis et al. 2016). In this study, we identify Cladosporium anthropophilum and $C$. subuliforme as endophytes for the first time from healthy leaves of Magnolia candolli in Yunnan Province, China.

Cladosporium anthropophilum Sand.-Den., Gené \& Wiederh., Persoonia 36: 290 (2016) Fig. 2 Index Fungorum number: IF815334; Facesoffungi number: FoF06275

Endophytic in fresh leaves of Magnolia candolli. Colonies on PDA white aerial mycelia and grey mycelia on pine needles. Mycelia superficial and immersed composed of septate, branched, 2$3 \mu \mathrm{m}$ wide, hyaline, with smooth and thick-walled hyphae. Sexual morph: Undetermined. Asexual 
morph: Hyphomycetous sporulated on PDA. Conidiophores $20-60 \times 2-4 \mu \mathrm{m}(\bar{x}=30 \times 3 \mu \mathrm{m})$, hyaline, erect, cylindrical, septate with a thickened wall. Conidiogenous cells inconspicuous. Conidia $4-10 \times 3-5 \mu \mathrm{m}(\bar{x}=7 \times 4 \mu \mathrm{m})$, hyaline, ellipsoidal to subcylindrical, solitary, aseptate, smooth and tapering towards both ends of conidia.

Culture characteristics - Colonies on PDA reaching $30 \mathrm{~mm}$ diameter after 7 days at $25^{\circ} \mathrm{C}$, colonies circular, margin wavy, fluffy appearance in the middle and on pine needles, colony from above: greyish white and; reverse: dark grey centre and grey margin.

Material examined - CHINA, Yunnan Province, Xishuangbanna, healthy leaves of Magnolia candolli (Magnoliaceae), 26 April 2017, N. I. de Silva, MT11, living culture, KUMCC 17-0217.

GenBank numbers - ITS: MW219731, tef1: MW219604.

Notes - A new fungal isolate was identified as Cladosporium anthropophilum that clustered with the ex-type strain of $C$. anthropophilum (CBS 140685) and sister to C. anthropophilum (UTHSC DI 13-226) in the combined ITS and tefl phylogenetic analysis with $100 \% \mathrm{ML}, 100 \%$ MP and 1.00 BYPP support (Fig. 1). The type of $C$. anthropophilum was isolated from human bronchoalveolar lavage fluid in the USA and has also been recorded from an animal abscess, human cerebrospinal fluid, human foot skin, a human hand and human pleural fluid in the USA (Sandoval-Denis et al. 2016). To our knowledge, this is the first report of C. anthropophilum occurring on fresh leaves of Magnolia candolli (Sandoval-Denis et al. 2016). Cladosporium anthropophilum was reported on seed coat of Pinus armandii as saprobe or weak pathogen in Yunnan Province, China (Tibpromma et al. 2019). Therefore, we report C. anthropophilum as the first record from Magnolia candolli in Yunnan Province, China.

Cladosporium subuliforme Bensch, Crous \& U. Braun, Studies in Mycology 67: 77 (2010) Fig. 3 Index Fungorum number: IF517090; Facesoffungi number: FoF09439.

See description in Bensch et al. (2010)

Culture characteristics - Colonies on PDA reaching $28 \mathrm{~mm}$ diameter after 5 days at $25^{\circ} \mathrm{C}$, colonies circular, margin wavy, flat, velvety appearance with greyish aerial mycelia in the middle, colony from above: greyish brown and; reverse: dark brown centre and brown margin.

Material examined - CHINA, Yunnan Province, Xishuangbanna, healthy leaves of Magnolia candolli (Magnoliaceae), 26 April 2017, N. I. de Silva, MT10 (MFLU 19-0516, dried culture); living culture, MFLUCC 19-0051 = KUMCC 17-0216.

GenBank numbers - ITS: MW219730, tef1: MW219605.

Notes - According to the combined ITS and tefl phylogeny, this new isolate (MT10) clustered with Cladosporium subuliforme (CBS 126500) with 64\% ML, 72\% MP and 0.85 BYPP support (Fig. 1). We were unable to observe asexual or sexual morph characters in the culture. Cladosporium subuliforme was previously recorded from Chamaedorea metallica (Arecaceae) in Chiang Mai, Thailand (Bensch et al. 2010). In addition, C. subuliforme was recorded as a pathogen causing yellow leafspots on Capsicum annuum (Solanaceae) in Cuba (Ramos et al. 2016) and leafspots on Carya illinoinensis (Juglandaceae) (Walker et al. 2018). Cladosporium subuliforme was also recorded from indoor air in China (Bensch et al. 2018). Here we record the endophytic lifestyle of $C$. subuliforme from leaves of Magnolia candolli Yunnan Province, China.

Subclass Pleosporomycetidae C.L. Schoch et al.

Pleosporales Luttr. ex M.E. Barr

Corynesporascaceae Sivan.

Corynesporascaceae was introduced by Sivanesan (1996) with Corynesporasca as type genus and $C$. caryotae the type species. Corynesporasca was considered as the sexual morph of Corynespora (Sivanesan 1996). Rossman et al. (2015) recommended using the generic name Corynespora over Corynesporasca due to the extensive use of this name as plant pathogenic fungi. Corynespora was typified by $C$. mazei, a synonym of $C$. cassiicola (Rossman et al. 2015). Hongsanan et al. (2020) accepted Corynesporasca and Corynespora as distinct genera in Corynesporascaceae until molecular data of the type species are available. 


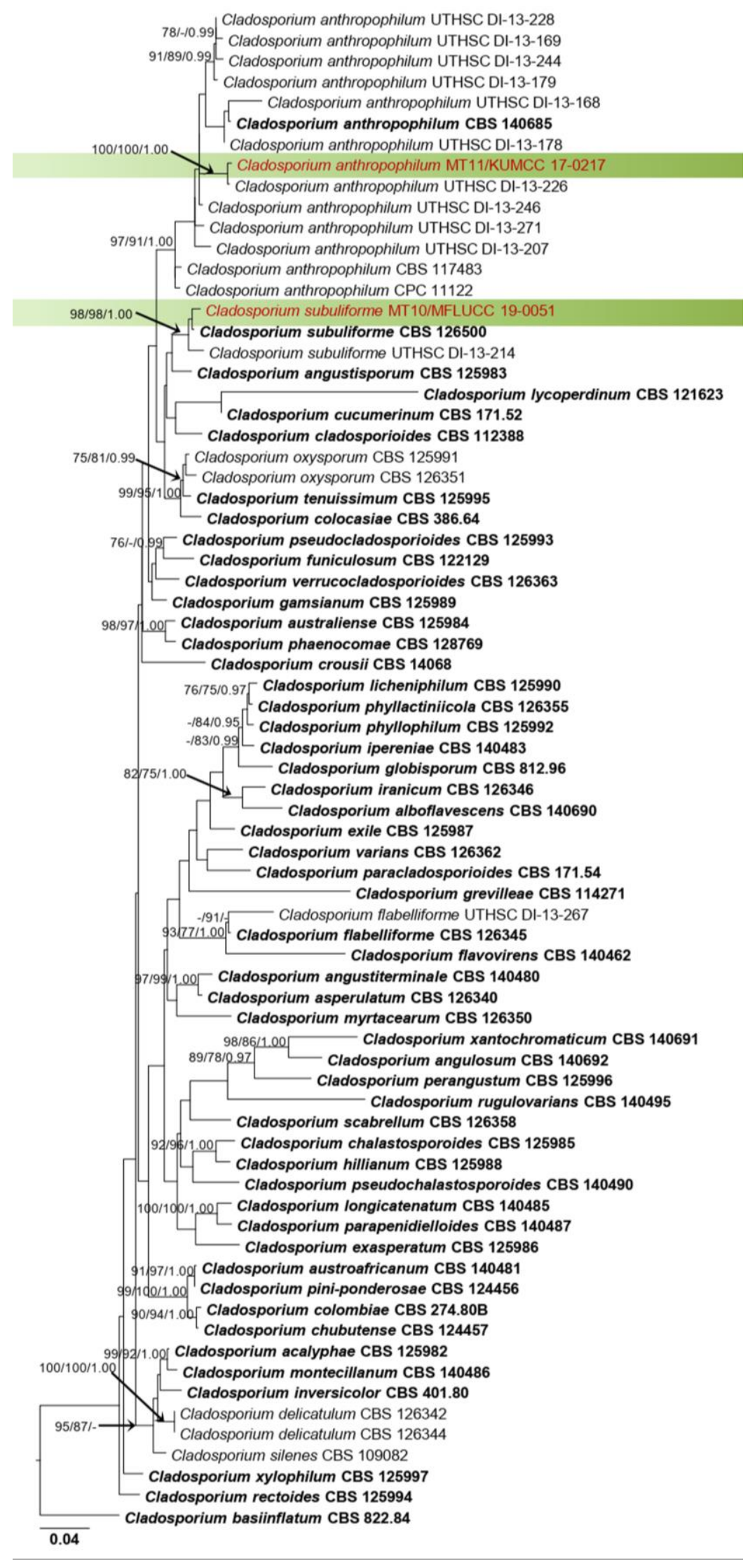

Figure 1 - Phylogram generated from maximum likelihood analysis based on combined ITS and tefl sequence data. Related sequences of Cladosporium cladosporioides complex were obtained from Sandoval-Denis et al. (2016). Seventy-three strains are included in the combined gene analyses comprising 2501 characters after alignment (850 characters for ITS and 634 characters for tef1). Cladosporium basiinflatum (CBS 822.64) is used as the outgroup taxon from C. herbarum 
complex. The best RAxML tree with a final likelihood value of -7888.749966 is presented. The matrix had 424 distinct alignment patterns, with $16.96 \%$ undetermined characters or gaps. Estimated base frequencies were as follows: $\mathrm{A}=0.237147, \mathrm{C}=0.277351, \mathrm{G}=0.257682, \mathrm{~T}=$ 0.227821; substitution rates $\mathrm{AC}=1.988191, \mathrm{AG}=3.176027, \mathrm{AT}=2.194815, \mathrm{CG}=0.863163, \mathrm{CT}$ $=7.079129, \mathrm{GT}=1.000000$; gamma distribution shape parameter $\alpha=0.633049$. Bootstrap values for maximum likelihood and maximum parsimony equal to or greater than $75 \%$ and Bayesian posterior probabilities equal or greater than 0.95 are placed above the branches. The newly generated sequences are indicated in red. Type and ex-type strains are in bold.
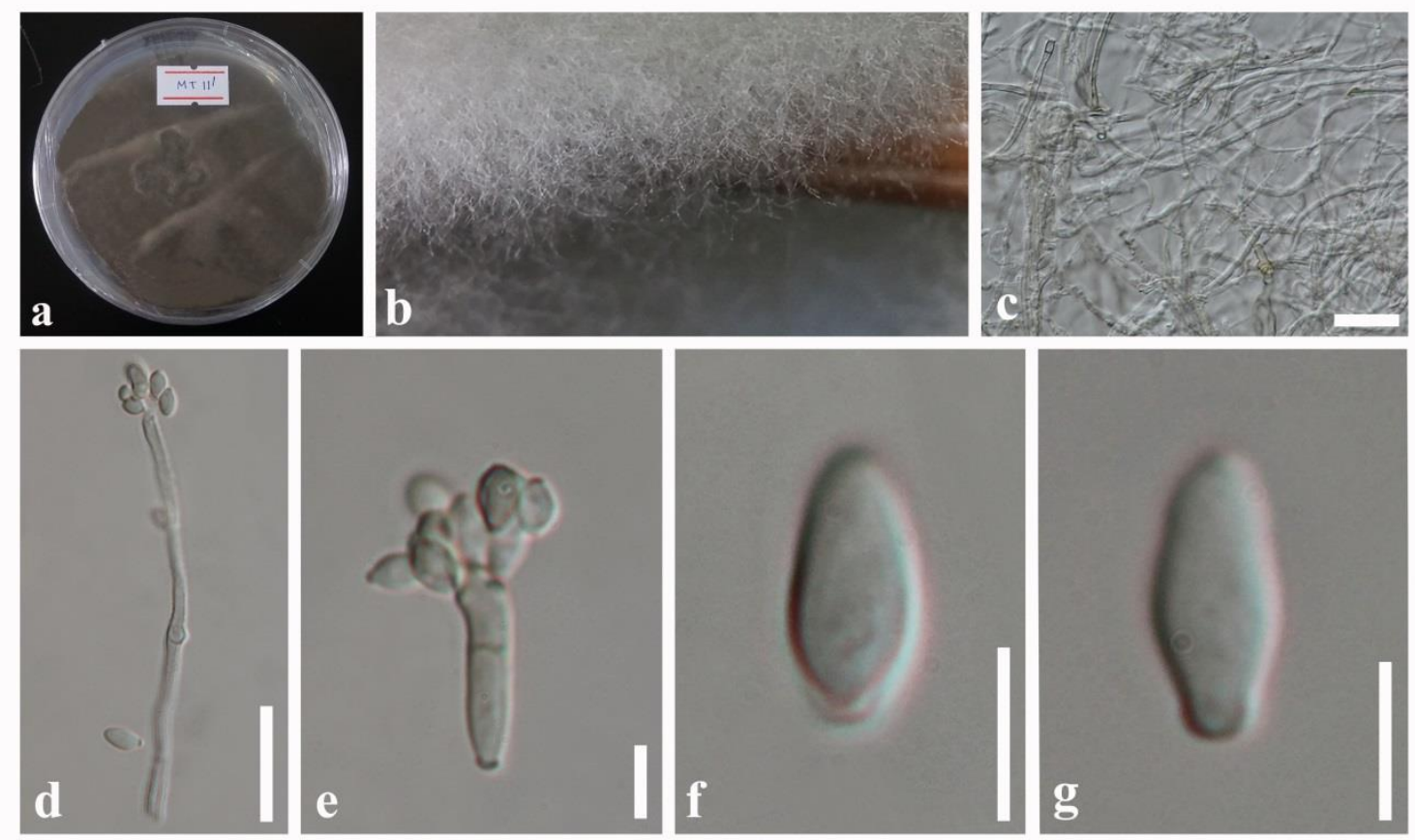

Figure 2 - Cladosporium anthropophilum (KUMCC 17-0217, new host record). a Colonies on PDA. b Mycelia masses on pine needle. c Mycelia masses. d Conidiophores and developing conidia. e Secondary ramoconidia and conidia. f, g Conidia. Scale bars: $\mathrm{c}, \mathrm{d}=20 \mu \mathrm{m}$, e-g $=5 \mu \mathrm{m}$.
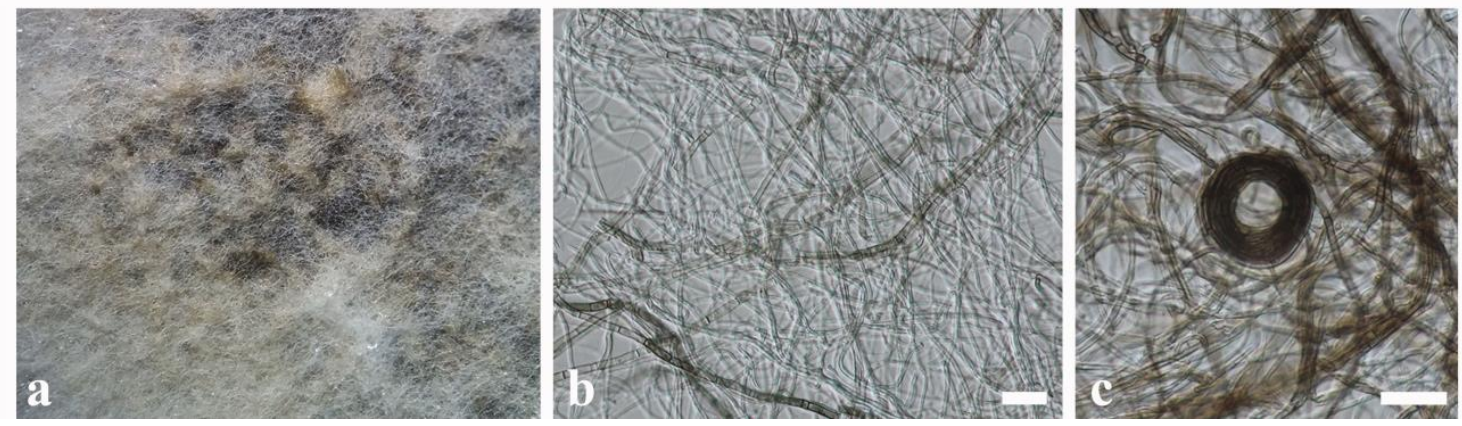

Figure 3 - Cladosporium subuliforme (MFLUCC 19-0051, new geographical and host record). a Mycelia on PDA. b, c Mycelia masses with hyphal coils. Scale bars: $b=50 \mu \mathrm{m}, \mathrm{c}=30 \mu \mathrm{m}$.

\section{Corynespora Güssow}

Species of Corynespora are pathogens occurring on a broad range of substrates and causing diseases on leaves to twigs of forest plants in tropics and subtropics regions (Kumar \& Singh 2016, Crous et al. 2018). Corynespora includes approximately 200 species names (Rossman et al. 2015, Voglmayr \& Jaklitsch 2017). There are 208 epithets listed in Index Fungorum (2021). Some species of Corynespora are reported as endophytes and saprobes (Pujade-Renaud et al. 2019). Pathogenic C. cassiicola is the causal agent of the economically important Corynespora leaf fall 
(Pujade-Renaud et al. 2019). Corynespora cassiicola has been recorded as not only as a pathogen but also as an endophyte in asymptomatic rubber leaves collected in Brazil (Pujade-Renaud et al. 2019). In this study, we report the endophytic lifestyle of $C$. cassiicola from Magnolia candolli in Yunnan Province, China.

Corynespora cassiicola (Berk. \& M.A. Curtis) C.T. Wei, Mycological Papers 34: 5 (1950)

Fig. 5 Index Fungorum number: IF296024; Facesoffungi number: FoF06664

Endophytic in fresh leaves of Magnolia candolli. Colonies on PDA white aerial mycelia and brown mycelia on pine needles. Mycelia superficial and immersed composed of septate, branched, 2-4 $\mu \mathrm{m}$ wide, hyaline and brown, with smooth and thick-walled hyphae. Sexual morph: Undetermined. Asexual morph: Hyphomycetous sporulated on PDA. Conidiophores 22-50 $\times$ 5-6 $\mu \mathrm{m}(\bar{x}=35 \times 5.4 \mu \mathrm{m})$, hyaline, simple, erect or slightly curved. Conidiogenous cells not observed. Conidia $18-30 \times 5-8 \mu \mathrm{m}(\bar{x}=26 \times 6 \mu \mathrm{m})$, hyaline to light brown, oblong, sometimes tapering towards the base of the conidia, solitary or in false chains with $0-2$ septa.

Culture characteristics - Colonies on PDA reaching $25 \mathrm{~mm}$ diameter after 7 days at $25^{\circ} \mathrm{C}$, colonies circular, margin entire, feathery appearance with white aerial mycelia and brown mycelia on pine needles, colony from above: white and brown on pine needles and; reverse: grey centre and dark grey margin.

Material examined - CHINA, Yunnan Province, Xishuangbanna, healthy leaves of Magnolia candolli (Magnoliaceae), 26 April 2017, N. I. de Silva, MT21 (MFLU 19-0520, dried culture); living culture, MFLUCC 19-0054 = KUMCC 17-0224.

GenBank numbers - LSU: MW209728, SSU: MW209736, ITS: MW219736, tef1: MW205018.

Notes - A new isolate (MFLUCC 19-0054) was recovered from healthy leaves of Magnolia candolli in Yunnan, China. The isolate has a close phylogenetic affinity to Corynespora cassiicola (CBS 161.60) in combined ITS, LSU, SSU and tef1 sequence data analyses (Fig. 4). Corynespora cassiicola causes corynespora leaf fall in rubber plantations in Asia and Africa and responsible for yield loss in rubber (Pujade-Renaud et al. 2019). Corynespora cassiicola has been recorded from many plant species viz. Acanthus ilicifolius, Bambusa sp., Calotropis gigantean, Cassia sp. and Eucalyptus sp. (Farr \& Rossman 2021). Previously, C. cassiicola was recorded from Magnolia garrettii as endophytes and saprobes in Thailand (Promputtha et al. 2010). In this study, we provide the first endophytic association of this species with $M$. candolli as a new host record.

\section{Didymellaceae Gruyter et al.}

De Gruyter et al. (2009) established the family with the type Didymella Sacc (emend. Q. Chen \& L. Cai). Members of this family are cosmopolitan and distributed across a wide range of host plant families (such as Caprifoliaceae, Orchidaceae, Poaceae, Tamaricaceae) (Chen et al. 2015, 2017, Hyde et al. 2018, Jayasiri et al. 2019, Raza et al. 2019). Species of Didymellaceae are plant pathogens on a wide range of hosts, mainly causing leaf and stem lesions (Chen et al. 2017), endophytic, saprobic, fungicolous and lichenicolous (Aveskamp et al. 2010), as well as a few human pathogens (de Hoog et al. 2011). The family comprises 35 genera (Hongsanan et al. 2020).

\section{Epicoccum Link}

Epicoccum was introduced by Link (1815) and emended by Chen et al. (2015). The genus comprises plant pathogens (Raza et al. 2019), saprobes (Jayasiri et al. 2017) and endophytes (Dzoyem et al. 2017). Epicoccum nigrum is one of the frequently isolated endophytes of sugarcane plants (Favaro et al. 2012). Favaro et al. (2012) reported that Epicoccum nigrum enhance the root system biomass and inhibit the in vitro growth of sugarcane pathogens, Ceratocystis paradoxa, Colletotrichum falcatum, Fusarium verticillioides and Xanthomomas albilineans. These findings suggest that endophytic Epicoccum nigrum could be used as a natural antagonist for plant pathogens in sugarcane. Epicoccum has hyphomycetous and coelomycetous synanamorphs (Jayasiri et al. 2017, Thambugala et al. 2017). The hyphomycetous anamorph is characterized in 
having dark sporodochia with branched conidiophores and mono- to polyblastic, colourless conidiogenous cells that produce coloured, sometimes verruculose, dictyoconidia (Seifert et al. 2011). The coelomycetous synanamorph is characterized by the formation of conidia in pycnidial conidiomata (Chen et al. 2015).

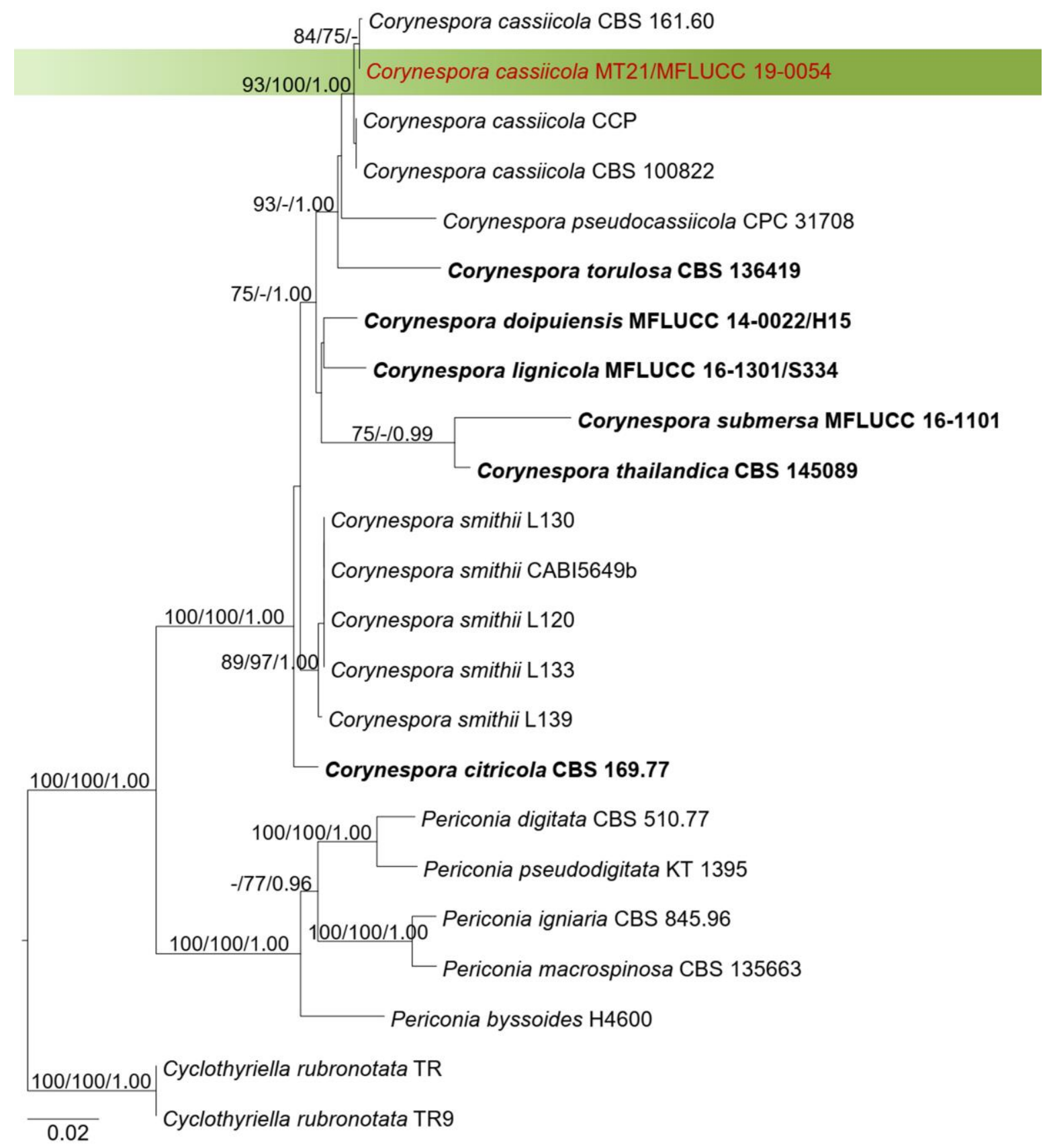

Figure 4 - Phylogram generated from maximum likelihood analysis based on combined ITS, LSU, SSU and tefl sequence data. Related sequences of Corynespora were obtained from Hyde et al. (2020c). Twenty three strains are included in the combined gene analyses comprising 3280 characters after alignment (580 characters for ITS, 850 characters for LSU, 1010 characters for SSU and 840 characters for tef1). Two strains of Cyclothyriella rubronotata (TR and TR9) are used as outgroup taxa. The best RAxML tree with a final likelihood value of -10047.444970 is presented. The matrix had 591 distinct alignment patterns, with $27.28 \%$ undetermined characters or gaps. Estimated base frequencies were as follows: $\mathrm{A}=0.241833, \mathrm{C}=0.255051, \mathrm{G}=0.272435, \mathrm{~T}=$ 0.230681; substitution rates $\mathrm{AC}=1.847808, \mathrm{AG}=2.414015, \mathrm{AT}=1.809939, \mathrm{CG}=1.229651, \mathrm{CT}$ $=8.652446, \mathrm{GT}=1.000000$; gamma distribution shape parameter $\alpha=0.731416$. Bootstrap values 
for maximum likelihood and maximum parsimony equal to or greater than $75 \%$ and Bayesian posterior probabilities equal or greater than 0.95 are placed above the branches. The newly generated sequence is indicated in red. Type and ex-type strains are in bold.
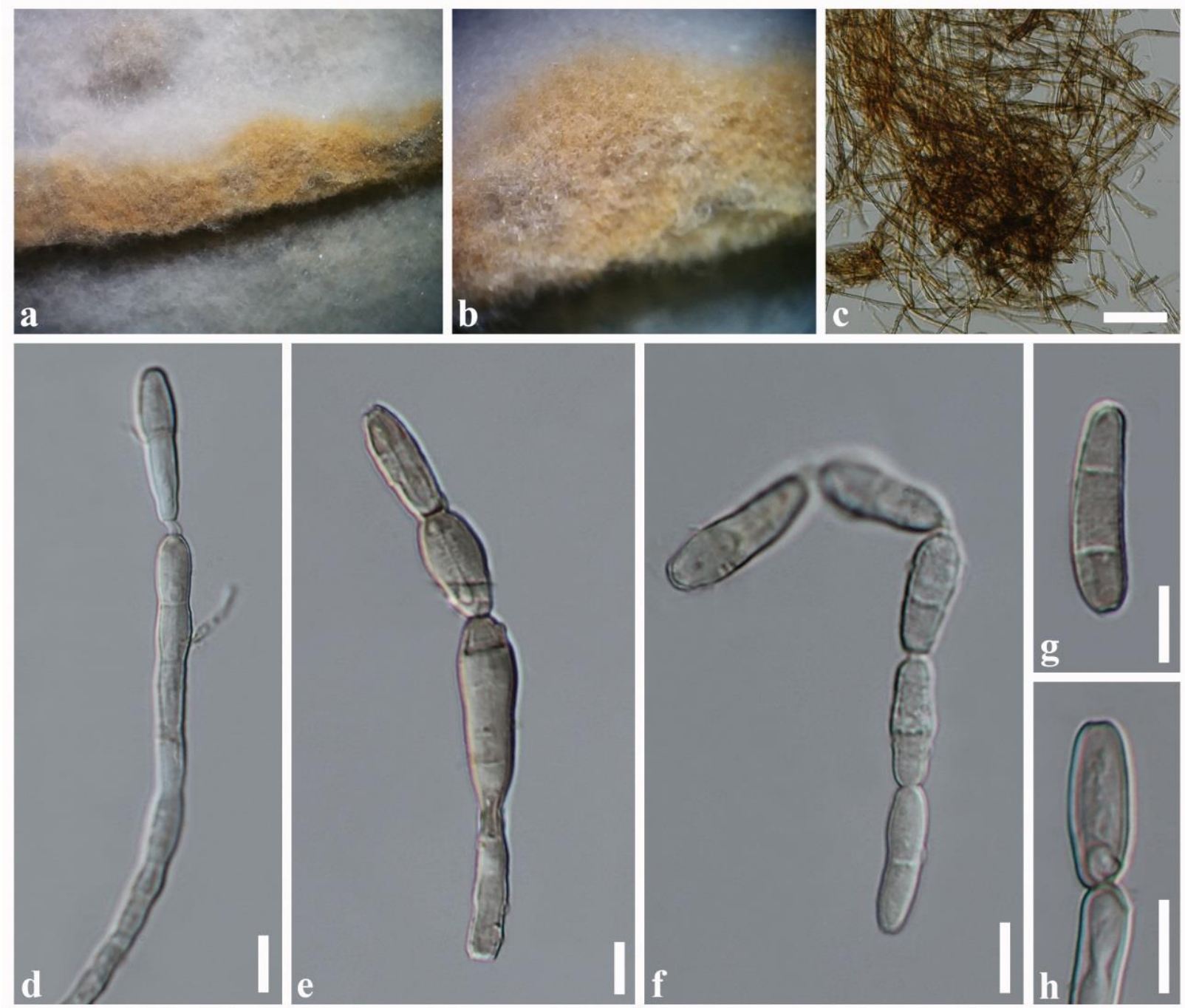

Figure 5 - Corynespora cassiicola (MT21/MFLUCC 19-0054, new host record). a, b Brown mycelial masses on a pine needle. c Brown and hyaline mycelia. d, e Conidiophores bearing conidia. f Conidial chain. $\mathrm{g}$, $\mathrm{h}$ Conidia. Scale bars: $\mathrm{c}=50 \mu \mathrm{m}, \mathrm{d}-\mathrm{h}=10 \mu \mathrm{m}$.

Epicoccum endophyticum N.I. de Silva, Lumyong \& K.D. Hyde, sp. nov.

Fig. 7

Index Fungorum number: IF556133; Facesoffungi number: FoF09491

Etymology - The epithet "endophyticum" refers to the endophytic lifestyle of this fungus.

Holotype - MFLU 20-0584

Endophytic in fresh leaves of Magnolia candolli. Colonies on PDA cream and white mycelia. Mycelia superficial and immersed composed of septate, branched, 1-3 $\mu \mathrm{m}$ wide, hyaline and light brown, with smooth and thick-walled hyphae. Sexual morph: Undetermined. Asexual morph: Conidiomata sporodochial, solitary or aggregated, semi-immersed or superficial and brown covered with hyphal growth. Conidiophores micronematous, inconspicuous. Conidia 10-15 $\times 8-10$ $\mu \mathrm{m}(\bar{x}=13 \times 9 \mu \mathrm{m})$, brown to dark brown, mostly ellipsoid, rarely globose to subglobose, verrucose and sometimes with a basal cell.

Culture characteristics - Colonies on PDA reaching $25 \mathrm{~mm}$ diameter after 7 days at $25^{\circ} \mathrm{C}$, colonies circular, margin entire, velvety appearance with cream and white mycelia, colony from above: white and light brown; reverse: brown. 


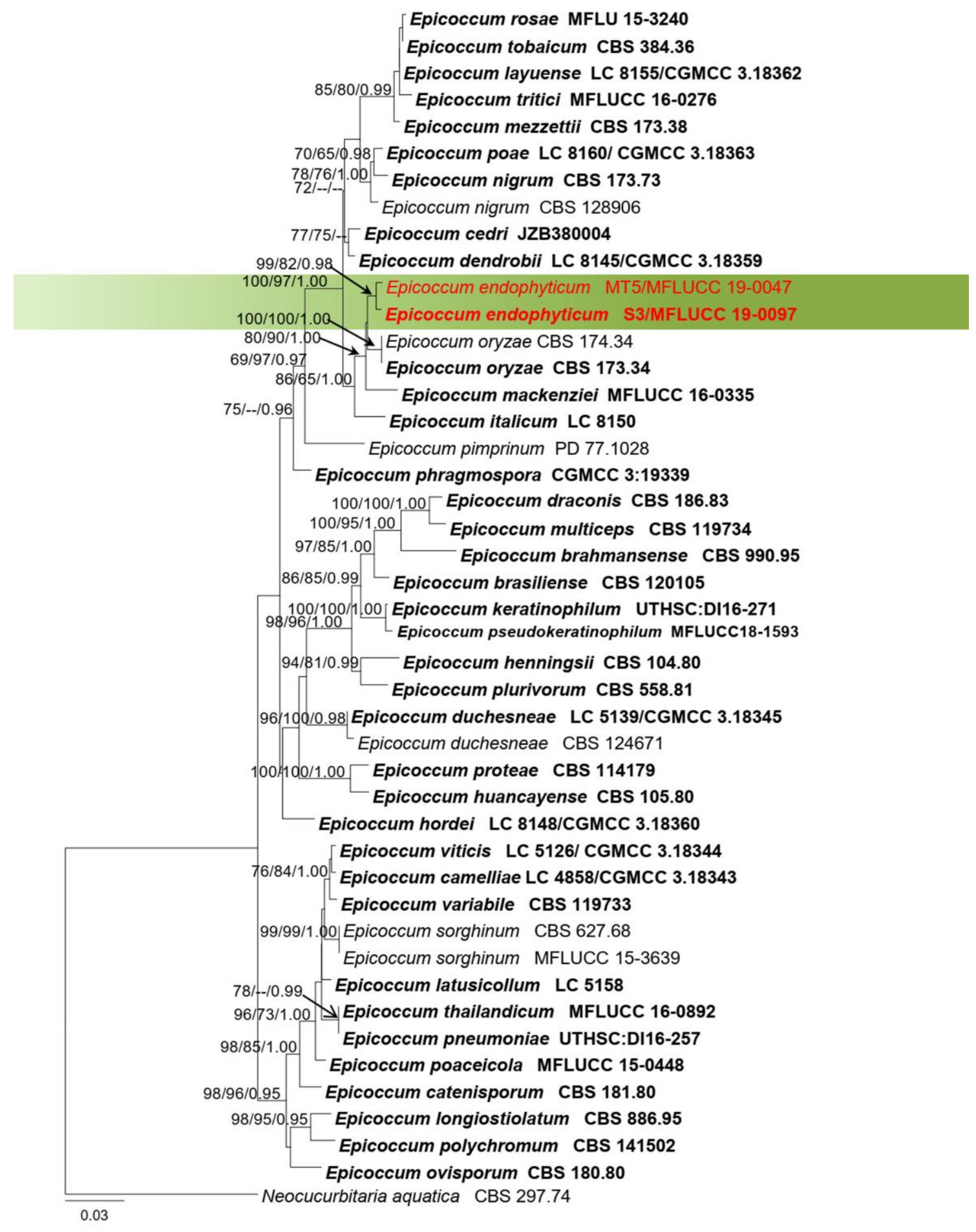

Figure 6 - Phylogram generated from maximum likelihood analysis based on combined LSU, ITS, tub2, and RPB2 sequence data. Related sequences of Epicoccum were obtained from Raza et al. (2019). Fourty-five strains are included in the combined gene analyses comprising 3050 characters after alignment (1300 characters for LSU, 500 characters for ITS, 350 characters for $t u b 2$ and 900 characters for RPB2). Neoccucurbitaria aquatica (CBS 297.74) is used as outgroup taxon. The best RAxML tree with a final likelihood value of -12694.220358 is presented. The matrix had 741 distinct alignment patterns, with $25.52 \%$ undetermined characters or gaps. Estimated base frequencies were as follows: $\mathrm{A}=0.241547, \mathrm{C}=0.244332, \mathrm{G}=0.273655, \mathrm{~T}=0.240465$; substitution rates $\mathrm{AC}=1.588918, \mathrm{AG}=5.144466, \mathrm{AT}=1.850477, \mathrm{CG}=1.096518, \mathrm{CT}=$ 12.554057, GT $=1.000000$; gamma distribution shape parameter $\alpha=0.492764$. Bootstrap values for maximum likelihood and maximum parsimony equal to or greater than $75 \%$ and Bayesian 
posterior probabilities equal or greater than 0.95 are placed above the branches. The newly generated sequences are indicated in red. Type and ex-type strains are in bold.

Material examined - CHINA, Yunnan Province, Xishuangbanna, healthy leaves of Magnolia candolli (Magnoliaceae), 26 April 2017, N. I. de Silva, S3 (MFLU 20-0584, holotype, dried culture); ex-type living culture, MFLUCC 19-0097 = KUMCC 17-0229.

Additional materials - CHINA, Yunnan Province, Xishuangbanna, healthy leaves of Magnolia candolli (Magnoliaceae), 26 April 2017, N. I. de Silva MT5 (MFLU 19-0510, dried culture); living culture, MFLUCC 19-0047 = KUMCC 17-0211.

GenBank numbers: (S3) LSU: MW209730, ITS: MW219739, RPB2: MW240860; (MT5) LSU: MW209729, ITS: MW219738, RPB2: MW240859.

Notes - According to the phylogeny, Epicoccum endophyticum is closely related to the exneotype of $E$. oryzae (CBS 173.34) with 56\% ML and 0.80 BYPP support (Fig. 6). A comparison of the RPB2 gene region of E. endophyticum and ex-neotype of E. oryzae (CBS 173.34) reveals 15 base pair differences $(2.5 \%)$ across 600 nucleotides. Ito \& Iwadare (1934) introduced E. oryzae from rice grains causing "red blotch" disease in Hokkaido, Japan. Hou et al. (2020) proposed the ex-neotype (CBS 173.34) of E. oryzae that were deposited in CBS collection by the original author of the species. Epicoccum oryzae produced sporodochia consist of globose, subglobose, or pyriform, granular, 9.9-23.1 × 6.6-16.5 $\mu \mathrm{m}$ conidia. Epicoccum endophyticum differs from E. oryzae in having ellipsoidal, smaller conidia $(10-15 \times 8-10 \mu \mathrm{m})$, whereas $E$. oryzae has subglobose-pyriform, larger conidia $(9.9-23.1 \times 6.6-16.5 \mu \mathrm{m})$ (Ito \& Iwadare 1934). In addition, Epicoccum oryzae has been recorded as a pathogen on rice grains in Japan, while E. endophyticum was recorded as an endophyte from healthy leaves of Magnolia candolli in China. Therefore, we introduce Epicoccum endophyticum as a new species from China based on both morphology and phylogeny.
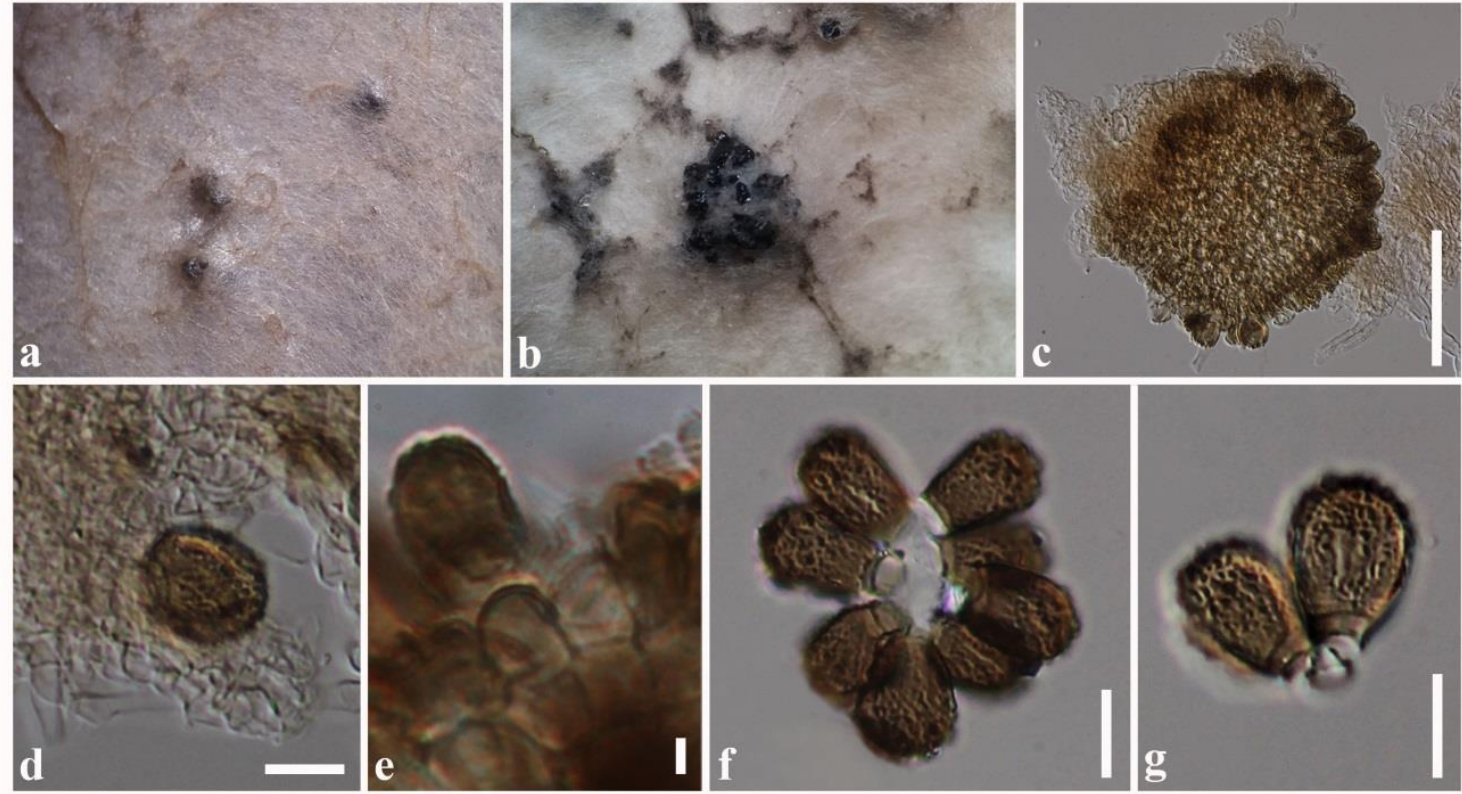

Figure 7 - Epicoccum endophyticum (MFLU 20-0584, holotype). a, b Sporodochia on PDA. c Section of sporodochium. d Conidia with mycelia. e Conidiogenous cells with attached conidium. $\mathrm{f}, \mathrm{g}$ Conidia. Scale bars: $\mathrm{c}=50 \mu \mathrm{m}, \mathrm{d}-\mathrm{h}=10 \mu \mathrm{m}$.

\section{Leptosphaerulina McAlpine}

Leptosphaerulina was introduced by McAlpine (1902) to accommodate L. australis as the type. Leptosphaerulina species have a cosmopolitan distribution and they have been recorded from various plant families of monocotyledons and dicotyledons in temperate and tropical countries 
(Phookamsak et al. 2013, Chen et al. 2017, Tennakoon et al. 2019). The genus is characterized by small, immersed ascomata, obpyriform asci with a large ocular chamber and an apical ring, muriform, ascospores which may be hyaline or pigmented (Zhang et al. 2012, Hyde et al. 2013, Phookamsak et al. 2013, Tennakoon et al. 2019). There are 64 Leptosphaerulina epithets in Index Fungorum (2021), but few species have molecular data. Species of Leptosphaerulina are reported as saprobic or parasitic on leaves or stems of various plants, including important crops (Phookamsak et al. 2013, Tennakoon et al. 2019). This is the first endophytic record of Leptosphaerulina from fresh leaves of Magnolia candolli in China.

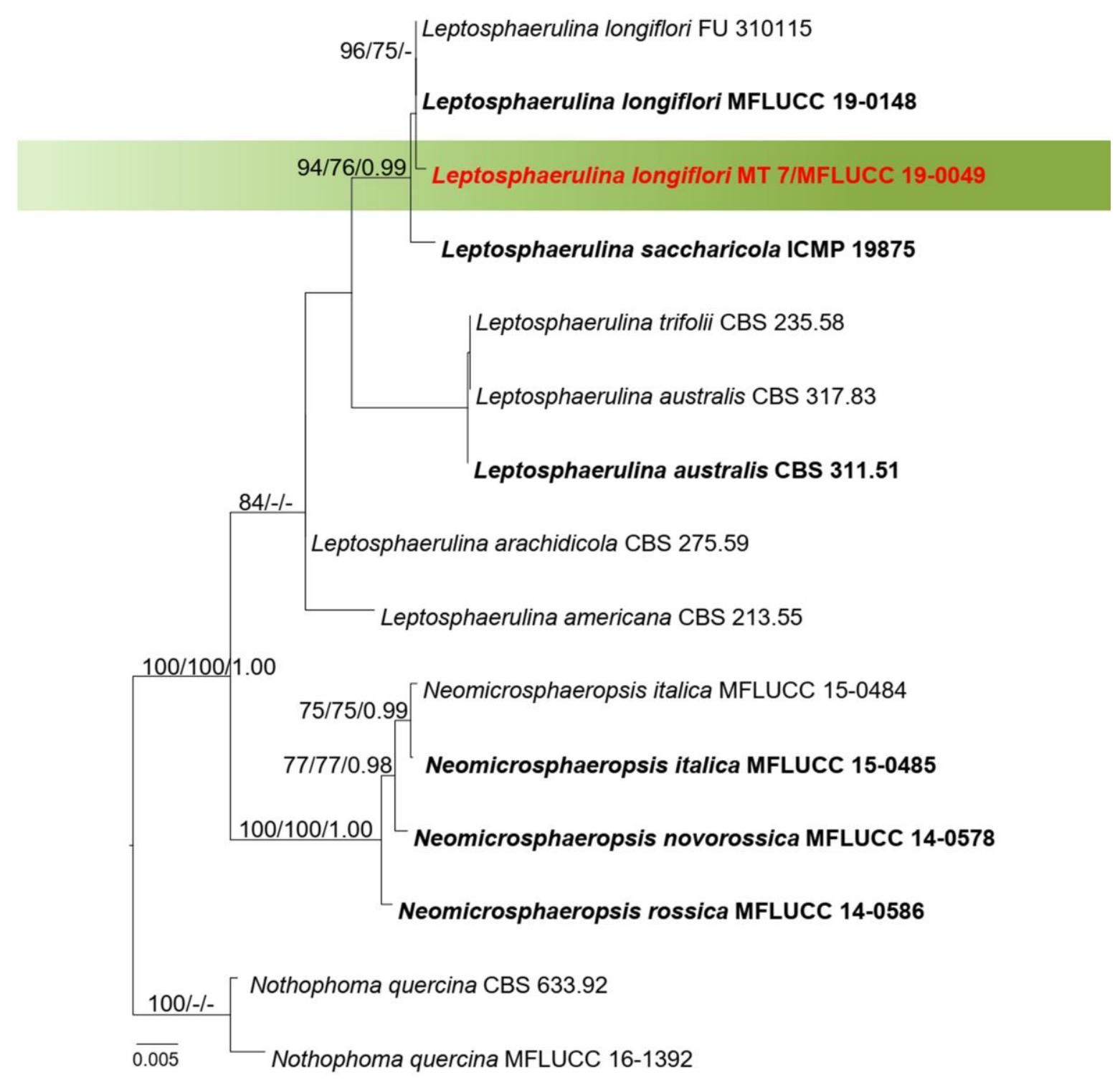

Figure 8 - Phylogram generated from maximum likelihood analysis based on combined LSU, SSU, ITS, tef1 and RPB2 sequence data. Related sequences of Leptosphaerulina were obtained from Tennakoon et al. (2019). Fifteen strains are included in the combined gene analyses comprising 3825 characters after alignment (875 characters for LSU, 1010 characters for SSU, 490 characters for ITS, 865 characters for tef1 and 595 characters for RPB2). Two strains of Nothophoma quercina (CBS 633.92 and MFLUCC 16-1392) are used as outgroup taxa. The best RAxML tree with a final likelihood value of -6985.333624 is presented. The matrix had 209 distinct alignment patterns, with $30.39 \%$ undetermined characters or gaps. Estimated base frequencies were as follows: $\mathrm{A}=0.245841, \mathrm{C}=0.236297, \mathrm{G}=0.270335, \mathrm{~T}=0.247527$; substitution rates $\mathrm{AC}=1.811712, \mathrm{AG}=5.570845, \mathrm{AT}=1.370567, \mathrm{CG}=0.734941, \mathrm{CT}=$ 19.045859, $\mathrm{GT}=1.000000$; gamma distribution shape parameter $\alpha=1.250398$. Bootstrap values 
for maximum likelihood and maximum parsimony equal to or greater than $75 \%$ and Bayesian posterior probabilities equal or greater than 0.95 are placed above the branches. The newly generated sequence is indicated in red. Type and ex-type strains are in bold.

Leptosphaerulina longiflori D.S. Tennakoon, C.H. Kuo \& K.D. Hyde, Asian Journal of Mycology 2(1): 93 (2019)

Fig. 9

Index Fungorum number: IF556240, Facesoffungi number: FoF05820

See description in Tennakoon et al. (2019)

Culture characteristics - Colonies on PDA reaching $25 \mathrm{~mm}$ diameter after 7 days at $25^{\circ} \mathrm{C}$, colonies circular, margin entire, velvety appearance with white aerial mycelia and black dots like small structures, colony from above: white and brown; reverse: dark brown. Not sporulated on PDA even after two months.

Material examined - CHINA, Yunnan Province, Xishuangbanna, healthy leaves of Magnolia candolli (Magnoliaceae), 26 April 2017, N. I. de Silva, MT7 (MFLU 19-0512, dried culture); living culture, MFLUCC 19-0049 = KUMCC 17-0213.

GenBank numbers - LSU: MW209731, SSU: MW209734, ITS: MW219737, tef1: MW233019.

Notes - In this study, we obtained an isolate of Leptosphaerulina longiflori from fresh leaves of Magnolia candolli that has a close phylogenetic affinity to the ex-type strain of L. longiflori (MFLUCC 19-0148) in the present multi-gene phylogenetic analyses (Fig. 8). The sexual morph of the type L. longiflori was isolated from dead leaves of Lilium longiflorum in Taiwan region (Tennakoon et al. 2019). By considering the molecular data and the host recorded, we consider our collection as a new host record of endophytic L. longiflori from Magnolia candolli.
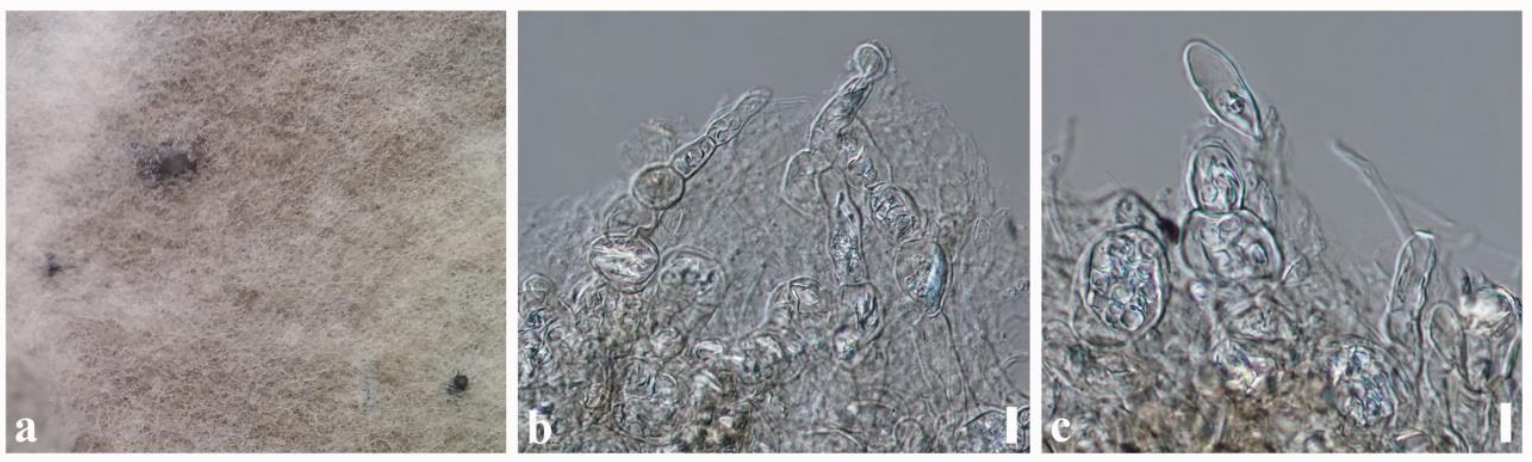

Figure 9 - Leptosphaerulina longiflori (MFLUCC 19-0049, new host record). a Mycelia on PDA. b, c Mycelia masses and chlamydospores. Scale bars: b, c $=10 \mu \mathrm{m}$.

\section{Didymosphaeriaceae Munk}

Munk (1953) introduced Didymosphaeriaceae and typified by Didymosphaeria. The family contains many saprobes, while other taxa are endophytes or pathogens in terrestrial and aquatic environments (Barr 2001, Zhang et al. 2012, Ariyawansa et al. 2014, Wanasinghe et al. 2016). Many studies have been conducted on the family and Ariyawansa et al. (2014) synonymized Montagnulaceae under Didymosphaeriaceae based on the priority of the oldest name. The family comprises 32 genera (Hongsanan et al. 2020).

\section{Letendraea Sacc.}

Saccardo (1880) introduced Letendraea with the type of L. eurotioides. Species of Letendraea are saprobic in terrestrial habitats, pathogenic associated with leaf spot disease in Cordyline sp. (Ariyawansa et al. 2014) and also recorded from marine environments (Huang et al. 2019). There are 20 epithets recorded in Index Fungorum (2021) of which four have molecular data. 


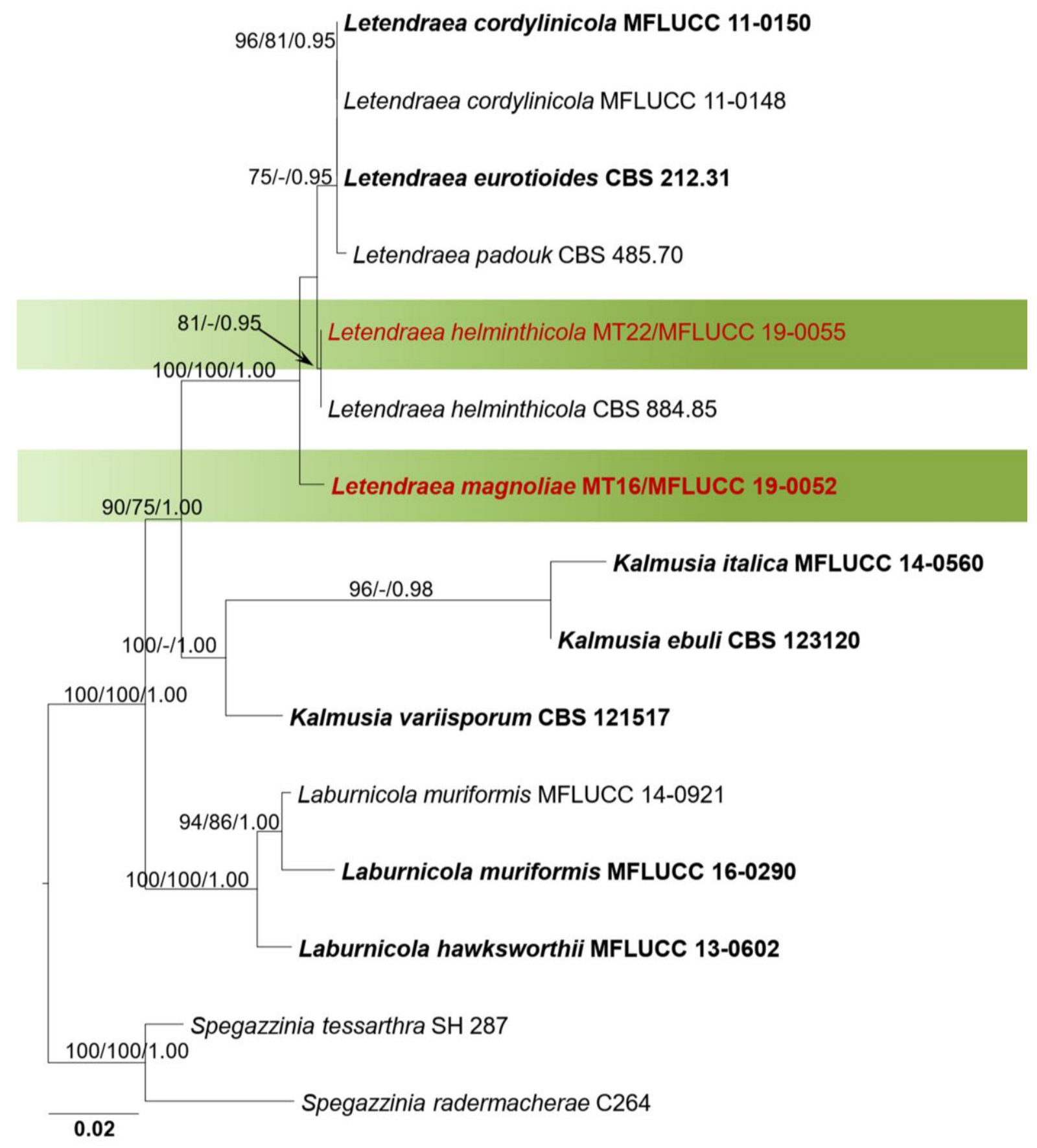

Figure 10 - Phylogram generated from maximum likelihood analysis based on combined LSU, SSU, ITS and tefl sequence data. Related sequences of Letendraea were obtained from Ariyawansa et al. (2014), Wanasinghe et al. (2016). Fifteen strains are included in the combined gene analyses comprising 3135 characters after alignment ( 850 characters for LSU, 975 characters for SSU, 550 characters for ITS and 760 characters for tef1). Spegazzinia tessartha (SH 287) and S. radermacherae (C264) are used as outgroup taxa. The best RAxML tree with a final likelihood value of -7478.513639 is presented. The matrix had 406 distinct alignment patterns, with $34.13 \%$ undetermined characters or gaps. Estimated base frequencies were as follows: $\mathrm{A}=0.242352, \mathrm{C}=$ $0.240745, \mathrm{G}=0.275677, \mathrm{~T}=0.241227$; substitution rates $\mathrm{AC}=1.299979, \mathrm{AG}=1.543467, \mathrm{AT}=$ $1.104724, \mathrm{CG}=0.913835, \mathrm{CT}=5.527514, \mathrm{GT}=1.000000$; gamma distribution shape parameter $\alpha$ $=0.641405$. Bootstrap values for maximum likelihood and maximum parsimony equal to or greater than $75 \%$ and Bayesian posterior probabilities equal or greater than 0.95 are placed above the branches. The newly generated sequences are indicated in red. Type and ex-type strains are in bold. 
Letendraea helminthicola (Berk. \& Broome) Weese, Transactions of the British Mycological Society 21(3-4): 277 (1938) [1937]

Index Fungorum number: IF252540; Facesoffungi number: FoF09440

Fig. 11

Endophytic in fresh leaves of Magnolia candolli. Colonies on PDA flat to slightly raised, light brown with velvety appearance. Mycelia superficial and immersed composed of septate, branched, 1-2 $\mu \mathrm{m}$ wide, hyaline, with smooth and thick-walled hyphae. Chlamydospores hyaline, subglobose or irregular shape.

Culture characteristics - Colonies on PDA reaching $23 \mathrm{~mm}$ diameter after 7 days at $25^{\circ} \mathrm{C}$, colonies circular, margin entire to slightly undulate, flat to slightly raised, dense, velvety appearance, light brown mycelia and colony from above: cream and light brown; reverse: brown.

Material examined - CHINA, Yunnan Province, Xishuangbanna, healthy leaves of Magnolia candolli (Magnoliaceae), 26 April 2017, N. I. de Silva, MT22, (MFLU 19-0521, dried culture); living culture, MFLUCC 19-0055 = KUMCC 17-0225.

GenBank numbers - LSU: MW209732, SSU: MW209735, ITS: MW222161, tef1: MW233020.

Notes - Sexual morph of Letendraea helminthicola was introduced as hyper-pathogenic fungi on Helminthosporium appendiculatum by Petch (1938) from the UK. Our new isolate (MFLU 190521) is phylogenetically related to L. helminthicola (CBS 884.85) with $81 \%$ ML, 50\% MP and 0.95 BYPP support (Fig. 10). Therefore, based on phylogenetic affinity, we identify our strain as $L$. helminthicola and it is reported here as a new host and geographical record.
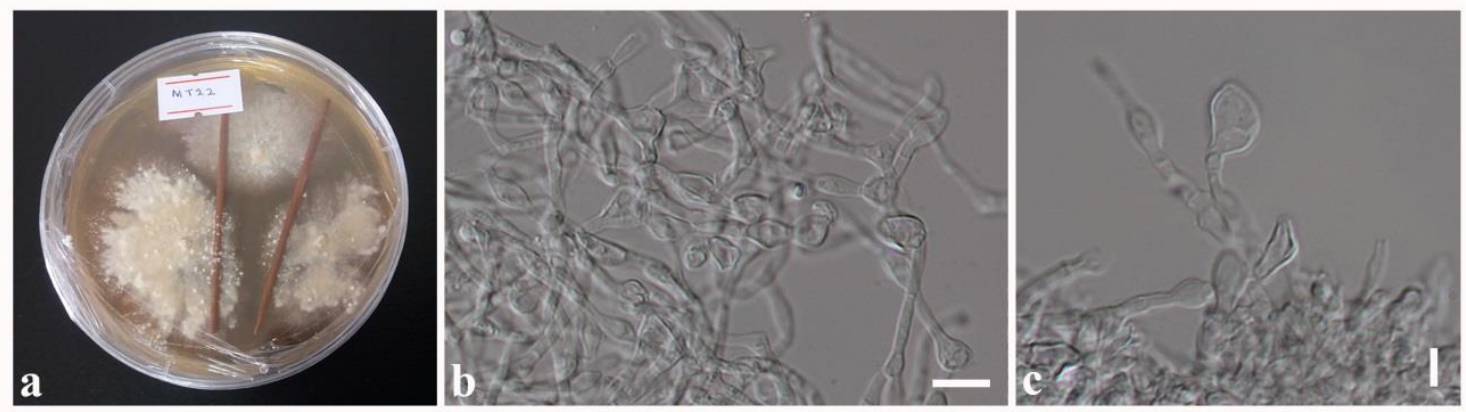

Figure 11 - Letendraea helminthicola (MFLUCC 19-0055, new host and geographical record). a Colonies on PDA. b, c Mycelia masses and chlamydospores. Scale bars: $b=10 \mu \mathrm{m}, \mathrm{c}=5 \mu \mathrm{m}$.

Letendraea magnoliae N.I. de Silva, Lumyong \& K.D. Hyde, sp. nov.

Fig. 12

Index Fungorum number: IF556134; Facesoffungi number: FoF09492 isolated.

Etymology - Name reflects the host genus Magnolia, from which the new species was

Holotype - MFLU 19-0517

Endophytic in fresh leaves of Magnolia candolli. Colonies on PDA flat, light brown with velvety appearance. Mycelia superficial and immersed composed of septate, branched, 1-2 $\mu \mathrm{m}$ wide, hyaline, with smooth and thick-walled hyphae. Sexual morph: sporulated on PDA. Ascomata 150-250 $\mu \mathrm{m}$ diam., brown, semi-immersed to superficial covered with mycelia, globose to subglobose, solitary or aggregated. Hamathecium not observed. Peridium 10-15 $\mu \mathrm{m}$ wide, composed of 7-8 layers, thin-walled with equal thickness, small, flattened pseudoparenchymatous, brown cells of textura angularis. Asci (immature asci) 40-50 4 4-7 $\mu \mathrm{m}(\bar{x}=46 \times 6 \mu \mathrm{m}), 8$-spored, bitunicate, cylindrical-clavate, slightly curved, sessile. Ascospores $14-16 \times 2-4 \mu \mathrm{m}(\bar{x}=15 \times 3$ $\mu \mathrm{m})$, olivaceous brown, ellipsoidal to fusiform, straight or slightly curved, one septate, acute at both ends, thick-walled with guttules. Asexual morph: Undetermined.

Culture characteristics - Colonies on PDA reaching $25 \mathrm{~mm}$ diameter after 7 days at $25^{\circ} \mathrm{C}$, colonies circular, margin entire, flat to slightly raised, dense, velvety appearance, orange mycelia and colony from above: orange; reverse: orangish brown. 

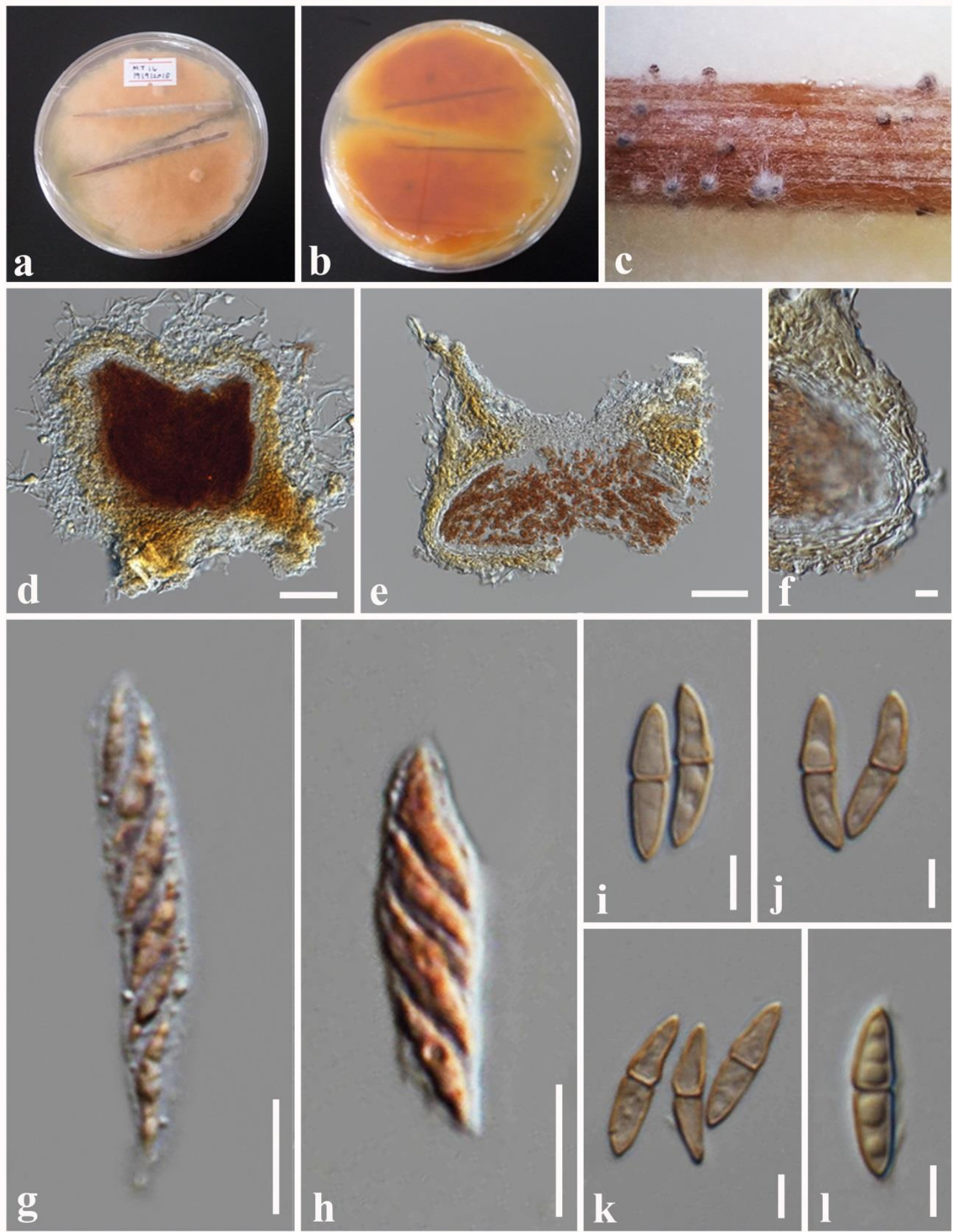

Figure 12 - Letendraea magnoliae (MFLU 19-0517, holotype). a, b Colonies on PDA (upper view and lower view). c Ascomata on a pine needle. d, e Sections through ascoma. f Peridium. $\mathrm{g}, \mathrm{h}$ Immature asci stained in congo red. $\mathrm{i}-1$ Ascospores. Scale bars: $\mathrm{d}, \mathrm{e}=50 \mu \mathrm{m}, \mathrm{f}-\mathrm{h}=10 \mu \mathrm{m}$, $\mathrm{i}-\mathrm{l}=5 \mu \mathrm{m}$.

Material examined - CHINA, Yunnan Province, Xishuangbanna, healthy leaves of Magnolia candolli (Magnoliaceae), 26 April 2017, N. I. de Silva, MT16 (MFLU 19-0517, holotype, dried culture); ex-type living culture, MFLUCC 19-0052 = KUMCC 17-0221.

GenBank numbers - ITS: MW222160, tef1: MW233021.

Notes - Letendraea magnoliae obtained from healthy leaves, clustered distinctly and basal to other Letendraea species in combined LSU, SSU, ITS and tef1 phylogenetic analysis with 100\% 
ML, 100\% MP and 1.00 BYPP support (Fig. 10). Ascospores of L. brasiliensis and L. cordylinicola differ from L. magnoliae in having mucilaginous sheath while L. magnoliae lacks mucilaginous sheath. Letendraea cordylinicola has distinct appendage at both ends whereas L. magnoliae does not have appendages. Letendraea magnoliae differs from L. eurotioides and L. helminthicola in having ascospores with acute ends. Letendraea eurotioides and L. helminthicola have ascospores with rounded ends.

Letendraea eurotioides is saprobic fungus introduced from the USA on dead branches of Rubi fruticosi, L. cordylinicola is a saprobic or parasitic fungus from Thailand on leaves of Cordyline sp. (Ariyawansa et al. 2014) and L. helminthicola is pathogenic fungus on Helminthosporium appendiculatum (Petch 1938).

In the current study, we introduce L. magnoliae as a new species from China associated with healthy leaves of Magnolia candolli based on morphology and phylogeny.

Class Sordariomycetes O.E. Erikss. \& Winka

Subclass Diaporthomycetidae Senan. et al.

Diaporthales Nannf.

Diaporthaceae Höhn. ex Wehm.

Diaporthaceae was introduced by von Höhnel (1917) and verified by Wehmeyer (1975) to accommodate Diaporthe and Mazzantia. Castlebury et al. (2002) confirmed Diaporthaceae comprised only Diaporthe and Mazzantia based on phylogenetic analyses of LSU rDNA sequence data. Lamprecht et al. (2011), Voglmayr \& Jaklitsch (2014) subsequently studied Diaporthaceae by adding new genera and Maharachchikumbura et al. (2015) revised the family placement in Diaporthales based on morphology and phylogeny. Wijayawardene et al. (2020) accepted following 15 genera: Apioporthella, Apiosphaeria, Chaetoconis, Chiangraiomyces, Diaporthe, Hyaliappendispora, Leucodiaporthe, Massariothea, Mazzantia, Ophiodiaporthe, Paradiaporthe, Phaeocytostroma, Phaeodiaporthe, Pustulomyces and Stenocarpella.

\section{Diaporthe Nitschke}

Diaporthe species are important plant pathogens, endophytes or saprobes and is typified by D. eres Nitschke (Udayanga et al. 2011, 2014a, Gomes et al. 2013, Senanayake et al. 2017, 2018). Pathogenic species are responsible for severe diebacks, cankers, leaf-spots, blights, decay or wilts on a broad range of economically important agricultural crops (Udayanga et al. 2011, Gomes et al. 2013, Gao et al. 2017). Previously, Diaporthe species were largely identified based on morphological characters and host association (Dissanayake et al. 2017a, b, Gao et al. 2017). Recently, multi-locus DNA data together with morphology and ecology have been used for Diaporthe species delimitation (Dissanayake et al. 2017a, b, Gao et al. 2017, Marin-Felix et al. 2019). Few species complexes have been identified in Diaporthe, such as D. arecae, D. eres and $D$. sojae based on phylogenetic analyses (Udayanga et al. 2014b, 2015, Marin-Felix et al. 2019).

Diaporthe apiculata Y.H. Gao \& L. Cai, in Gao, Liu \& Cai, Systematics and Biodiversity Journal 14: 106 (2016)

Fig. 14

Index Fungorum number: IF811217; Facesoffungi number: FoF08403

See description in Gao et al. (2016)

Culture characteristics - Colonies on PDA reaching $23 \mathrm{~mm}$ diameter after 7 days at $25^{\circ} \mathrm{C}$, colonies circular, margin entire, flat, velvety appearance with a thick texture, dark brown and yellowish mycelia on pine needles, colony from above: initially white, became brown and yellowish; reverse: dark brown. The culture did not produce any spores even on prolonged incubation.

Material examined - THAILAND, Chiang Mai Province, healthy leaves of Magnolia garrettii (Magnoliaceae), 14 August 2017, N. I. de Silva, GMT16, living culture, MFLUCC 180938, GMT23, living culture MFLUCC 18-0941.

GenBank numbers - GMT16; ITS: MW187327, GMT23; ITS: MW187328. 


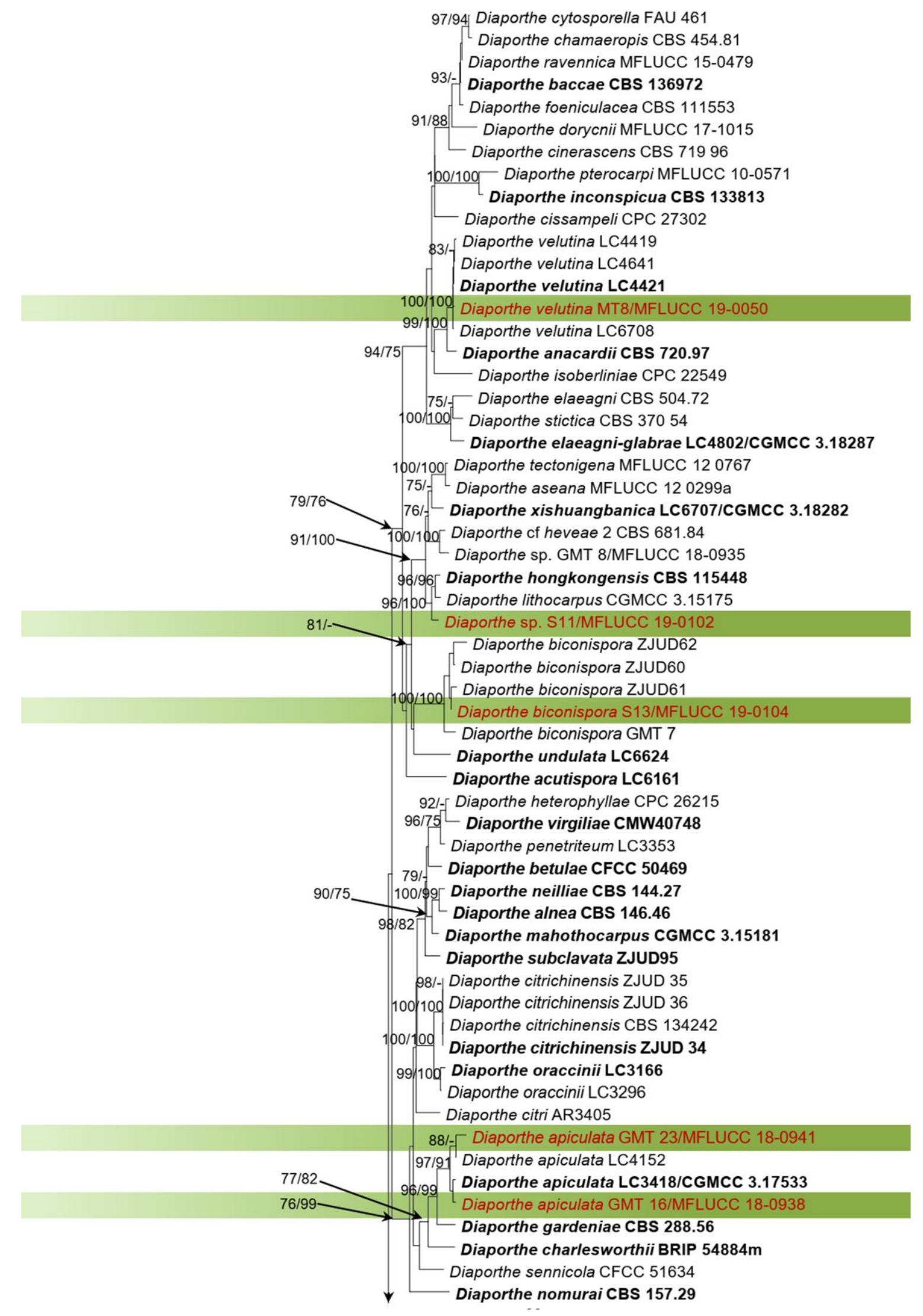

Figure 13 - Phylogram generated from maximum likelihood analysis based on combined ITS, tub2, tef1 and CAL sequence data (with additional strains that closely related to newly generated sequences and removed some distantly related sequences). Related sequences of Diaporthe were obtained from Manawasinghe et al. (2019). One hundred and seven strains are included in the combined gene analyses comprising 1700 characters after alignment (530 characters for ITS, 410 
characters for tub2, 320 characters for tef1 and 440 characters for CAL). Diaporthella corylina (CBS 121124) is used as outgroup taxon. The best RAxML tree with a final likelihood value of 27814.096708 is presented. The matrix had 1264 distinct alignment patterns, with 31.70\% undetermined characters or gaps. Estimated base frequencies were as follows: $\mathrm{A}=0.217400, \mathrm{C}=$ $0.315962, \mathrm{G}=0.240127, \mathrm{~T}=0.226511$; substitution rates $\mathrm{AC}=1.078130, \mathrm{AG}=3.025956, \mathrm{AT}=$ 1.253018, $\mathrm{CG}=0.883162, \mathrm{CT}=4.360330, \mathrm{GT}=1.000000$; gamma distribution shape parameter $\alpha$ $=0.970320$. Bootstrap values for maximum likelihood and maximum parsimony equal to or greater than $75 \%$ are placed above the branches. The newly generated sequences are indicated in red. Type and ex-type strains are in bold.

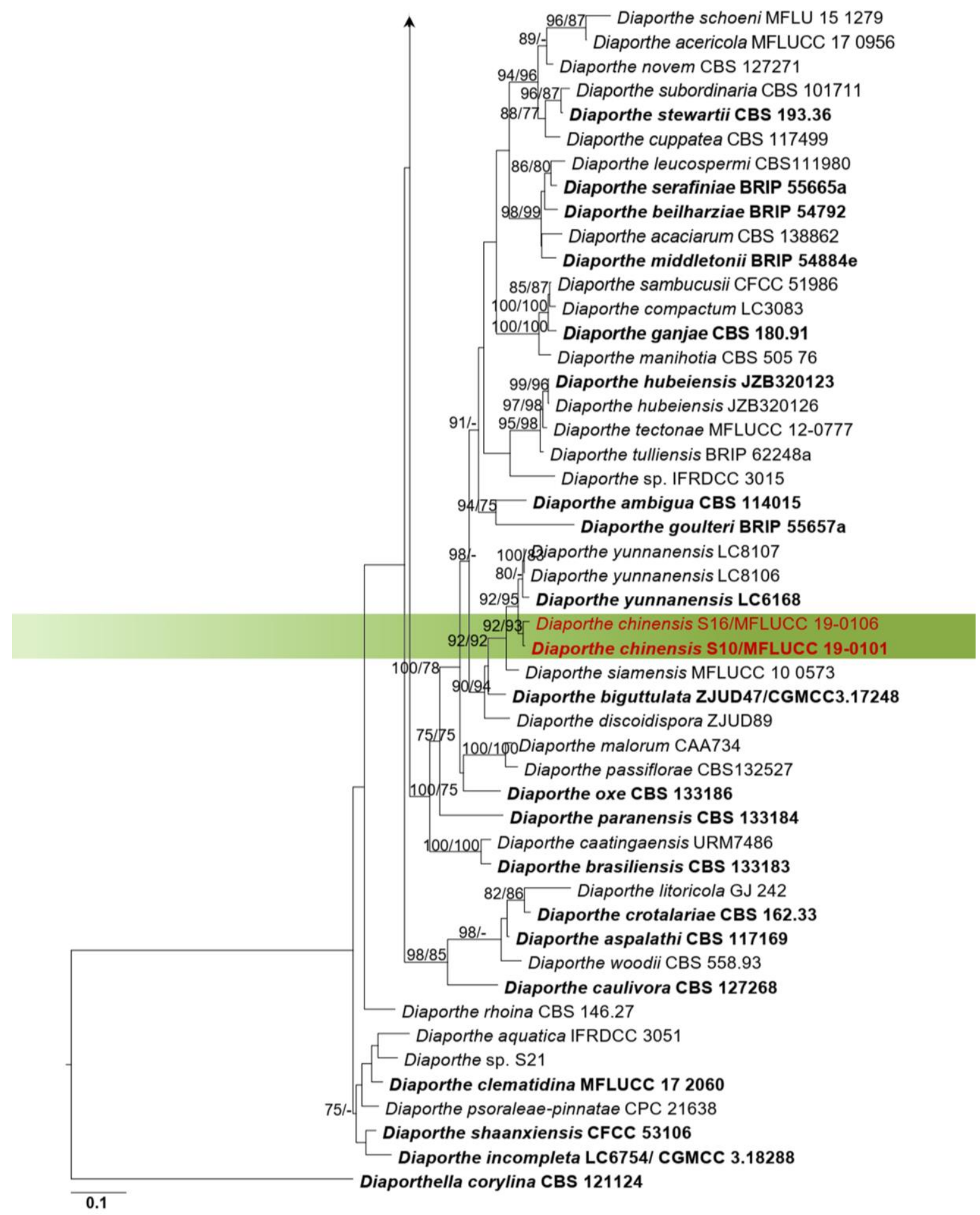

Figure 13 - Continued. 


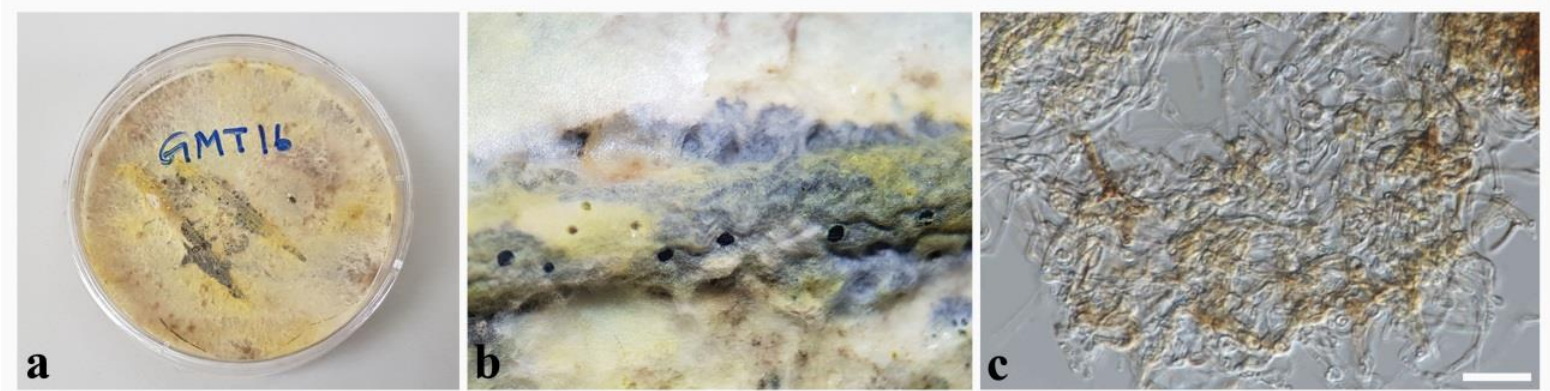

Figure 14 - Diaporthe apiculata (MFLUCC 18-0938, new host record). a Upper view of culture on PDA. b Mycelia on PDA. c Mycelia masses with chlamydospores. Scale bars: $c=20 \mu \mathrm{m}$.

Notes - Diaporthe apiculata was introduced by Gao et al. (2016) from healthy leaves of Camellia sinensis in Jiangxi Province, China and was also recorded as a pathogen on diseased leaves of $C$. sinensis. Two new isolates of GMT16 and GMT23 share a close phylogenetic affinity to ex-type of D. apiculata (LC 3418) in the present combined ITS, tub2, tef1 and CAL gene data analyses. This species has not been reported from the plant family Magnoliaceae (Farr \& Rossman 2021) and here we provide the first association of this species with plant host Magnolia.

Diaporthe biconispora F. Huang, K.D. Hyde \& Hong Y. Li, Fungal Biology 119(5): 338 (2015)

Index Fungorum number: IF810578; Facesoffungi number: FoF08406

Fig. 15

See description in Huang et al. (2015)

Culture characteristics - Colonies on PDA reaching $25 \mathrm{~mm}$ diameter after 7 days at $25^{\circ} \mathrm{C}$, colonies circular, margin entire, flat, velvety appearance, white and light brown mycelia, elevated mycelia masses (pycnidia like structures), colony from above: white and light brown; reverse: dark brown. The culture did not produce any spores even on prolonged incubation.

Material examined - CHINA, Yunnan Province, Xishuangbanna, healthy leaves of Magnolia candolli (Magnoliaceae), 26 April 2017, N. I. de Silva, S13 (MFLU 20-0590, dried culture); living culture, MFLUCC 19-0104 = KUMCC 17-0238.

GenBank numbers - ITS: MW192407, tub2: MW233024, CAL: MW294201.

Notes - A new isolate (S13) clustered with Diaporthe biconispora (ex-type; ZJUD62 and two other strains; ZJUD60 and ZJUD61) with 100\% ML and 100\% MP support (Fig. 13). Huang et al. (2015) introduced endophytic D. biconispora from the symptomless branch of Citrus grandis in Fujian Province, China. And also, D. biconispora recorded from symptomless branch of Fortunella margarita in Guangxi Province, China (Huang et al. 2015). The current collection of endophytes revealed D. biconispora associated with healthy leaves of Magnolia candolli in Yunnan Province, China and on M. garrettii Chiang Mai Province, Thailand.
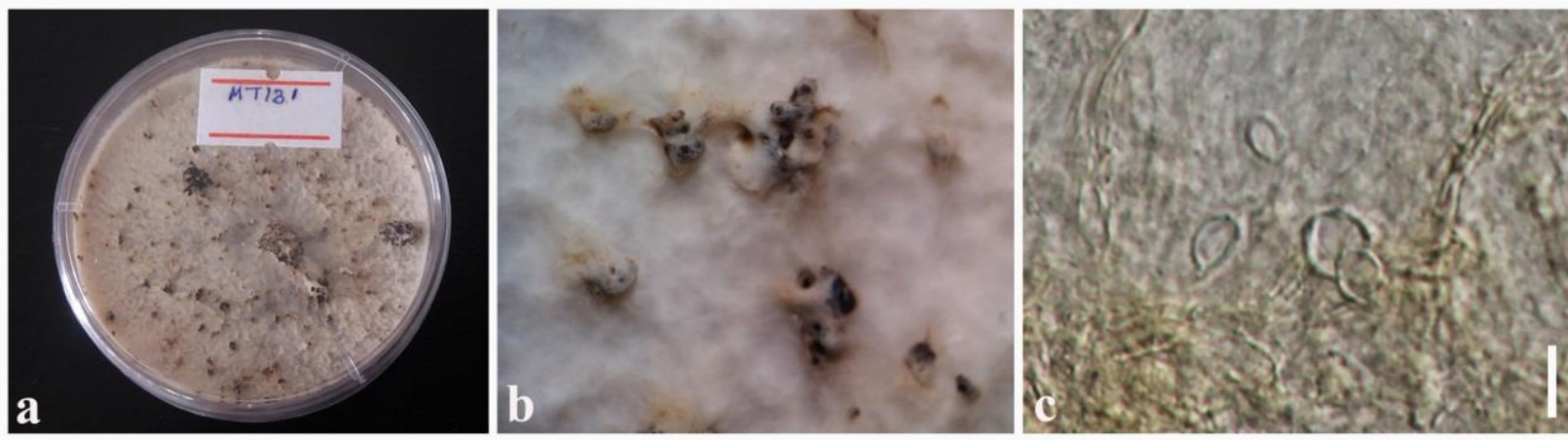

Figure 15 - Diaporthe biconispora (MFLUCC 19-0104, new host record). a Upper view of culture on PDA. b Mycelia on PDA. c Mycelia masses with chlamydospores. Scale bars: $c=10 \mu \mathrm{m}$. 
Diaporthe chinensis N.I. de Silva, Lumyong \& K.D. Hyde, sp. nov.

Fig. 16

Index Fungorum number: IF556135; Facesoffungi number: FoF09493

Etymology - Referring to the country where the specimen was collected, China.

Holotype - MFLU 20-0587

Endophytic in fresh leaves of Magnolia candolli. Colonies on PDA flat, white, felted appearance. Mycelia superficial and immersed composed of septate, branched, 2-3 $\mu \mathrm{m}$ wide, hyaline, with smooth and thick-walled hyphae. Sexual morph: Undetermined. Asexual morph: conidial masses with mycelia in culture on PDA. Conidiophores $12-15 \times 2-3 \mu \mathrm{m}(\bar{x}=13 \times 2.6$ $\mu \mathrm{m})$, hyaline, cylindrical, straight or slightly curved. Conidiogenous cells not observed. Alpha conidia $10-14 \times 3-6 \mu \mathrm{m}(\bar{x}=12 \times 5 \mu \mathrm{m})$, hyaline, fusiform, both ends obtuse with single guttulate. Beta conidia not observed.

Culture characteristics - Colonies on PDA reaching $25 \mathrm{~mm}$ diameter after 7 days at $25^{\circ} \mathrm{C}$, colonies circular, margin entire, flat, felted appearance, white mycelia, colony from above: white; reverse: cream.

Material examined - CHINA, Yunnan Province, Xishuangbanna, healthy leaves of Magnolia candolli (Magnoliaceae), 26 April 2017, N. I. de Silva S10 (MFLU 20-0587, holotype, dried culture); living culture, MFLUCC 19-0101 = KUMCC 17-0235.

Additional materials - CHINA, Yunnan Province, Xishuangbanna, healthy leaves of Magnolia candolli (Magnoliaceae), 26 April 2017, N. I. de Silva, S16, living culture, MFLUCC 19-0106 = KUMCC 17-0241.

GenBank numbers - (S10); ITS: MW187324, tub2: MW245013, tef1: MW205017, CAL: MW294199, (S16); ITS: MW187325, tub2: MW245014, tef1: MW219603, CAL: MW294200.
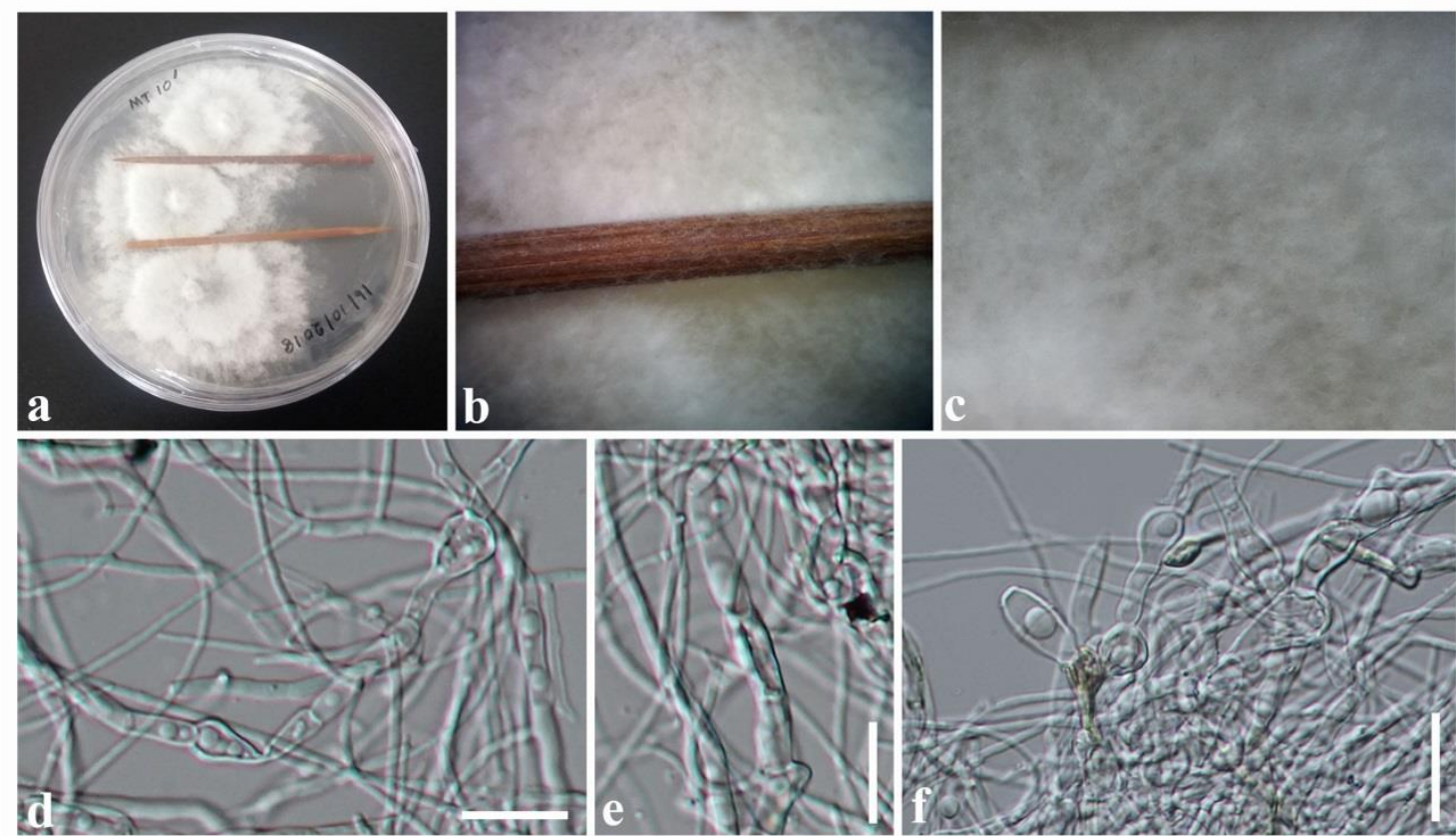

Figure 16 - Diaporthe chinensis (MFLU 20-0587). a Upper view of culture on PDA. b, c Mycelia on PDA. $d$, e Mycelia masses and chlamydospores. $\mathrm{f}$ Conidia with mycelium. Scale bars: $\mathrm{d}-\mathrm{f}=20$ $\mu \mathrm{m}$.

Notes - Based on combined multi-gene phylogenetic analysis, Diaporthe chinensis clustered separately, sister to D. yunnanensis with 92\% ML and 95\% MP support (Fig. 13). Alpha conidia of D. chinensis $(10-14 \times 3-6 \mu \mathrm{m})$ are larger than those of D. yunnanensis $(3-6.5 \times 1-2.5 \mu \mathrm{m})(\mathrm{Gao}$ et al. 2017). Diaporthe chinensis can also be distinguished from the ex-type of D. yunnanensis (LC 6168) considering base pair differences of ITS, tub2, tefl and CAL; $13 / 490=2.65 \%$ in ITS, $14 / 397$ $=3.52 \%$ in $t u b 2,13 / 293=4.43 \%$ in tefl, $12 / 410=2.92 \%$ in CAL. Diaporthe yunnanensis was 
isolated from healthy leaves of Coffea sp. in Xishuangbanna, Yunnan Province, China (Gao et al. 2017). Diaporthe chinensis found to associate with healthy leaves of Magnolia candolli in Xishuangbanna, Yunnan Province, China. Therefore, herein we introduce D. chinensis as a new species from China associated with healthy leaves of $M$. candolli based on morphology and phylogeny.

Diaporthe velutina Y.H. Gao \& L. Cai, IMA Fungus 8(1): 178 (2017)

Fig. 17

Index Fungorum number: IF820684; Facesoffungi number: FoF09441

See description in Gao et al. (2017)

Culture characteristics - Colonies on PDA reaching $22 \mathrm{~mm}$ diameter after 7 days at $25^{\circ} \mathrm{C}$, colonies circular, margin entire, flat, felted appearance, white and yellowish mycelia, colony from above: white and yellowish; reverse: brown. The culture did not produce any spores even on prolonged incubation.

Material examined - CHINA, Yunnan Province, Xishuangbanna, healthy leaves of Magnolia candolli (Magnoliaceae), 26 April 2017, N. I. de Silva, MT8 (MFLU 19-0513, dried culture); living culture, MFLUCC 19-0050 = KUMCC 17-0214.

GenBank numbers - ITS: MW187323, tub2: MW233022, tef1: MW182425.

Notes - Pathogenic Diaporthe velutina was introduced from diseased leaves of Neolitsea sp. in Jiangxi Province, China (Gao et al. 2017). Gao et al. (2017) additionally reported pathogenic D. velutina from diseased leaves of Callerya cinerea and Camellia sinensis in China. An endophytic strain also recovered from healthy leaves of $C$. sinensis in Xishuangbanna, Yunnan Province, China (Gao et al. 2017). A new endophytic strain, MT8 clustered with D. velutina with $100 \%$ ML and $100 \%$ MP support in the combined ITS, tub2, tefl and CAL phylogeny (Fig. 13). Therefore, we consider this is the first record of endophytic D. velutina from healthy leaves of Magnolia candolli.
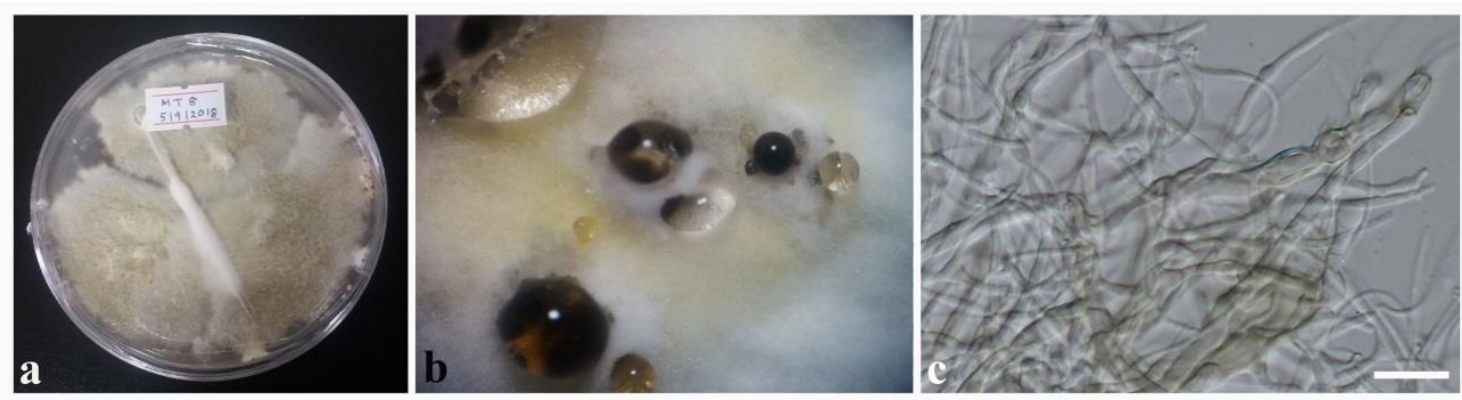

Figure 17 - Diaporthe velutina (MFLUCC 19-0050, new host record). a Upper view of culture on PDA. b Mycelia on PDA. c Mycelia masses. Scale bars: $c=20 \mu \mathrm{m}$.

\section{Diaporthe sp. 1}

Fig. 18

Endophytic in fresh leaves of Magnolia candolli. Colonies on PDA flat, brown felted appearance. Mycelia superficial and immersed composed of septate, branched, 2-3 $\mu \mathrm{m}$ wide, hyaline and light brown with smooth and thick-walled hyphae. Conidia were not observed. Some thick-walled, light brown, ovoid, 0-2-septate, chlamydospore-like structures, embedded in hyphae were observed.

Culture characteristics - Colonies on PDA reaching $25 \mathrm{~mm}$ diameter after 7 days at $25^{\circ} \mathrm{C}$, colonies circular, margin entire, flat, velvety appearance, light brown mycelia and white aerial mycelia and colony from above: light brown; reverse: dark brown.

Material examined - CHINA, Yunnan Province, Xishuangbanna, healthy leaves of Magnolia candolli (Magnoliaceae), 26 April 2017, N. I. de Silva, S11 (MFLU 20-0588, dried culture); living culture, MFLUCC 19-0102 = KUMCC 17-0236.

GenBank numbers - ITS: MW192408, tub2: MW233023, tef1: MW173088, CAL: MW294202. 
Notes - Based on combined multi-gene phylogenetic analysis, the new isolate (S11) clustered separately, sister to Diaporthe hongkongensis and D. lithocarpus with 96\% ML and 100\% MP support (Fig. 13). This new isolate did not sporulate in culture. Therefore it was not possible to observe conidial characters. The ex-type of D. hongkongensis (CBS 115448) was isolated on fruits of Dichroa febrifuga in Hong Kong (Gomes et al. 2013). The ex-type of D. lithocarpus (CGMCC 3.15175) was isolated from leaf spots of Lithocarpus glabra in Zhejiang Province, China (Gao et al. 2014). The new isolate (S11) found to associate with healthy leaves of Magnolia candolli in Xishuangbanna, Yunnan Province, China. The new isolate (S11) might be a distinct taxon based on our phylogenetic analyses and host association. However, we do not propose a new species of Diaporthe here, as we were unable to observe complete morphology of the fungus.
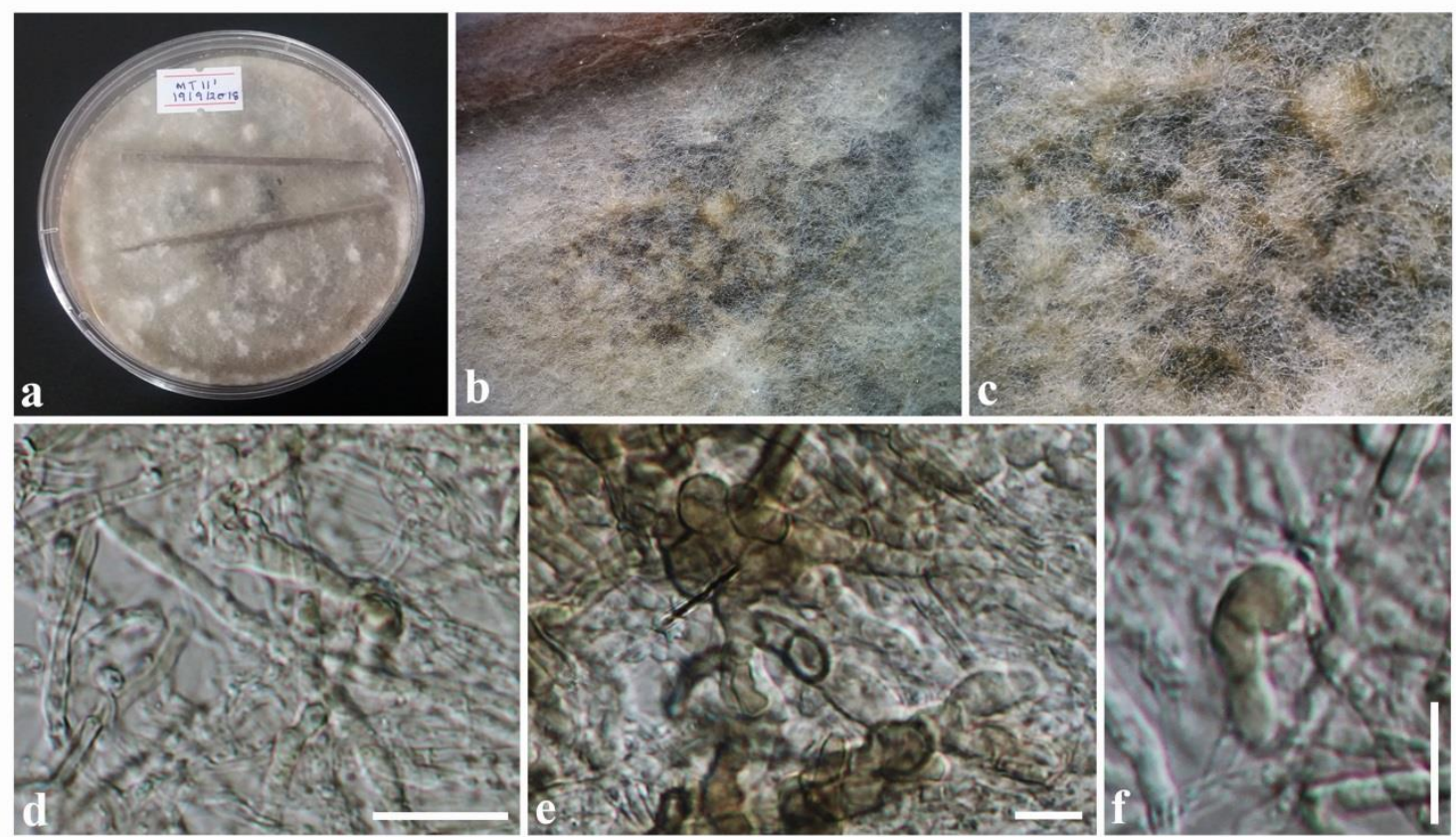

Figure 18 - Diaporthe sp. 1 (MFLU 20-0588). a Upper view of culture on PDA. b, c Mycelium on PDA. $d-f$ Mycelia masses and chlamydospore-like structures. Scale bars: $d=20 \mu \mathrm{m}, \mathrm{e}, \mathrm{f}=10 \mu \mathrm{m}$.

Subclass Hypocreomycetidae O.E. Erikss. \& Winka

Glomerellales Chadef. ex Re'blova' et al.

Glomerellaceae Locq.

Glomerellaceae (Glomerellales, Sordariomycetes), consists of the sole member of Colletotrichum (Jayawardena et al. 2016, Hyde et al. 2020b). Species of this genus are important pathogens; some are endophytes as well as saprobes (Hyde et al. 2014, Jayawardena et al. 2016).

\section{Colletotrichum Corda}

Colletotrichum is one of the major economically important plant pathogenic genera with worldwide distribution and studies revealed that these pathogens may exhibit as saprophytic or endophytic lifestyles in nature (Damm et al. 2012, Gautam 2014, Jayawardena et al. 2016). Pathogenic species infect plants using different methods for invading host tissue, ranging from intracellular hemibiotrophic to subcuticular intramural necrotrophy (Gautam 2014). Index Fungorum (2021) lists 928 species epithets for Colletotrichum.

Multigene phylogenetic analyses detected new species and several species complexes in this genus (Cannon et al. 2012, Jayawardena et al. 2016, 2020). Recent studies used phylogenetic analysis based on concatenated genes for species delimitation within the genus (Jayawardena et al. 2016). Jayawardena et al. (2020) identified 14 species complexes in Colletotrichum and 20 singleton species. The gloeosporioides species complex mainly consists of plant pathogens (Weir et 
al. 2012), but some species were isolated as endophytes (C. endophytica, C. fructicola, C. gloeosporioides) (Promputtha et al. 2005, Prihastuti et al. 2009, Liu et al. 2015a, Jayawardena et al. 2016, 2020, Ma et al 2018).

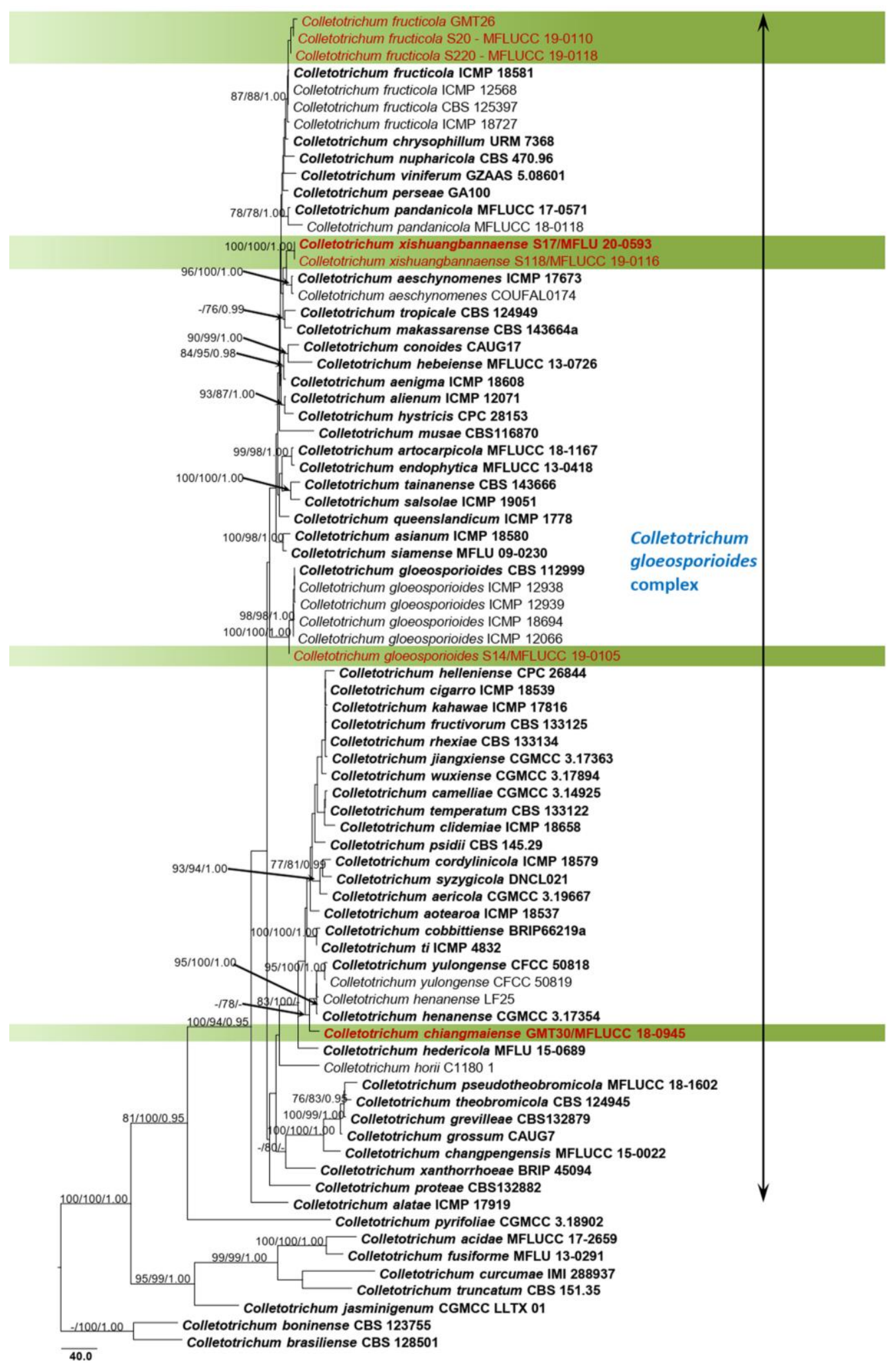

Figure 19 - Phylogram generated from maximum parsimony analysis based on combined ITS, GAPDH, CHS, ACT and tub2 sequence data. Related sequences of Colletotrichum (C. gloeosporioides complex) were obtained from Jayawardena et al. (2020). Seventy eight strains are included in the combined gene analyses comprising 1760 characters after alignment (500 
characters for ITS, 250 characters for GAPDH, 280 characters for CHS, 250 characters for ACT and 480 characters for tub2). Colletotrichum boninense (CBS 123755) and C. brasilliense (CBS 128501) are used as outgroup taxa. The best RAxML tree with a final likelihood value of 13102.992629 is presented. The matrix had 1042 distinct alignment patterns, with $20.67 \%$ undetermined characters or gaps. Estimated base frequencies were as follows: $\mathrm{A}=0.229409$, $\mathrm{C}=0.295382, \mathrm{G}=0.243801, \mathrm{~T}=0.231407$; substitution rates $\mathrm{AC}=1.015583, \mathrm{AG}=2.923416, \mathrm{AT}$ $=1.312931, \mathrm{CG}=0.864260, \mathrm{CT}=4.263907, \mathrm{GT}=1.000000$; gamma distribution shape parameter $\alpha=1.566948$. Bootstrap values for maximum parsimony, maximum likelihood equal to or greater than $75 \%$ and Bayesian posterior probabilities equal or greater than 0.95 are placed above the branches. The newly generated sequences are indicated in red. Type and ex-type strains are in bold.

Colletotrichum chiangmaiense N.I. de Silva, Lumyong \& K.D. Hyde, sp. nov.

Fig. 20 Index Fungorum number: IF556379; Facesoffungi number: FoF09494

Etymology - Referring to the location where the fungus was discovered, Chiang Mai Province, Thailand.

Holotype - MFLU 20-0604

Endophytic in fresh leaves of Magnolia garrettii. Colonies on water agar (WA), flat, white, velvety appearance. Mycelia superficial and immersed composed of septate, branched, 2-3 $\mu \mathrm{m}$ wide, hyaline and light brown with smooth and thick-walled hyphae. Sexual morph: Undetermined. Asexual morph: acervulus with conidial masses and mycelia in culture on WA. Conidiophores not observed. Conidiogenous cells $2-4 \times 1-2 \mu \mathrm{m}(\bar{x}=3 \times 1.4 \mu \mathrm{m})$, hyaline, short, cylindrical or ampulliform, formed directly from vegetative hyphae. Conidia 4-7 $\times 2-3.5 \mu \mathrm{m}(\bar{x}=5 \times 2 \mu \mathrm{m})$, hyaline, fusiform, ellipsoidal to cylindrical with one end slightly acute when immature state, both ends obtuse when mature.

Culture characteristics - Colonies on WA reaching $20 \mathrm{~mm}$ diameter after 7 days at $25^{\circ} \mathrm{C}$, colonies circular, margin entire, flat, velvety appearance, white aerial mycelia and colony from above: white; reverse: cream.

Material examined - THAILAND, Chiang Mai Province, healthy leaves of Magnolia garrettii (Magnoliaceae), 14 August 2017, N. I. de Silva, GMT30 (MFLU 20-0604, holotype, dried culture); ex-type living culture, MFLUCC 18-0945.

GenBank numbers - ITS: MW346499, GAPDH: MW548592, CHS: MW623653, ACT: MW655578.

Notes - Colletotrichum chiangmaiense (GMT30) has a close phylogenetic affinity to $C$. henanense and C. yulongense and clustered separately to those two sister taxa with $65 \% \mathrm{MP}, 78 \%$ ML and 0.79 BYPP support (Fig. 19). Conidia of $C$. chiangmaiense $(4-7 \times 2-3.5 \mu \mathrm{m})$ is smaller than those of $C$. henanense $(8-17 \times 3-5.5 \mu \mathrm{m})$ (Liu et al. 2015a) and $C$. yulongense $(11-13 \times 4-5$ $\mu \mathrm{m})$ (Wang et al. 2019).

In a BLASTn search of GenBank, the ITS sequence had $100 \%$ similarity to $C$. siamense (bl20), the GAPDH sequence had 98\% similarity to C. camelliae (MZ 12), the CHS had 100\% similarity to $C$. camelliae (FWY41) and the ACT sequence had 93\% similarity to $C$. aotearoa (BM2). Comparison of nucleotides differences between $C$. chiangmaiense and $C$. henanense reveals $3 / 480=0.62 \%$ in ITS, $6 / 220=2.72 \%$ in GAPDH, $10 / 220=4.54 \%$ in ACT. CHS sequence data is not available for $C$. henanense. Comparison of nucleotides differences between $C$. chiangmaiense and $C$. yulongense reveals $5 / 480=1.04 \%$ in ITS, $11 / 200=5.5 \%$ in GAPDH, $6 / 222$ $=2.7 \%$ in CHS, $11 / 198=5.5 \%$ in ACT . A PHI test revealed no significant recombination event among C. chiangmaiense and its closely related taxa (Fig. 21).

Colletotrichum henanense was isolated from Camellia sinensis in China (Liu et al. 2015a) and C. yulongense from healthy leaves of Vaccinium dunalianum var. urophyllum in China (Wang et al. 2019). There is a Colletotrichum species isolated from leaves of Magnolia grandiflora in Portugal named as C. magnoliae. Conidia of C. magnoliae (15-18 $\times 5-6 \mu \mathrm{m})$ (Saccardo 1931) are larger than those of $C$. chiangmaiense. In this study, $C$. chiangmaiense is introduced as a novel taxon based on morphology and phylogeny. 


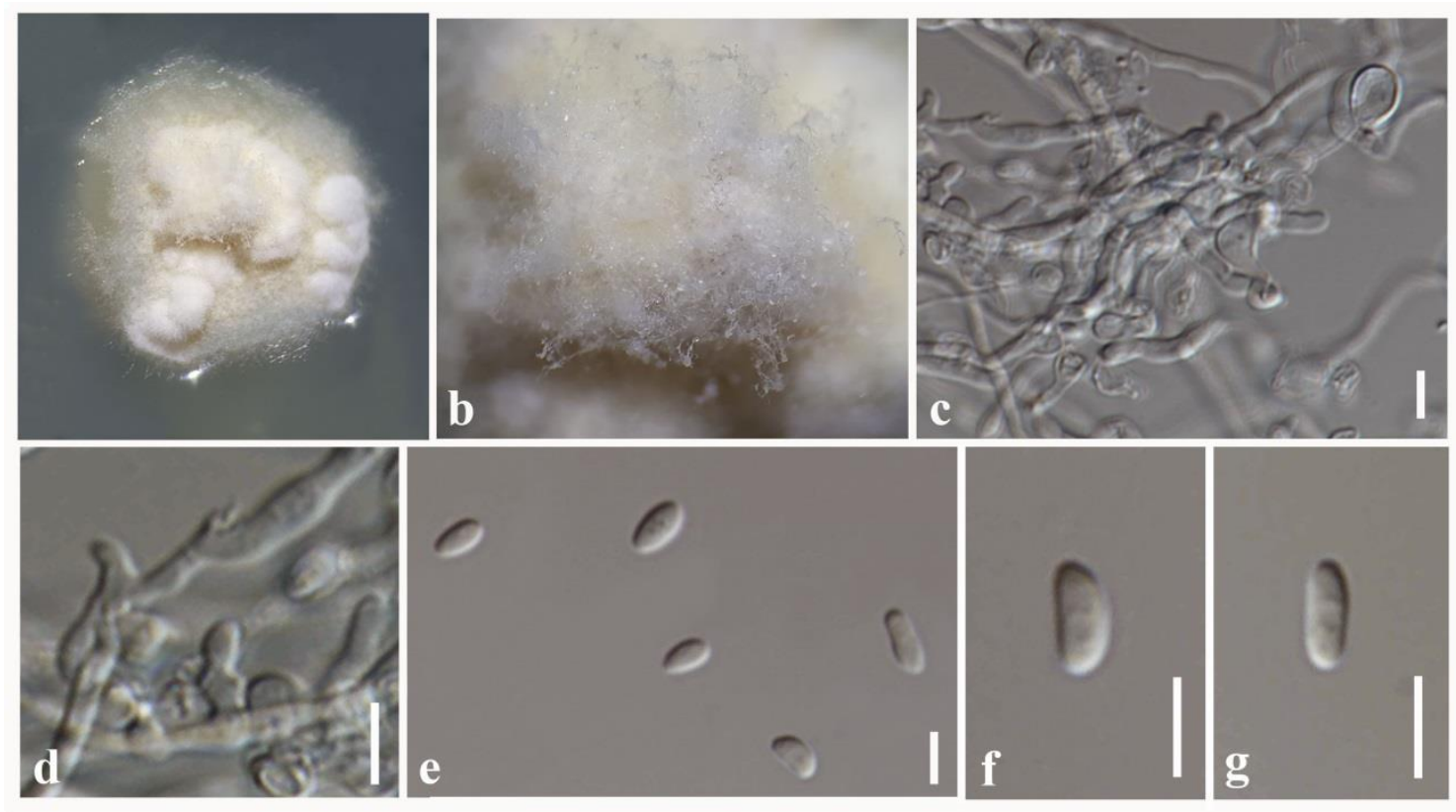

Figure 20 - Colletotrichum chiangmaiense (MFLU 20-0604, holotype), a, b Mycelia on WA. c Mycelia. d Developing conidia. e-g Conidia. Scale bars: $\mathrm{c}-\mathrm{g}=5 \mu \mathrm{m}$.

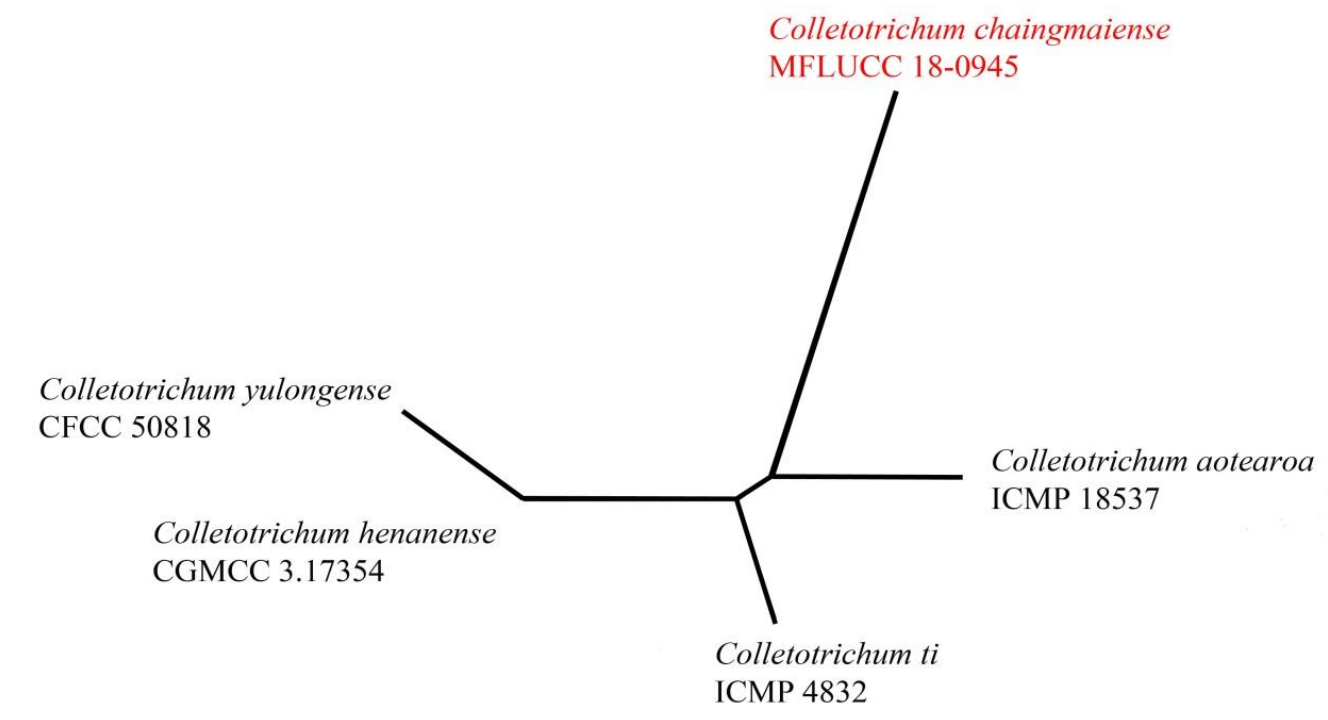

$\overline{0.01}$

$\Phi \mathrm{W}=1.0$

Figure 21 - The splits graph from the pairwise homoplasy index (PHI) test generated from the concatenated gene set of ITS, GAPDH, CHS, ACT and tub2 sequence data of closely related species of Colletotrichum using both LogDet transformation and splits decomposition. PHI test result $\left(\Phi_{\mathrm{w}}\right)<0.05$ indicates significant recombination within the dataset. The strain determined in this study is in red.

Colletotrichum fructicola Prihast., L. Cai \& K.D. Hyde, Fungal Diversity 39: 96 (2009)

Fig. 22

Index Fungorum number: IF515409; Facesoffungi number: FoF06767

Endophytic in fresh leaves of Magnolia candolli. Colonies on PDA, flat, brown, velvety appearance with white aerial mycelia. Mycelia superficial and immersed composed of septate, branched, 2-3 $\mu \mathrm{m}$ wide, hyaline and light brown with smooth and thick-walled hyphae. Asexual morph: black conidial masses on pine needle. Conidiophores micronematous, inconspicuous. 
Conidiogenous cells $6-8 \times 2-3 \mu \mathrm{m}(\bar{x}=7 \times 2.3 \mu \mathrm{m})$, hyaline, cylindrical, formed directly from vegetative hyphae. Conidia 10-13 $\times 4-6 \mu \mathrm{m}(\bar{x}=12 \times 5 \mu \mathrm{m})$, hyaline, cylindrical, the apex and base rounded, straight, aseptate, smooth-walled. Sexual morph: Ascomata black, semi-immersed to superficial covered with mycelia, globose to subglobose, solitary or aggregated. Asci 60-80 × 6-10 $\mu \mathrm{m}(\bar{x}=72 \times 8 \mu \mathrm{m})$, hyaline, 8-spored, unitunicate, cylindrical, cylindrical-clavate, slightly curved, sessile. Ascospores $15-20 \times 3-5 \mu \mathrm{m}(\bar{x}=17 \times 4 \mu \mathrm{m})$, hyaline, fusiform, straight or slightly curved, obtuse to somewhat acute or acute both end, smooth-walled.

Culture characteristics - Colonies on PDA reaching $23 \mathrm{~mm}$ diameter after 7 days at $25^{\circ} \mathrm{C}$, colonies circular, margin entire, flat, velvety appearance, white aerial mycelia and colony from above: brown; reverse: cream.

Material examined - CHINA, Yunnan Province, Xishuangbanna, healthy leaves of Magnolia candolli (Magnoliaceae), 26 April 2017, N. I. de Silva, S220 (MFLU 20-0602, dried culture); living culture, MFLUCC 19-0118 = KUMCC 17-0254, S20, living culture, MFLUCC 19-0110), THAILAND, Chiang Mai Province, healthy leaves of Magnolia garrettii (Magnoliaceae), 14 August 2017, N. I. de Silva GMT26.

GenBank numbers - (S220); ITS: MW346500, GAPDH: MW459185, CHS: MW560178, ACT: MW652293, (S20); ITS: MW346501, GAPDH: MW459186, CHS: MW560177, ACT: MW652292, (GMT 26); ITS: MW346502, GAPDH: MW465945, CHS: MW560179.

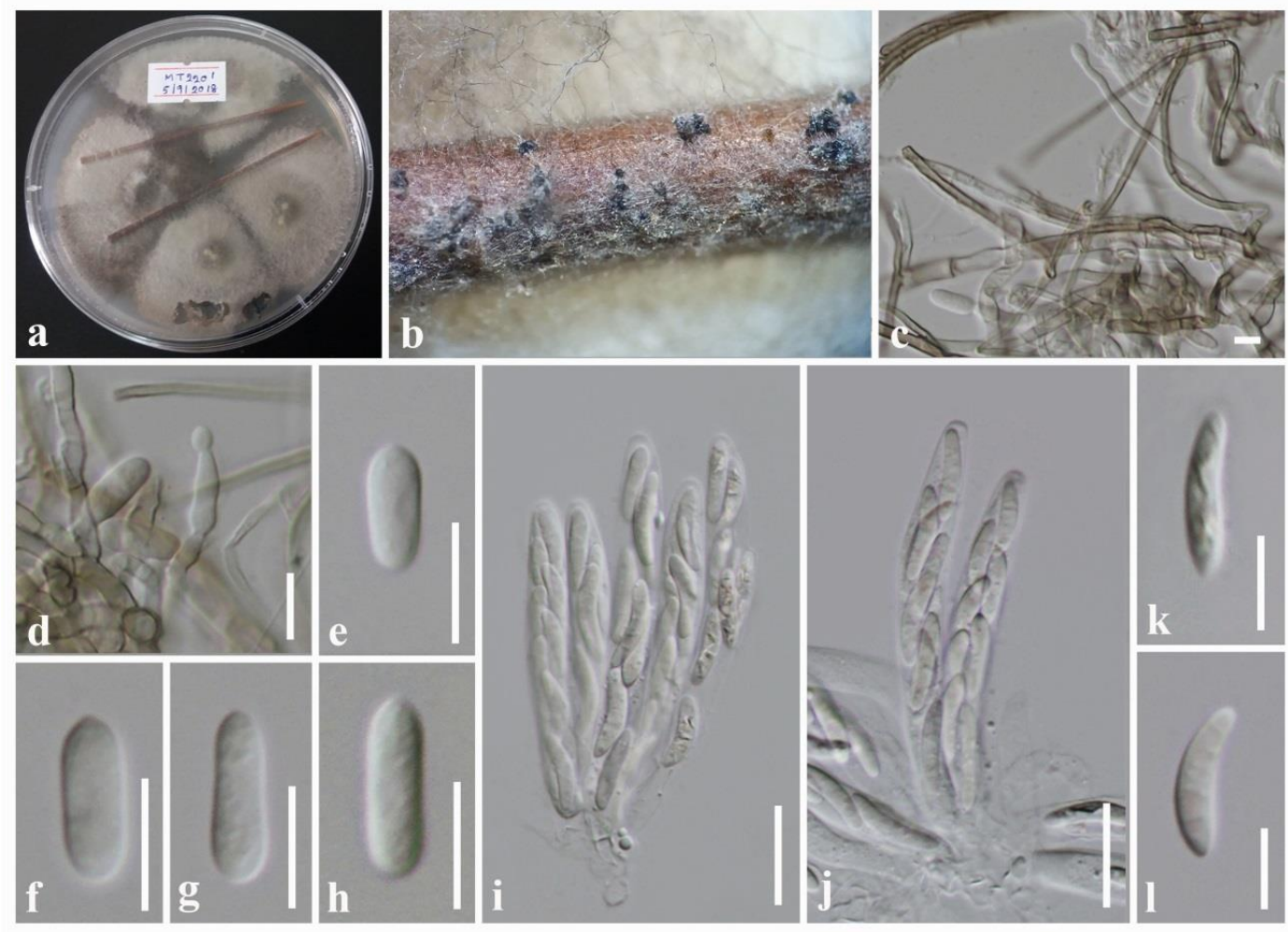

Figure 22 - Colletotrichum fructicola (MFLUCC 19-0118, new host and geographical record). $\mathrm{a}, \mathrm{b}$ Conidial masses and ascomata on pine needle. c Mycelia. d Conidiogenus cells with conidia. $\mathrm{e}-\mathrm{h}$ Conidia. i, j Asci. k, 1 Ascospores. Scale bars: $\mathrm{c}=5 \mu \mathrm{m}, \mathrm{d}-\mathrm{h}=10 \mu \mathrm{m}, \mathrm{i}, \mathrm{j}=20 \mu \mathrm{m}, \mathrm{k}, \mathrm{l}=10$ $\mu \mathrm{m}$.

Notes - Phylogenetic analyses of a concatenated ITS, GAPDH, CHS, ACT and tub2 sequence data showed that our strains (S220, S20 and GMT26) group together with $C$. fructicola (Fig. 19). The new isolate (S220) shares similar morphology with the type of C. fructicola (MFLU 09-0228) in having hyaline, cylindrical conidia with obtuse to slightly rounded ends and hyaline, slightly curved to curved ascospores with obtuse to slightly rounded ends (Prihastuti et al. 2009). Conidia of new isolate $(\mathrm{S} 220)(12-14 \times 4-5 \mu \mathrm{m})$ and the type $C$. fructicola $(9.7-14 \times 3-4.3 \mu \mathrm{m})$ 
have overlapping size range (Prihastuti et al. 2009). Ascospores of new isolate (S220) $(15-18 \times 3-5$ $\mu \mathrm{m})$ are slightly larger than the type $C$. fructicola $(9-14 \times 3-4 \mu \mathrm{m})$ (Prihastuti et al. 2009). The type of C. fructicola was introduced on berries of Coffea arabica in Chiang Mai Province, Thailand (Prihastuti et al. 2009). Colletotrichum fructicola was isolated as endophytes and saprobes from Coffea arabica (Prihastuti et al. 2009). Colletotrichum fructicola has a wide host range and geographical distribution including Arachis sp. (Fabaceae), Citrus bergamia (Rutaceae) in China; Cymbopogon citrates (Poaceae) in Thailand; Dioscorea alata in Nigeria, Ficus sp. (Dioscoreaceae) in Germany, Fragaria $\times a n a n a s s a$ (Rosaceae) in Canada and the USA, Limonium sp. (Plumbaginaceae) in Israel, Malus domestica (Rosaceae) in Australia, Brazil and Uruguay; Mangifera indica (Anacardiaceae) in India and Brazil; Persea americana (Lauraceae) in Australia, Pyrus pyrifolia (Rosaceae) in Japan, Theobroma cacao (Malvaceae) and Tetragastris panamensis (Burseraceae) in Panama, Pennisetum purpureum (Poaceae) in Thailand; and Camellia sinensis (Wang et al. 2016), Rubus glaucus (Rosaceae) and Vitis vinifera (Vitaceae) in China (Jayawardena et al. 2016). In this study, we report an isolate associate with healthy leaves of Magnolia garrettii in Chiang Mai Province, Thailand. Furthermore, we identified two isolates of C. fructicola and reported its occurrence associate with healthy leaves of Magnolia candolli in Yunnan, China, for the first time.

Colletotrichum gloeosporioides (Penz.) Penz. \& Sacc., Atti Reale Ist. Veneto di Scienze, Lettere ed arti. Series 6, 2: 670. 1884

Index Fungorum number: IF158410; Facesoffungi number: FoF09424

See description in Weir et al. (2012)

Culture characteristics - Colonies on PDA reaching $25 \mathrm{~mm}$ diameter after 7 days at $25^{\circ} \mathrm{C}$, colonies circular, margin entire, flat, velvety appearance, white aerial mycelia and colony from above: white; reverse: cream. The culture did not produce any spores even on prolonged incubation.

Material examined - CHINA, Yunnan Province, Xishuangbanna, healthy leaves of Magnolia candolli (Magnoliaceae), 26 April 2017, N. I. de Silva, S14, living culture, MFLUCC 19-0105 = KUMCC 17-0239.

GenBank numbers - ITS: MW346486, GAPDH: MW512652, CHS: MW602917, ACT: MW652296.

Notes - Multigene phylogenetic analyses show that the new strain S14 is sister to the ex-type of Colletotrichum gloeosporioides (CBS 112999) with 100\% MP, 100\% ML and 1.00 BYPP support (Fig. 19). Colletotrichum gloeosporioides has reported from different geographical regions and various host plants, i.e. on Citrus sinensis (ex-epitype culture of C. gloeosporioides, CBS 112999) in Italy, on Carya illinoinensis in Australia, on Citrus sp., on Ficus sp. in New Zealand, on Mangifera indica in South Africa, on Pueraria lobata, on Citrus sp. on Vitis vinifera in the USA (Weir et al. 2012). Colletotrichum gloeosporioides was recorded from Magnolia liliifera in Thailand as endophytic lifestyle (Promputtha et al. 2005). In addition, C. gloeosporioides was recorded on Magnolia denudata in China, M. grandiflora in India, North Carolina, Magnolia officinalis var. biloba in China and Magnolia sp. in Poland (Farr \& Rossman 2021). Therefore, we identify S14 as C. gloeosporioides based on phylogeny and our isolate is introduced here as a new endophytic host record from $M$. candolli collected in China.

Colletotrichum xishuangbannaense N.I. de Silva, Lumyong \& K.D. Hyde, sp. nov.

Fig. 23

Index Fungorum number: IF556380; Facesoffungi number: FoF09495

Etymology - Referring to the location where the fungus was discovered, Xishuangbanna, Yunnan Province, China.

Holotype - MFLU 20-0593

Endophytic in fresh leaves of Magnolia candolli. Colonies on PDA slightly raised cream mycelia. Mycelia superficial and immersed composed of septate, branched, 2-3 $\mu \mathrm{m}$ wide, hyaline and light brown with smooth and thick-walled hyphae. Sexual morph: Undetermined. Asexual 
morph: coelomycetous, conidial masses with mycelia in culture on PDA. Conidiophores not observed. Conidiogenous cells 15-18 $\times 1.5-2 \mu \mathrm{m}(\bar{x}=16 \times 1.7 \mu \mathrm{m})$, hyaline, cylindrical, smoothwalled. Conidia 9-12 $\times 3-4 \mu \mathrm{m}(\bar{x}=11 \times 3.5 \mu \mathrm{m})$, hyaline, cylindrical with the apex and base rounded. Appressoria not observed.

Culture characteristics - Colonies on PDA reaching $27 \mathrm{~mm}$ diameter after 7 days at $25^{\circ} \mathrm{C}$, colonies circular, margin undulate, slightly raised, velvety appearance, cream aerial mycelia and colony from above: light brown; reverse: brown.

Material examined - CHINA, Yunnan Province, Xishuangbanna, healthy leaves of Magnolia candolli (Magnoliaceae), 26 April 2017, N. I. de Silva, S17 (MFLU 20-0593, holotype, dried culture); ex-type living culture, MFLUCC 19-0107 = KUMCC 17-0242.

Additional materials - CHINA, Yunnan Province, Xishuangbanna, healthy leaves of Magnolia candolli (Magnoliaceae), 26 April 2017, N. I. de Silva S118, living culture, MFLUCC 19-0116.

GenBank numbers - (S17); ITS: MW346469, GAPDH: MW537586, CHS: MW660832, ACT: MW652294, (S118); ITS: MW346470, GAPDH: MW537587, CHS: MW660833, ACT: MW652295.

Notes - Colletotrichum xishuangbannaense clustered closely related to $C$. aeschynomenes with 40\% MP, 25\% ML, 0.83 BYPP support (Fig. 19). Morphologically, C. xishuangbannaense differs from $C$. aeschynomenes in having small conidia. Colletotrichum aeschynomenes has 14-20 $\times$ 4-5 $\mu \mathrm{m}$ conidia (Weir et al. 2012) and C. xishuangbannaense has 9-12 × 3-4 $\mu \mathrm{m}$ conidia. Colletotrichum magnoliae was isolated from leaves of Magnolia grandiflora in Portugal (Saccardo 1931). Conidia of $C$. magnoliae $(15-18 \times 5-6 \mu \mathrm{m})$ (Saccardo 1931) are larger than $C$. xishuangbannaense.
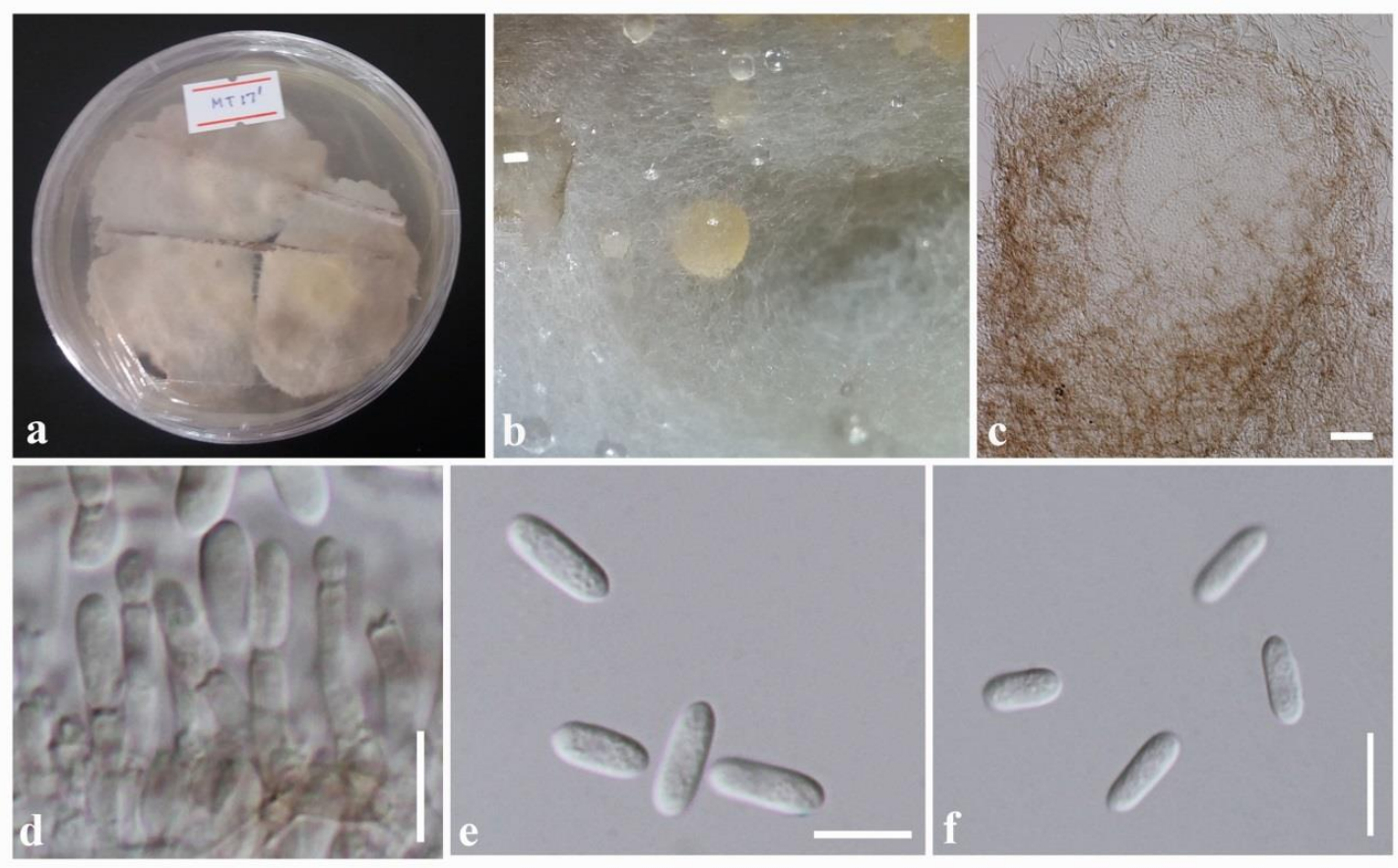

Figure 23 - Colletotrichum xishuangbannaense (MFLU 20-0593, holotype). a Colonies on PDA. b Conidial masses. c Mycelia and conidial masses. d Conidiogenus cells with conidia. e, f Conidia. Scale bars: $\mathrm{c}=50 \mu \mathrm{m}, \mathrm{d}-\mathrm{f}=10 \mu \mathrm{m}$.

In a BLASTn search of GenBank, the ITS sequence had $100 \%$ similarity to $C$. aenigma (GQH124), the GAPDH sequence had 98\% similarity to $C$. fructicola (TS-B173), the CHS had 98\% similarity to $C$. siamense (ccmi3) and the ACT sequence had $99 \%$ similarity to $C$. siamense (LC0537). Comparison of nucleotides differences between C. xishuangbannaense and the ex-type C. aeschynomenes (ICMP 17673) reveals $3 / 480=0.62 \%$ in ITS, $5 / 220=2.27 \%$ in GAPDH, $5 / 250$ 
$=2 \%$ in CHS and 4/230 $=1.73 \%$ ACT. A PHI test revealed no significant recombination event among $C$. xishuangbannaense and its closely related taxa (Fig. 24). Colletotrichum aeschynomenes was isolated as a pathogen of stem lesion from Aeschynomene virginica in the USA (Weir et al. 2012). In this study, we introduce $C$. xishuangbannaense as a novel taxon based on phylogeny and morphology.

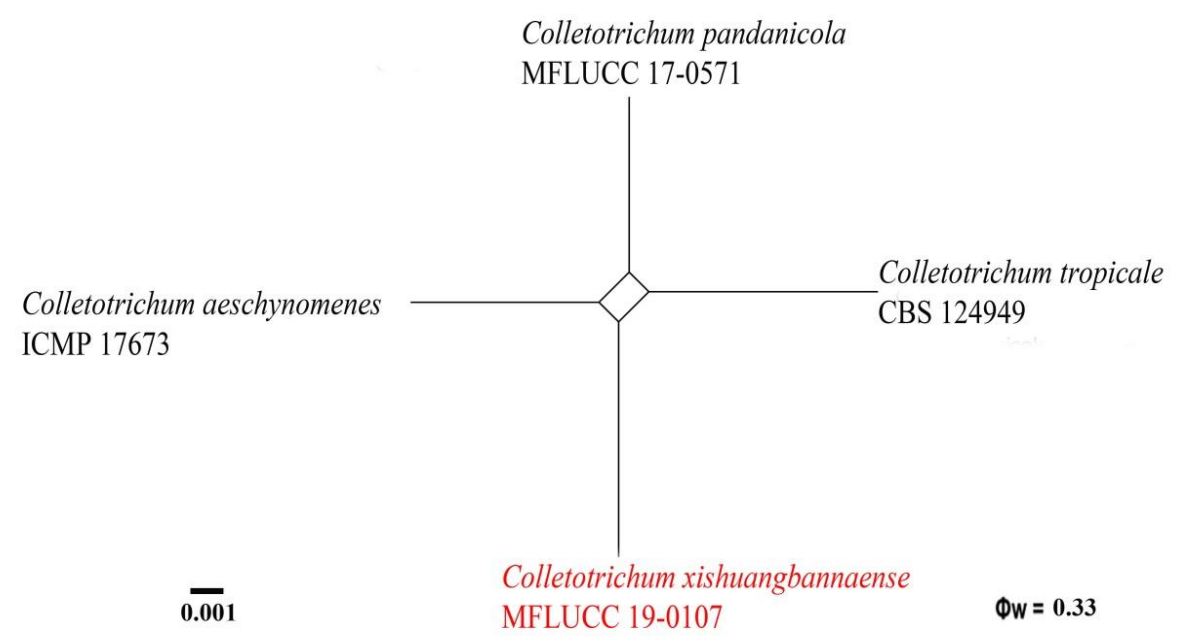

Figure 24 - The splits graph from the pairwise homoplasy index (PHI) test generated from the concatenated gene set of ITS, GAPDH, CHS, ACT and tub2 sequence data of closely related species of Colletotrichum using both LogDet transformation and splits decomposition. PHI test result $\left(\Phi_{\mathrm{w}}\right)<0.05$ indicates significant recombination within the dataset. The strain determined in this study is in red.

Colletotrichum karsti You L. Yang, Zuo Y. Liu, K.D. Hyde \& L. Cai [as 'karstii'], Cryptogamie in Mycology 32(3): 241 (2011)

Fig. 26

Index Fungorum number: IF581687; Facesoffungi number: FoF09442

Endophytic in fresh leaves of Magnolia candolli. Colonies on PDA, slightly raised, cream, light brown mycelia. Mycelia superficial and immersed composed of septate, branched, 2-3 $\mu \mathrm{m}$ wide, hyaline and light brown with smooth and thick-walled hyphae. Sexual morph: Undetermined. Asexual morph: dark brown conidial masses on PDA. Conidiophores not observed. Conidiogenous cells inconspicuous. Conidia 20-22 $\times 5-7 \mu \mathrm{m}(\bar{x}=21 \times 6 \mu \mathrm{m})$, hyaline, cylindrical, the apex and base obtuse, straight and or slightly curved, aseptate, smooth-walled with small guttules.

Culture characteristics - Coelomycetous with acervuli in culture. Colonies on PDA reaching $36 \mathrm{~mm}$ diameter after 7 days at $25^{\circ} \mathrm{C}$, colonies circular, margin entire, slightly raised, cream and light brown mycelia, colony from above: cream, reverse: light brown.

Material examined - THAILAND, Chiang Mai Province, healthy leaves of Magnolia garrettii (Magnoliaceae), 14 August 2017, N. I. de Silva GMT20, living culture, MFLUCC 180939, GMT5, living culture, MFLUCC 18-0934, CHINA, Yunnan Province, Xishuangbanna, healthy leaves of Magnolia candolli (Magnoliaceae), 26 April 2017, N. I. de Silva, MT9, living culture, KUMCC 17-0215.

GenBank numbers - (GMT20); ITS: MW346472, GAPDH: MW452329, CHS: MW631937, ACT: MW664999, (GMT5); ITS: MW346471, GAPDH: MW452328, CHS: MW631936, ACT: MW664998, tub2: MW727264, (MT9); ITS: MW346473, GAPDH: MW452330.

Notes - Colletotrichum karsti was introduced by Yang et al. (2011) associate with anthracnose lesions on leaves of Vanda sp. in China. The new collection differs from the holotype (GZAAS 090006), in having larger (20-22 × 5-7 $\mu \mathrm{m})$ conidia. Colletotrichum karsti has 12.5-19.5 $\times 6-8.5 \mu \mathrm{m}$ conidia (Yang et al. 2011). Colletotrichum karsti has a wide host species range from 
Orchidaceae as a pathogen causing dark brown to black, ellipsoid lesions on leaves of Arundina graminifolia, Calanthe argenteo-striata, Eria Coronaria and also isolated as an endophyte of roots of Pleione bulbocodioides (Yang et al. 2011). The new collection is reported as a new host record of $C$. karsti associated with healthy leaves of Magnolia candolli (Magnoliaceae) for the first time.

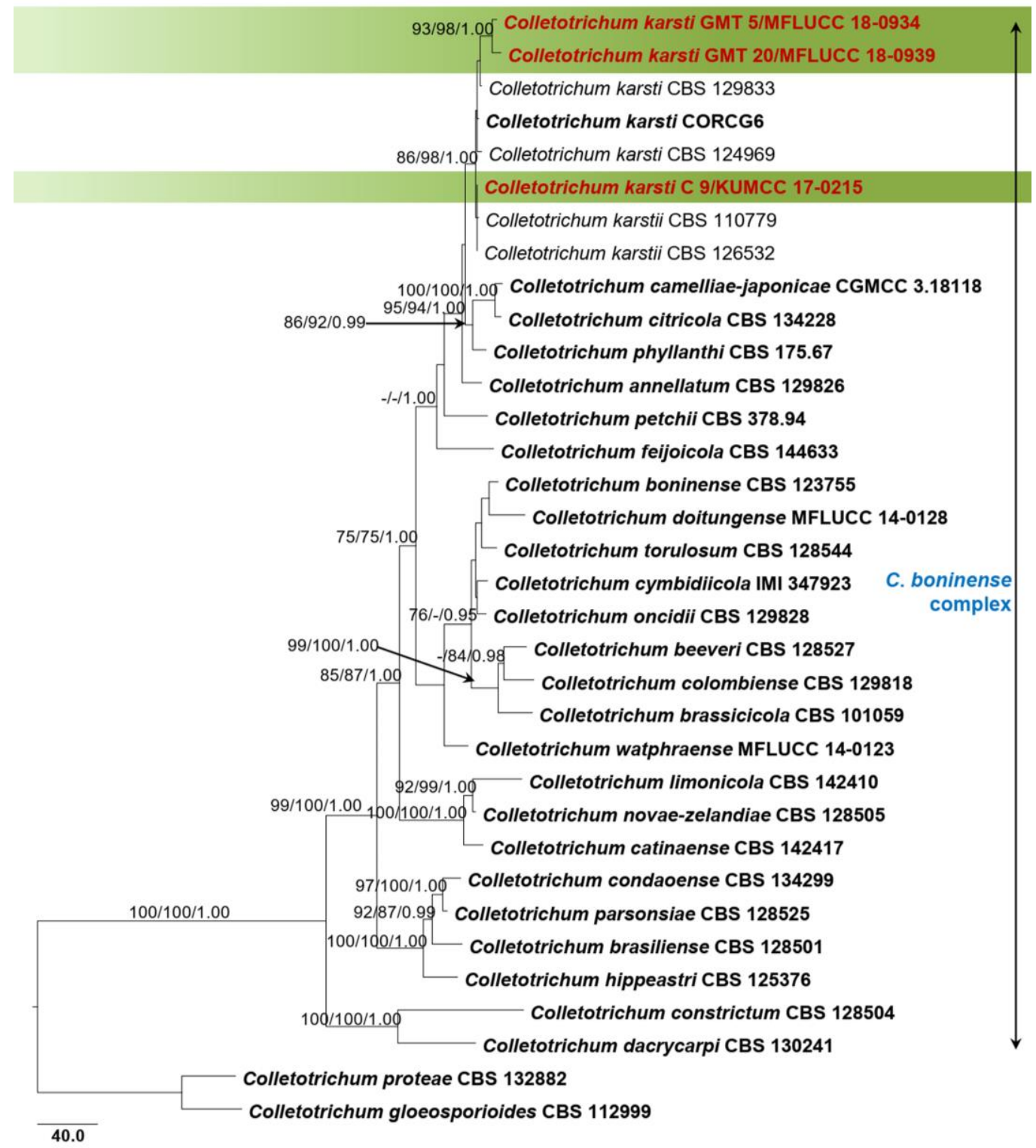

Figure 25 - Phylogram generated from maximum parsimony analysis based on combined ITS, GAPDH, CHS, ACT and $t u b 2$ sequence data. Related sequences of $C$. boninense complex were obtained from Jayawardena et al. (2020). Thirty four strains are included in the combined gene analyses comprising 1810 characters after alignment (540 characters for ITS, 250 characters for GAPDH, 270 characters for CHS, 260 characters for ACT and 490 characters for tub2). Colletotrichum gloeosporioides (CBS 112999) and C. proteae (CBS 132882) are used as outgroup taxa. The best RAxML tree with a final likelihood value of -8649.542487 is presented. The matrix had 715 distinct alignment patterns, with $11.03 \%$ undetermined characters or gaps. Estimated base frequencies were as follows: $\mathrm{A}=0.227512, \mathrm{C}=0.297420, \mathrm{G}=0.250297, \mathrm{~T}=0.224771$; substitution rates $\mathrm{AC}=1.332056, \mathrm{AG}=3.193250, \mathrm{AT}=1.057960, \mathrm{CG}=0.931964, \mathrm{CT}=$ 4.681567, GT $=1.000000$; gamma distribution shape parameter $\alpha=1.481581$. Bootstrap values for maximum parsimony and maximum likelihood equal to or greater than $75 \%$ and Bayesian posterior probabilities $\geq 0.95$ (PP) are placed above the branches. The newly generated sequences are indicated in red. Type and ex-type strains are in bold. 

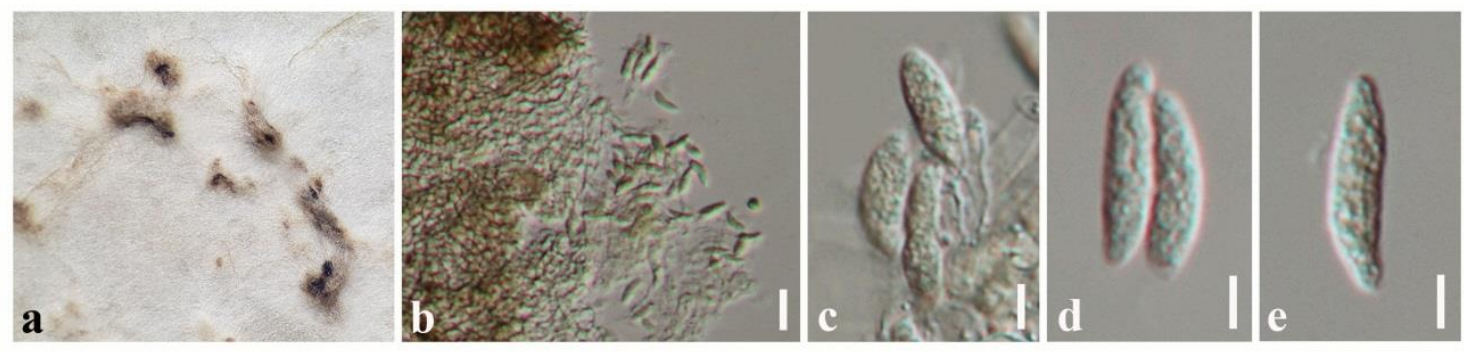

Figure 26 - Colletotrichum karsti (MFLUCC 18-0939, new host record). a Conidial masses on PDA. b Mycelia and conidia. $\mathrm{c}-\mathrm{e}$ Conidia. Scale bars: $\mathrm{b}=10 \mu \mathrm{m}, \mathrm{c}-\mathrm{e}=5 \mu \mathrm{m}$.

Subclass Xylariomycetidae O.E. Erikss. \& Winka

Amphisphaeriales D. Hawksw. \& O.E. Erikss.

Sporocadaceae Corda

Sporocadaceae was introduced by Corda (1842) with the type genus Sporocadus. Members of Sporocadaceae are appendaged coelomycetes and they exhibit as endophytes, plant pathogens or saprobes in a wide range of host plants (Liu et al. 2019). Sporocadaceae mostly consists of asexual morph genera with acervular coelomycetes with appendages (Jaklitsch et al. 2016, Liu et al. 2019). Liu et al. (2019) showed that Sporocadaceae as a well-defined family in the Xylariales and identified 30 genera based on phylogenetic analyses and morphological comparison. Hyde et al. (2020b) accepted 32 genera in the family.

Neopestalotiopsis Maharachch., K.D. Hyde \& Crous

Neopestalotiopsis was introduced by Maharachchikumbura et al. (2014b). They are plant pathogenic, saprobic and endophytic species commonly present in tropical and subtropical ecosystems (Maharachchikumbura et al. 2014b, Jayawardena et al. 2019). Morphologically Neopestalotiopsis species can differ from Pestalotiopsis and Pseudopestalotiopsis in having somewhat versicolorous median cells (Maharachchikumbura et al. 2014b). Pestalotiopsis and Pseudopestalotiopsis species generally possess concolourous median cells (Maharachchikumbura et al. 2014b). Neopestalotiopsis infects many crops, i.e. blueberry, grapes, strawberry, sweet potatoes, causing leaf spots, trunk diseases, post-harvest fruit rots and root rots worldwide (Jayawardena et al. 2019). There are 43 species epithets are recorded in Index Fugorum (2020). Neopestalotiopsis clavispora and $N$. saprophytica were recorded from Magnolia species (Magnoliaceae) (Maharachchikumbura et al. 2014b, Farr \& Rossman 2021). We report three new records in this study from Magnolia species (Magnoliaceae).

Neopestalotiopsis chiangmaiensis Tibpromma \& K.D. Hyde, Fungal Diversity: [139] (2018b)

Index Fungorum number: IF554515; Facesoffungi number: FoF04525

Fig. 28

Endophytic in fresh leaves of Magnolia candolli. Colonies on PDA flat, spreading, with aerial mycelia. Mycelia superficial and immersed composed of septate, branched, 2-3 $\mu \mathrm{m}$ wide, hyaline and brown with smooth and thick-walled hyphae. Sexual morph: Undetermined. Asexual morph: Conidiomata pycnidial in culture on PDA, globose, solitary or aggregated, embedded or semiimmersed, black. Conidia 18-23 $\times 3-5 \mu \mathrm{m}(\bar{x}=20 \times 4 \mu \mathrm{m})$, ellipsoid, fusoid, straight to slightly curved, 4-septate; basal cell 3-5 $\mu \mathrm{m}$ long, hyaline, obconic, smooth- and thin-walled; three median cells $12-15 \times 3-5 \mu \mathrm{m}(\bar{x}=13 \times 4 \mu \mathrm{m})$ brown, doliiform, (the second cell from base $4-6 \mu \mathrm{m}$ long, third cell 4-5 $\mu \mathrm{m}$ long, fourth cell 4-6 $\mu \mathrm{m}$ long); apical cell 3-4 $\mu \mathrm{m}$ long, cylindrical to subcylindrical, conic to bell-shaped, hyaline, smooth- and thin-walled, with 2 tubular apical appendages, $12-15 \mu \mathrm{m}$ long, arising from the apical crest, filiform, basal appendage 3-5 $\mu \mathrm{m}$ long, single, tubular, unbranched, straight and centric. 


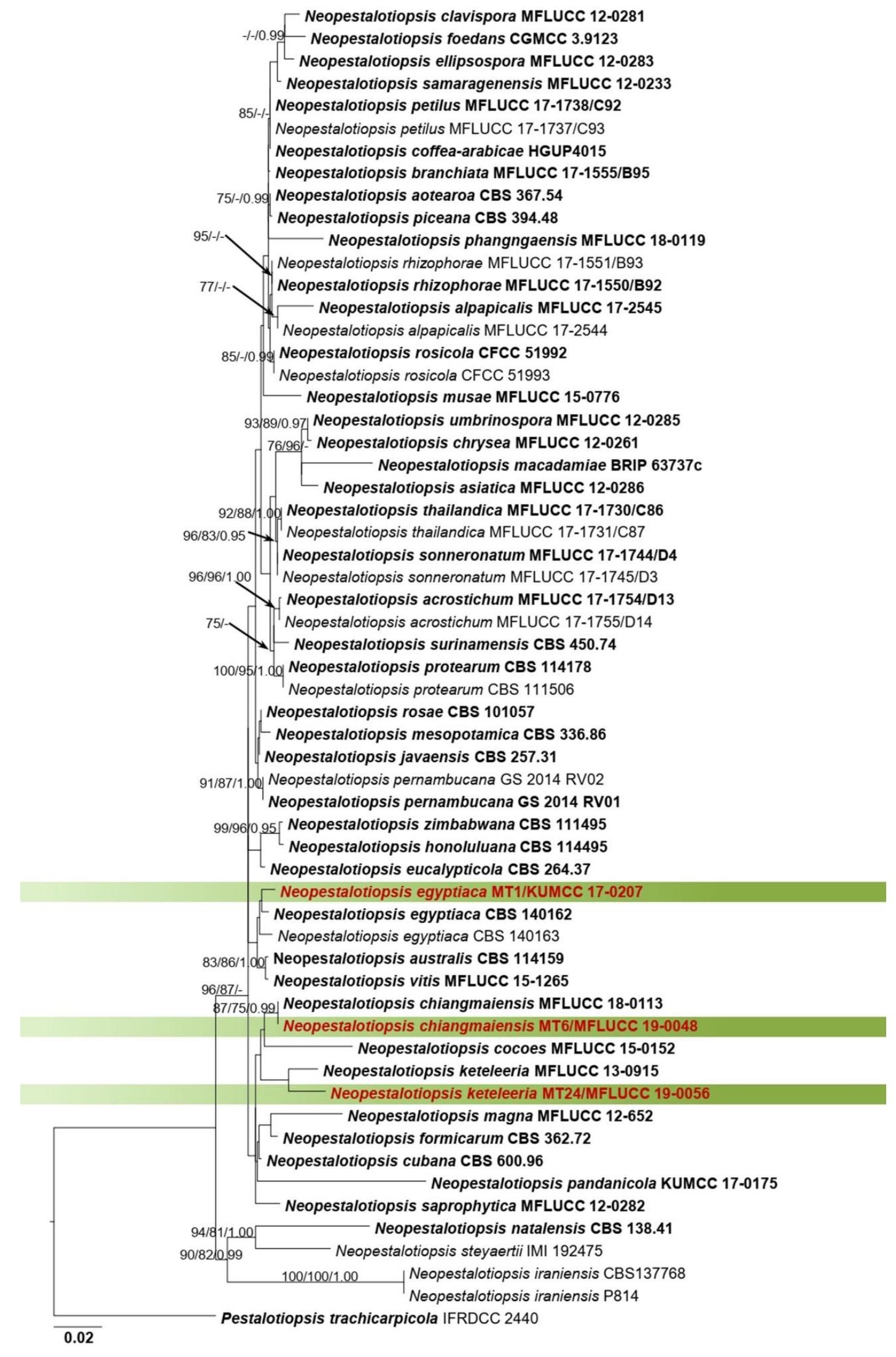

Figure 27 - Phylogram generated from maximum likelihood analysis based on combined ITS, tub2 and tefl sequence data. Fifty nine strains are included in the combined gene analyses comprising 1290 characters after alignment (500 characters for ITS, 420 characters for $t u b 2$, and 370 characters for tef1). Pestalotiopsis trachicarpicola (IFRDCC 2440) is used as outgroup taxon. The best RAxML tree with a final likelihood value of -6323.092983 is presented. The matrix had 508 
distinct alignment patterns, with $14.46 \%$ undetermined characters or gaps. Estimated base frequencies were as follows: $\mathrm{A}=0.229682, \mathrm{C}=0.268940, \mathrm{G}=0.212769, \mathrm{~T}=0.288609$; substitution rates $\mathrm{AC}=1.171186, \mathrm{AG}=3.097006, \mathrm{AT}=1.486836, \mathrm{CG}=0.944370, \mathrm{CT}=$ 4.032044, GT = 1.000000; gamma distribution shape parameter $\alpha=0.818017$. Bootstrap values for maximum likelihood and maximum parsimony equal to or greater than $75 \%$ and Bayesian posterior probabilities equal or greater than 0.95 are placed above the branches. The newly generated sequences are indicated in red. Type and ex-type strains are in bold.

Culture characteristics - Colonies on PDA reaching $33 \mathrm{~mm}$ diameter after 7 days at $25^{\circ} \mathrm{C}$, colonies circular, margin entire, flat, slightly raised, white mycelia, colony from above: white; reverse: light yellow.

Material examined - CHINA, Yunnan Province, Xishuangbanna, healthy leaves of Magnolia candolli (Magnoliaceae), 26 April 2017, N. I. de Silva, MT6 (MFLU 19-0511, dried culture), living culture, MFLUCC 19-0048 = KUMCC 17-0212.

GenBank numbers - ITS: MW248391, tef1: MW259070

Notes - Neopestalotiopsis chiangmaiensis was introduced based on a collection on Pandanus sp. in Thailand by Tibpromma et al. (2018b). In this study, our new isolate clustered with the extype of $N$. chiangmaiensis (MFLUCC 18-0113) with 87\% ML, 75\% MP and 0.99 BYPP support (Fig. 27). ITS sequence data of the ex-type N. chiangmaiensis (MFLUCC 18-0113) and tub2 sequence data of our isolate (MT6) are not available. The tefl gene region of both the ex-type $N$. chiangmaiensis (MFLUCC 18-0113) and the new isolate (MT6) are identical. Therefore, we treat our new isolate as $N$. chiangmaiensis and this is the first record of $N$. chiangmaiensis associated with Magnolia candolli in China.
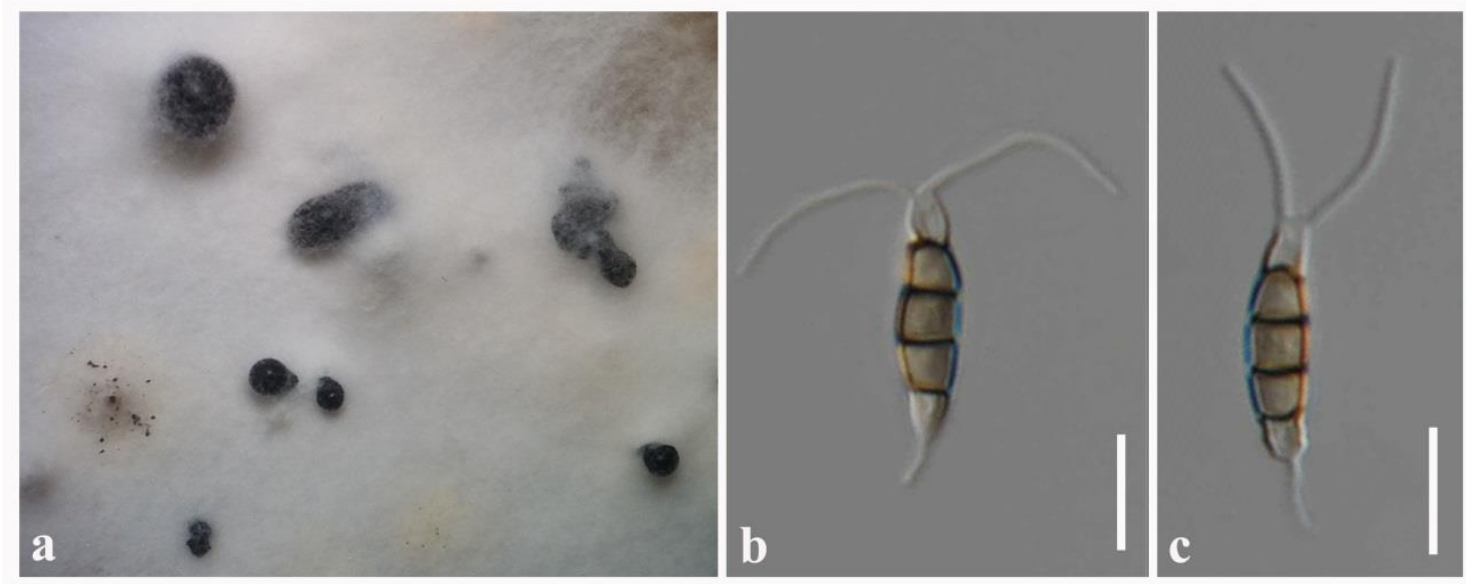

Figure 28 - Neopestalotiopsis chiangmaiensis (MFLUCC 19-0048, new host record). a Colony on PDA producing conidia masses. $\mathrm{b}$, c Conidia. Scale bars: $\mathrm{b}, \mathrm{c}=10 \mu \mathrm{m}$.

Neopestalotiopsis egyptiaca A.M. Ismail, G. Perrone \& Crous, Persoonia 35: 271 (2015) Fig. 29 Index Fungorum number: IF813837; Facesoffungi number: FoF09443

Endophytic in fresh leaves of Magnolia candolli. Colonies on PDA flat, fluffy appearance with white aerial mycelia. Mycelia superficial and immersed composed of septate, branched, 2-4 $\mu \mathrm{m}$ wide, hyaline and brown with smooth and thick-walled hyphae. Sexual morph: Undetermined. Asexual morph: Conidiomata pycnidial in culture on PDA, globose, solitary or aggregated, embedded or semi-immersed, exuding black conidial masses. Conidia 20-23 $\times 5-7 \mu \mathrm{m}(\bar{x}=20 \times 6$ $\mu \mathrm{m})$, ellipsoid, fusoid, straight to slightly curved, 4-septate; basal cell 3-4 $\mu \mathrm{m}$ long, hyaline, obconic, smooth- and thin-walled; three median cells $12-14 \times 3-5 \mu \mathrm{m}(\bar{x}=13 \times 4 \mu \mathrm{m})$, brown, doliiform, (the second cell from base 4-5 $\mu \mathrm{m}$ long, third cell 4-5 $\mu \mathrm{m}$ long, fourth cell 4-5 $\mu \mathrm{m}$ long); apical cell 4-5 $\mu \mathrm{m}$ long, cylindrical to subcylindrical, conic to bell-shaped, hyaline, smooth- 
and thin-walled, with 3 tubular apical appendages, 18-20 $\mu \mathrm{m}$ long, arising from the apical crest, filiform, basal appendage 3-4 $\mu \mathrm{m}$ long, single, tubular, unbranched, straight and centric.

Culture characteristics - Colonies on PDA reaching $36 \mathrm{~mm}$ diameter after 7 days at $25^{\circ} \mathrm{C}$, colonies circular, margin entire, flat, fluffy appearance with white mycelia, colony from above: white; reverse: cream.

Material examined - CHINA, Yunnan Province, Xishuangbanna, healthy leaves of Magnolia candolli (Magnoliaceae), 26 April 2017, N. I. de Silva MT1, living culture, KUMCC 17-0207.

GenBank numbers - ITS: MW248393, tub2: MW287363, tef1: MW259069

Notes - The phylogenetic analyses of combined ITS, tub2 and tef1 sequence data showed that the new isolate (MT1) clustered with N. egyptiaca (Fig. 27). Neopestalotiopsis egyptiaca was introduced on a collection from diseased leaves of Mangifera indica in Egypt (Crous et al. 2015). This species has not been reported so far from Magnoliaceae (Farr \& Rossman 2021). Conidia of new isolate have similar morphology with the ex-type of $N$. egyptiaca (CBS 140162) in having fusiform, 4-septate conidia with brown median cells and 2-3 apical appendages (Crous et al. 2015). Conidia of the new isolate (MT1) $(20-23 \times 5-7 \mu \mathrm{m})$ is slightly smaller than the ex-type $N$. egyptiaca (CBS 140162) (22.5-28 × 6-7.5 $\mu \mathrm{m})$ (Crous et al. 2015). The ITS gene region of both the ex-type $N$. egyptiaca (CBS 140162) and the new isolate (MT1) is similar. We introduce our new isolate, $N$. egyptiaca as a new host record from Magnolia candolli and geographical record from China.
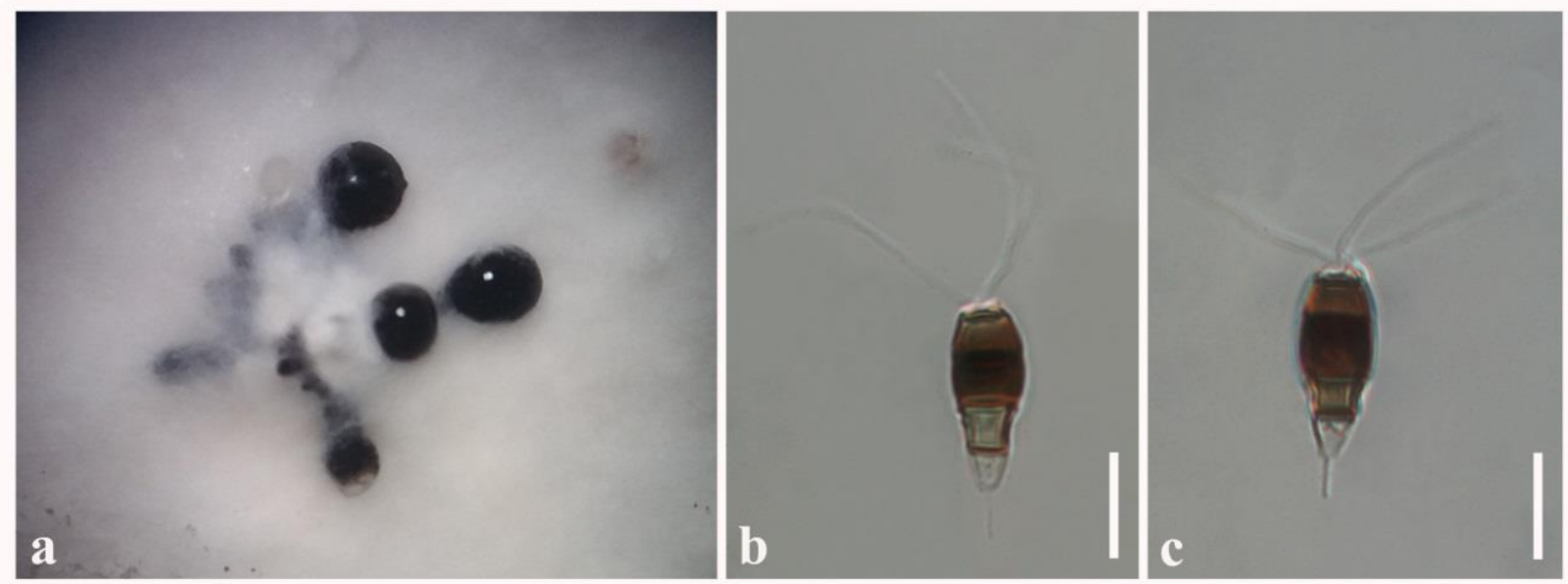

Figure 29 - Neopestalotiopsis egyptiaca (KUMCC 17-0207, new host record). a Colony on PDA producing conidia masses. b, c Conidia. Scale bars: b, $\mathrm{c}=10 \mu \mathrm{m}$.

Neopestalotiopsis keteleeria Y. Song, K.D. Hyde \& Yong Wang, Chiang Mai Journal of Science 41(4), 888 (2014a)

Index Fungorum number: IF825388; Facesoffungi number: FoF09444

Fig. 30

Endophytic in fresh leaves of Magnolia candolli. Colonies on PDA, fluffy appearance, white aerial mycelia. Mycelia superficial and immersed composed of septate, branched, 2-3 $\mu \mathrm{m}$ wide, hyaline and brown with smooth and thick-walled hyphae. Sexual morph: Undetermined. Asexual morph: Conidiomata pycnidial on pine needles, globose, solitary or aggregated, embedded or semiimmersed, exuding black conidial masses. Conidia 18-23 5 5-7 $\mu \mathrm{m}(\bar{x}=20 \times 6 \mu \mathrm{m})$, ellipsoid, fusoid, straight to slightly curved, 4-septate; basal cell 3-5 $\mu \mathrm{m}$ long, hyaline, obconic, smooth- and thin-walled; three median cells $12-15 \times 5-7 \mu \mathrm{m}(\bar{x}=13 \times 6 \mu \mathrm{m})$, brown, doliiform, (the second cell from base 4-5 $\mu \mathrm{m}$ long, third cell 4-5 $\mu \mathrm{m}$ long, fourth cell 4-5 $\mu \mathrm{m}$ long); apical cell 4-5 $\mu \mathrm{m}$ long, cylindrical to subcylindrical, conic to bell-shaped, hyaline, smooth- and thin-walled, with 3 tubular apical appendages, 25-30 $\mu \mathrm{m}$ long, arising from the apical crest, filiform, basal appendage 3-4 $\mu \mathrm{m}$ long, single, tubular, unbranched, straight and centric. 
Culture characteristics - Colonies on PDA reaching $38 \mathrm{~mm}$ diameter after 7 days at $25^{\circ} \mathrm{C}$, colonies circular, margin entire, fluffy appearance, white mycelia, colony from above: white; reverse: cream.

Material examined - CHINA, Yunnan Province, Xishuangbanna, healthy leaves of Magnolia candolli (Magnoliaceae), 26 April 2017, N. I. de Silva, MT24 (MFLU 19-0522, dried culture); living culture, MFLUCC 19-0056 = KUMCC 17-0226.

GenBank numbers - ITS: MW248392, tub2: MW287364, tef1: MW259071

Notes - The new strain is phylogenetically closely related to the ex-type of $N$. keteleeria (MFLUCC 13-0915) (Fig. 27). Neopestalotiopsis keteleeria was introduced by Song et al. (2014a) on disease leaves of Keteleeria pubescens in China. The ITS gene region of both the ex-type $N$. keteleeria (MFLUCC 13-0915) and the new isolate (MT24) is similar. A comparison of tub2 gene region indicates ten base pair differences between the ex-type $N$. keteleeria (MFLUCC 13-0915) and the new isolate (MT24) across 400 nucleotides. tefl sequence data of the ex-type of $N$. keteleeria (MFLUCC 13-0915) are not available. Conidia of $N$. keteleeria $(18.5-24 \times 7-9.5 \mu \mathrm{m})$ (Song et al. 2014a) and the new isolate (MT24) (18-23 ×6-8) share similar conidial dimensions. Therefore, we identified our current taxon as $N$. keteleeria. This is the first report of endophytic lifestyle of $N$. keteleeria associate with healthy leaves of Magnolia candolli.
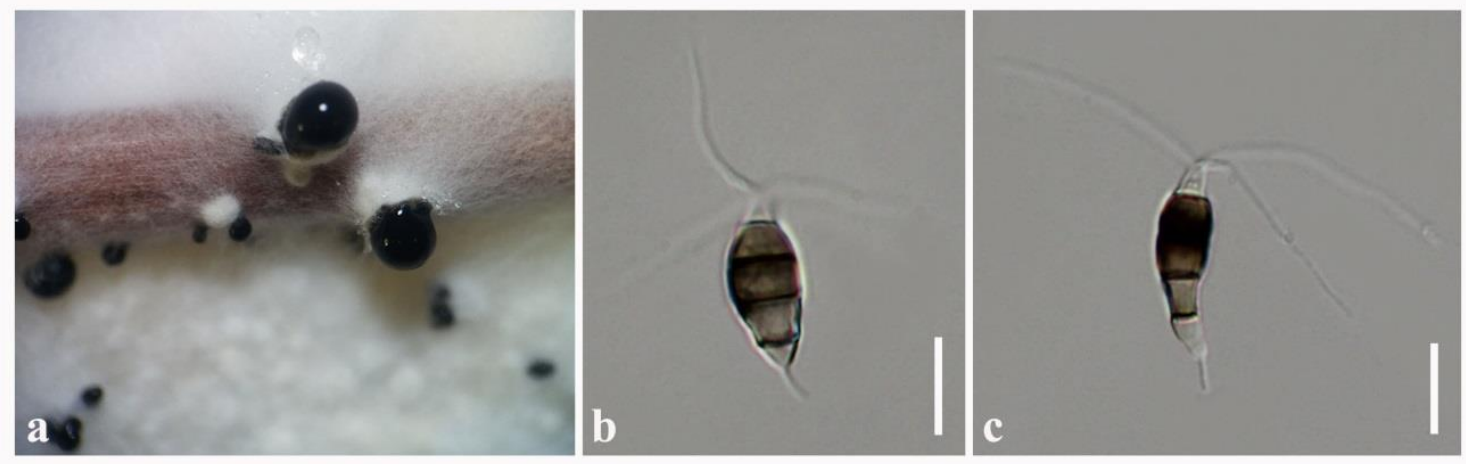

Figure 30 - Neopestalotiopsis keteleeria (MFLUCC 19-0056, new host record). a Conidial masses producing on pine needles. $b$, c Conidia. Scale bars: $b, c=10 \mu \mathrm{m}$.

\section{Pestalotiopsis Steyaert}

Species of Pestalotoiopsis are an appendage-bearing conidial anamorphic form (coelomycetes) commonly found in tropical and temperate ecosystems (Maharachchikumbura et al. 2011). The genus was introduced by Steyaert (1949) with the type P. maculans. Pestalotoiopsis species are known to cause diseases of foliage, stems and cause a considerable reduction on commercial production (Maharachchikumbura et al. 2011, 2013, 2014b, Liu et al. 2017). Pestalotiopsis are also isolated as endophytes or occur as saprobes (Maharachchikumbura et al. 2011, 2013, 2014b, Liu et al. 2017). They are able to switch life modes as endophytes, pathogens and saprobes (Maharachchikumbura et al. 2012, Jayawardena et al. 2019). Traditionally, Pestalotiopsis species were named according to their host associations and the conidial morphologies such as colour intensities of the median conidial cell (Maharachchikumbura et al. 2014a, Liu et al. 2017). Maharachchikumbura et al. (2012) recommended using combined ITS, tub2 and tef1 genes to delimination species boundaries in Pestalotiopsis species. There are 374 species epithets are recorded in Index Fungorum (2021). Wijayawardene et al. (2020) accepted 33 species in Pestalotiopsis.

Pestalotiopsis endophytica N.I. de Silva, Lumyong \& K.D. Hyde, sp. nov.

Fig. 32

Index Fungorum number: IF556381; Facesoffungi number: FoF09496

Etymology - The epithet "endophytica" refers to the endophytic lifestyle of this fungus.

Holotype - MFLU 20-0607 


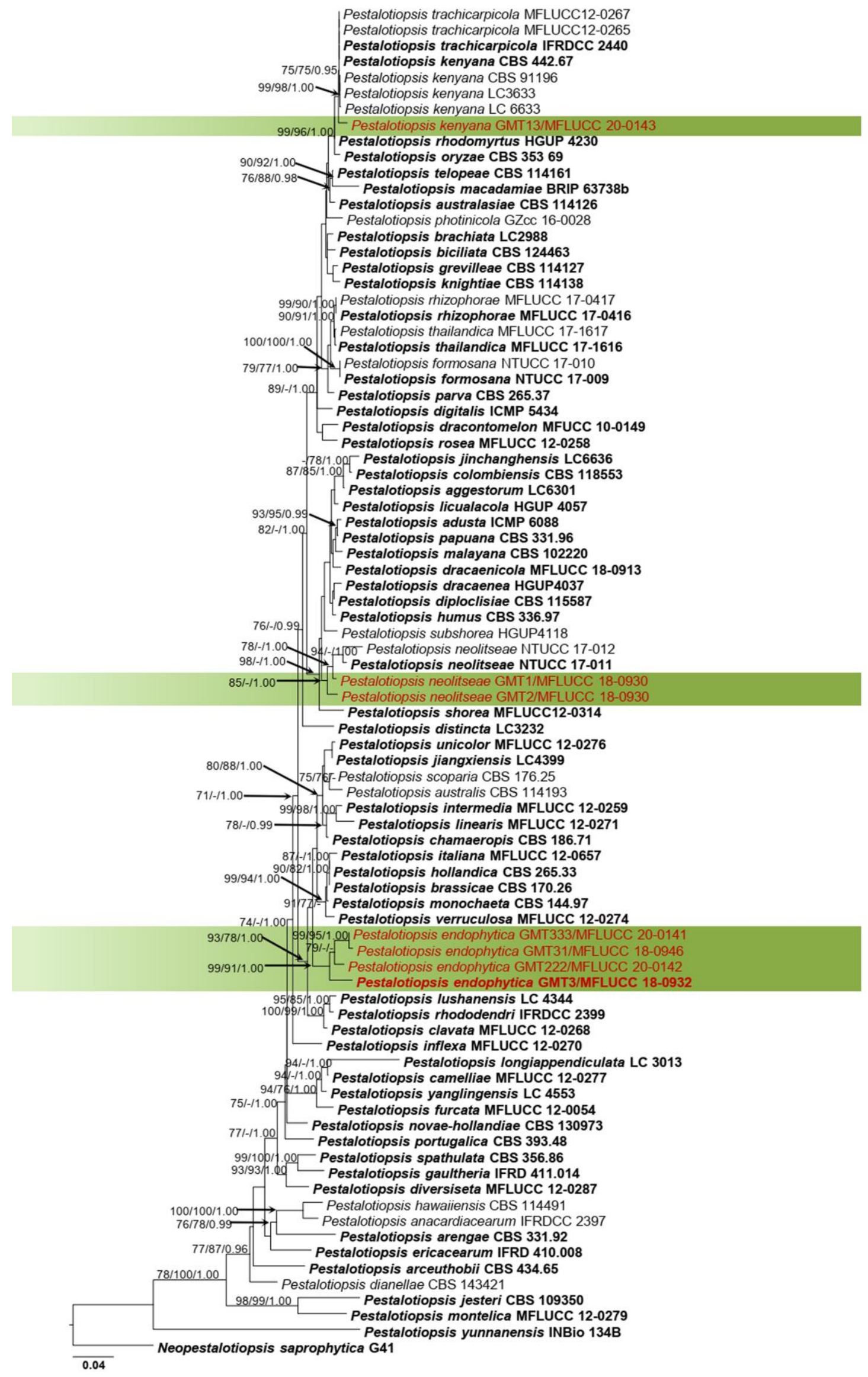

Figure 31 - Phylogram generated from maximum likelihood analysis based on combined ITS, tub2 and tefl sequence data. Eighty five strains are included in the combined gene analyses comprising 1460 characters after alignment (530 characters for ITS, 430 characters for $t u b 2,500$ characters for 
tef1). Neopestalotiopsis saprophytica (G41) is used as outgroup taxon. The best RAxML tree with a final likelihood value of -11991.194599 is presented. The matrix had 739 distinct alignment patterns, with $13.65 \%$ undetermined characters or gaps. Estimated base frequencies were as follows: $\mathrm{A}=0.234706, \mathrm{C}=0.291700, \mathrm{G}=0.212976, \mathrm{~T}=0.260619$; substitution rates $\mathrm{AC}=$ $0.978127, \mathrm{AG}=2.967800, \mathrm{AT}=1.111125, \mathrm{CG}=0.863582, \mathrm{CT}=3.577924, \mathrm{GT}=1.000000$; gamma distribution shape parameter $\alpha=0.727318$. Bootstrap values for maximum likelihood and maximum parsimony equal to or greater than $75 \%$ and Bayesian posterior probabilities equal or greater than 0.95 are placed above the branches. The newly generated sequences are indicated in red. Type and ex-type strains are in bold.

Endophytic in fresh leaves of Magnolia candolli. Colonies on PDA flat slightly raised, spreading, with abundant aerial mycelia. Mycelia superficial and immersed composed of septate, branched, 2-4 $\mu \mathrm{m}$ wide, hyaline and brown with smooth and thick-walled hyphae. Sexual morph: Undetermined. Asexual morph: Conidiomata pycnidial in culture on PDA, globose, solitary or aggregated, embedded or semi-immersed, black, exuding globose, brown to black conidial masses. Conidiophores reduced to conidiogenous cells. Conidiogenous cells $7-10 \times 3-5 \mu \mathrm{m}(\bar{x}=8 \times 4$ $\mu \mathrm{m})$, discrete, hyaline, cylindrical to subcylindrical and smooth-walled. Conidia $25-30 \times 5-7 \mu \mathrm{m}$ $(\bar{x}=28 \times 6 \mu \mathrm{m})$, ellipsoid, fusoid, straight to slightly curved, 4-septate; basal cell 5-7 $\mu \mathrm{m}$ long, hyaline, obconic, smooth- and thin-walled; three median cells $15-18 \times 5-7 \mu \mathrm{m}(\bar{x}=16 \times 6 \mu \mathrm{m})$, brown, doliiform, (the second cell from base 4-6 $\mu \mathrm{m}$ long, third cell 6-7 $\mu \mathrm{m}$ long, fourth cell 5-7 $\mu \mathrm{m}$ long); apical cell 5-7 $\mu \mathrm{m}$ long, cylindrical to subcylindrical, conic to bell-shaped, hyaline, smooth- and thin-walled, with 2-3 tubular apical appendages (mostly 3), 20-23 $\mu \mathrm{m}$ long, arising from the apical crest, filiform, basal appendage 4-6 $\mu \mathrm{m}$ long, single, tubular, unbranched, straight and centric.

Culture characteristics - Colonies on PDA reaching $36 \mathrm{~mm}$ diameter after 7 days at $25^{\circ} \mathrm{C}$, colonies circular, margin entire, flat, slightly raised, velvety appearance, white mycelia, colony from above: white; reverse: cream.

Material examined - THAILAND, Chiang Mai Province, healthy leaves of Magnolia garrettii (Magnoliaceae), 14 August 2017, N. I. de Silva, GMT3 (MFLU 20-0607, holotype, dried culture); ex-type living culture, MFLUCC 18-0932.

Additional materials - THAILAND, Chiang Mai Province, healthy leaves of Magnolia garrettii (Magnoliaceae), 14 August 2017, N. I. de Silva, GMT31 living culture, MFLUCC 180946, GMT222 living culture, MFLUCC 20-0142, GMT333 living culture, MFLUCC 20-0141.

GenBank numbers - (GMT3); ITS: MW263946, tef1: MW417119, (GMT31); ITS: MW263947, tef1: MW729384, (GMT222); ITS: MW263948, (GMT333); ITS: MW263949.

Notes - Four new isolates clustered together in a distinct clade with 99\% ML, 91\% MP and 1.00 BYPP support (Fig. 31) and separated from the sister clade comprising P. australis, $P$. brassicae, $P$. chamaeropis, $P$. hollandica, $P$. intermedia, $P$. italiana, $P$. jiangxiensis, $P$. linearis, $P$. monochaeta, $P$. scoparia, $P$. unicolor and $P$. verruculosa. Pestalotiopsis endophytica differs from $P$. brassicae, $P$. hollandica, $P$. italiana and $P$. verruculos $a$ in having 3 apical appendages while $P$. brassicae, $P$. hollandica, $P$. italiana and $P$. verruculosa have more than 3 apical appeandages (Table 2). Pestalotiopsis monochaeta differs from $P$. endophytica in having single apical appendage (Maharachchikumbura et al. 2014b). Pestalotiopsis endophytica is morphologically similar to $P$. australis in having an overlapping range of conidial and appendage dimensions (Table 2). However, $P$. endophytica has slightly smaller $(25-30 \times 5-7 \mu \mathrm{m})$ conidia when compare to P. australis (2636) $\times 7-8.5 \mu \mathrm{m})($ Maharachchikumbura et al. 2014b). Further, phylogenetic analyses show $P$. endophytica is distinctly related to $P$. australis (Fig. 31). Therefore, we introduce P. endophytica as a novel species bases on morphology and phylogeny.

Pestalotiopsis kenyana Maharachch., K.D. Hyde \& Crous, Studies in Mycology 79: 166 (2014b)

Index Fungorum number: IF809741; Facesoffungi number: FoF06981 
Endophytic in fresh leaves of Magnolia garrettii. Colonies on PDA, fluffy appearance, white aerial mycelia. Mycelia superficial and immersed composed of septate, branched, 2-3 $\mu \mathrm{m}$ wide, hyaline and brown with smooth and thick-walled hyphae. Sexual morph: Undetermined. Asexual morph: Conidiomata pycnidial on PDA, globose, solitary or aggregated, embedded or semiimmersed, exuding black conidial masses. Conidia 20-23 $\times 4-6 \mu \mathrm{m}(\bar{x}=21 \times 5 \mu \mathrm{m})$, ellipsoid, fusoid, straight to slightly curved, 4-septate; basal cell 3-4 $\mu \mathrm{m}$ long, hyaline, obconic, smooth- and thin-walled; three median cells 14-17 $\times 4-6 \mu \mathrm{m}(\bar{x}=15 \times 6 \mu \mathrm{m})$, light brown, doliiform, (the second cell from base 5-6 $\mu \mathrm{m}$ long, third cell 4-5 $\mu \mathrm{m}$ long, fourth cell 5-6 $\mu \mathrm{m}$ long); apical cell 3$5 \mu \mathrm{m}$ long, cylindrical to subcylindrical, conic to bell-shaped, hyaline, smooth- and thin-walled, with 2-3 tubular apical appendages, 18-22 $\mu \mathrm{m}$ long, arising from the apical crest, filiform, basal appendage 2-3 $\mu \mathrm{m}$ long, single, tubular, unbranched, straight and centric.

Culture characteristics - Colonies on PDA reaching $36 \mathrm{~mm}$ diameter after 7 days at $25^{\circ} \mathrm{C}$, colonies circular, margin undulate, slightly raised, white mycelia, with black, gregarious conidiomata, colony from above: white; reverse: cream.

Material examined - THAILAND, Chiang Mai Province, healthy leaves of Magnolia garrettii (Magnoliaceae), 14 August 2017, N. I. de Silva, GMT13, living culture MFLUCC 200143.

GenBank numbers - ITS: MW263950, tef1: MW273931

Notes - The new isolate (GMT13) clustered with the ex-type Pestalotiopsis kenyana (CBS 442.67) in the combined ITS, tub2 and tefl phylogenetic analysis with 99\% ML, 98\% MP and 1.00 BYPP support (Fig. 31). ITS and tef1 gene regions of GMT13 is similar to the ex-type P. kenyana (CBS 442.67). The type of P. kenyana was recorded from twigs of Coffea sp. in Kenya (the type CBS H-15657) (Maharachchikumbura et al. 2014b) and on Camellia sinensis in China (Liu et al. 2017). Therefore, we report a new host record considering molecular data and host associations.
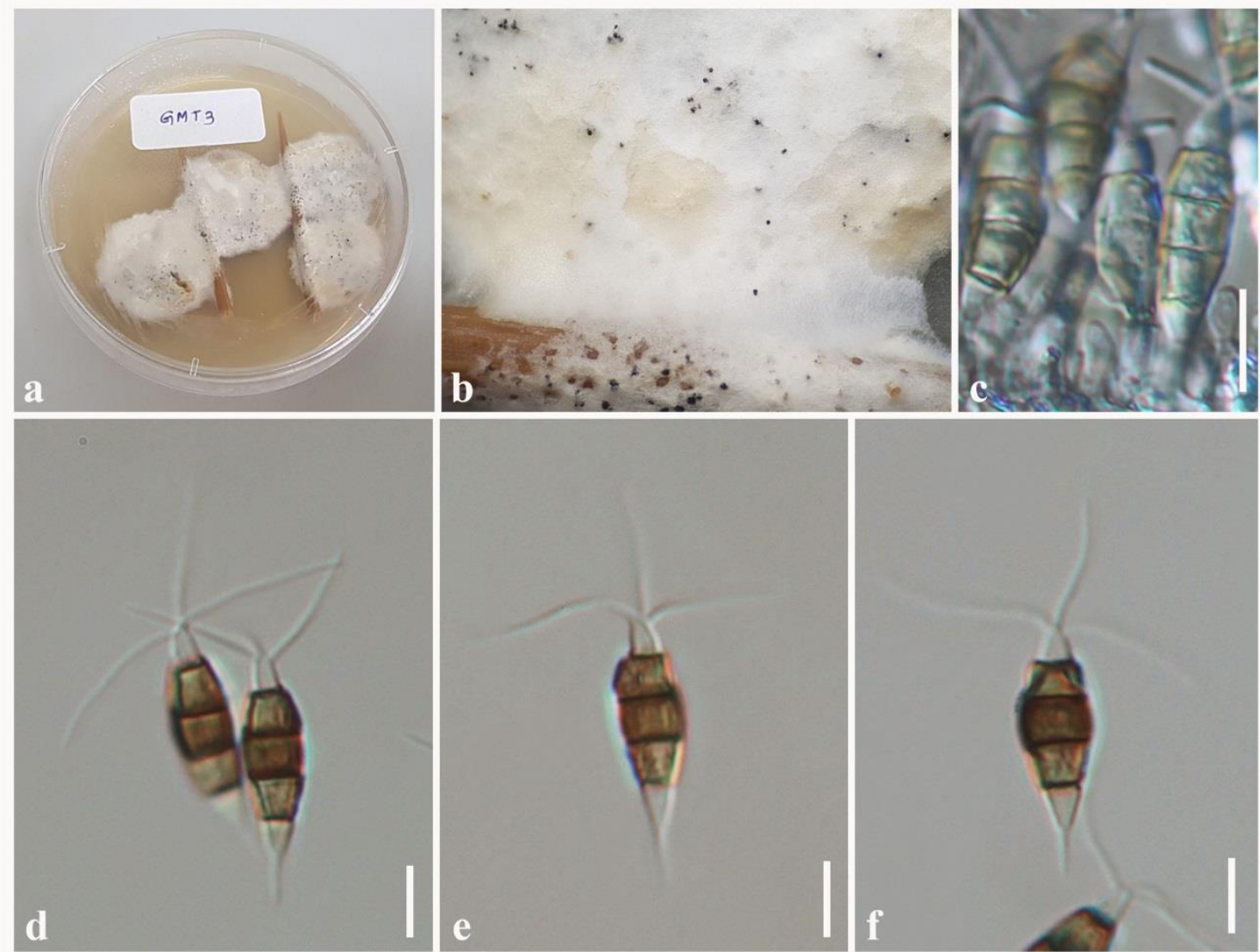

Figure 32 - Pestalotiopsis endophytica (MFLU 20-0607, holotype), a Colonies on PDA. $\mathrm{b}$ Conidial masses producing on PDA. c Conidiogenous cells. $\mathrm{d}-\mathrm{f}$ Conidia. Scale bars: $\mathrm{c}-\mathrm{f}=10 \mu \mathrm{m}$. 
Table 2 Synopsis of Pestalotiopsis endophytica and closely related species

\begin{tabular}{|c|c|c|c|c|c|c|c|c|}
\hline Species & $\begin{array}{l}\text { Conidia size } \\
(\mu \mathrm{m})\end{array}$ & $\begin{array}{l}\text { Three median } \\
\text { cells }(\mu \mathrm{m})\end{array}$ & $\begin{array}{l}\text { Number of } \\
\text { apical } \\
\text { appeandages }\end{array}$ & $\begin{array}{l}\text { Length of apical } \\
\text { appendage/s }(\mu \mathrm{m})\end{array}$ & $\begin{array}{l}\text { Length of } \\
\text { basal } \\
\text { appendage } \\
(\mu \mathrm{m}) \\
\end{array}$ & $\begin{array}{l}\text { Host and life } \\
\text { mode }\end{array}$ & Locality & Reference \\
\hline $\begin{array}{l}\text { Pestalotiopsis } \\
\text { australis }\end{array}$ & $\begin{array}{l}(26-) 27-34(- \\
36) \times 7-8.5 ;(x \\
=30.8 \times 7.7)\end{array}$ & $\begin{array}{l}(16-) 17-21(- \\
21.5) ;(\bar{x}= \\
19.1)\end{array}$ & $2-3$ & $\begin{array}{l}(11-) 12-20(-22) ; \\
(\bar{x}=15.5)\end{array}$ & $3-7$ & $\begin{array}{l}\text { Brabejum } \\
\text { stellatifolium, } \\
\text { Grevillea } \mathrm{sp} . \\
\text { and Protea } \\
\text { neriifolia } \times \\
\text { susannae }\end{array}$ & $\begin{array}{l}\text { Australia and } \\
\text { South Africa }\end{array}$ & $\begin{array}{l}\text { Maharachchikumbura } \\
\text { et al. (2014b) }\end{array}$ \\
\hline P. brassicae & $\begin{array}{l}29-) 30-37(- \\
40) \times(8-) 8.5- \\
11(-11.5) ;(\bar{x} \\
=34 \times 9.7)\end{array}$ & $\begin{array}{l}(20-) 20.5- \\
24.5(-25) ;(\bar{x}= \\
22.6)\end{array}$ & 3-5, (mostly 4) & $\begin{array}{l}(27-) 28.5-48(- \\
50) ; \bar{x}=37\end{array}$ & $10-25$ & $\begin{array}{l}\text { On seeds of } \\
\text { Brassica } \\
\text { napus }\end{array}$ & New Zealand & $\begin{array}{l}\text { Maharachchikumbura } \\
\text { et al. (2014b) }\end{array}$ \\
\hline P. chamaeropis & $\begin{array}{l}(21-) 22.5- \\
27(-28) \times(6- \\
) 7-9(-9.5) ;(\bar{x} \\
=25.2 \times 8)\end{array}$ & $\begin{array}{l}(15-) 16-17.5(- \\
18.5) ;(\bar{x}= \\
16.7)\end{array}$ & $2-3,($ mostly 3$)$ & $\begin{array}{l}13-) 14.5-23(-24) \\
\bar{x}=18\end{array}$ & $4-8.5$ & $\begin{array}{l}\text { On leaves of } \\
\text { Chamaerops } \\
\text { humilis }\end{array}$ & Italy & $\begin{array}{l}\text { Maharachchikumbura } \\
\text { et al. (2014b) }\end{array}$ \\
\hline P. endophytica & $\begin{array}{l}25-30 \times 5-7 \\
(\bar{x}=28 \times 6)\end{array}$ & $\begin{array}{l}15-18 \times 5-7 ;(\bar{x} \\
=16 \times 6)\end{array}$ & $2-3$ & $20-23$ & $4-6$ & $\begin{array}{l}\text { Endophytic on } \\
\text { healthy leaves } \\
\text { of Magnolia } \\
\text { candoll }\end{array}$ & $\begin{array}{l}\text { Chiang Mai } \\
\text { Province, } \\
\text { Thailand }\end{array}$ & This study \\
\hline P. hollandica & $\begin{array}{l}(25-) 25.5- \\
33(-34) \times 8.5- \\
10(-10.5) ;(\bar{x} \\
=28 \times 9.4)\end{array}$ & $\begin{array}{l}(16.5-) 17-23(- \\
24) ;(\bar{x}=28 \times \\
9.4)\end{array}$ & $1-4$ & $20-40 ; \bar{x}=27$ & $3-9$ & $\begin{array}{l}\text { On Sciadopitys } \\
\text { verticillata }\end{array}$ & Netherlands & $\begin{array}{l}\text { Maharachchikumbura } \\
\text { et al. (2014b) }\end{array}$ \\
\hline P. intermedia & $\begin{array}{l}24-28 \times 5.5- \\
6.5 ;(\bar{x}=25.7 \\
\times 6)\end{array}$ & $15-19 ;(\bar{x}=17)$ & $2-3,($ rarely 4) & $\begin{array}{l}10-28 ;(\bar{x}=18 \times \\
5)\end{array}$ & $6-10$ & $\begin{array}{l}\text { Saprobic/endo } \\
\text { phytic on } \\
\text { unidentified } \\
\text { trees, }\end{array}$ & $\begin{array}{l}\text { Hubei, } \\
\text { Yunnan } \\
\text { Province, } \\
\text { China } \\
\end{array}$ & $\begin{array}{l}\text { Maharachchikumbura } \\
\text { et al. (2012) }\end{array}$ \\
\hline P. italiana & $\begin{array}{l}26-35 \times 8-11 \\
(\bar{x}=30 \times 9.6)\end{array}$ & $18-28 ;(\bar{x}=23)$ & $\begin{array}{l}2-5, \text { (mostly } 3- \\
4)\end{array}$ & $20-40 ;(\bar{x}=32)$ & $6-10$ & $\begin{array}{l}\text { Dead twigs of } \\
\text { Cupressus } \\
\text { glabra }\end{array}$ & Italy & Liu et al. (2015c) \\
\hline
\end{tabular}


Table 2 Continued.

\begin{tabular}{|c|c|c|c|c|c|c|c|c|}
\hline Species & $\begin{array}{l}\text { Conidia size } \\
(\mu \mathrm{m})\end{array}$ & $\begin{array}{l}\text { Three median } \\
\text { cells }(\mu \mathrm{m})\end{array}$ & $\begin{array}{l}\text { Number of } \\
\text { apical } \\
\text { appeandages }\end{array}$ & $\begin{array}{l}\text { Length of } \\
\text { apical } \\
\text { appendage/s } \\
(\mu \mathrm{m})\end{array}$ & $\begin{array}{l}\text { Length of } \\
\text { basal } \\
\text { appendage } \\
(\mu \mathrm{m})\end{array}$ & $\begin{array}{l}\text { Host and life } \\
\text { mode }\end{array}$ & Locality & Reference \\
\hline P. jiangxiensis & $\begin{array}{l}22-29 \times 6-9 ; \\
(\bar{x}=25.7 \times \\
7.3)\end{array}$ & $\begin{array}{l}12.5-19 ;(\bar{x}= \\
15.9)\end{array}$ & $2-4,($ mostly 3$)$ & $\begin{array}{l}16.5-32 ;(\bar{x}= \\
22.4)\end{array}$ & $6.5-19.5$ & Camellia sp. & $\begin{array}{l}\text { Jiangxi } \\
\text { Province, } \\
\text { China }\end{array}$ & Liu et al. (2017) \\
\hline P. linearis & $\begin{array}{l}24-33 \times 4.7-6 \\
(\bar{x}=29.5 \times 5)\end{array}$ & $17-21 ;(\bar{x}=19)$ & $2-3,($ rarely 1$)$ & $10-20$ & $4-7$ & $\begin{array}{l}\text { Endophytic on } \\
\text { living leaves } \\
\text { of } \\
\text { Trachelosperm } \\
\text { um sp. and } \\
\text { Tsuga sp. }\end{array}$ & $\begin{array}{l}\text { Yunnan } \\
\text { Province, } \\
\text { China }\end{array}$ & $\begin{array}{l}\text { Maharachchikumbura } \\
\text { et al. (2012) }\end{array}$ \\
\hline P. monochaeta & $\begin{array}{l}(25-) 27-40(- \\
42) \times 7-11(- \\
11.5) ;(\bar{x}= \\
32.8 \times 9.6)\end{array}$ & $\begin{array}{l}(17-) 18-25(- \\
26) ;(\bar{x}=21)\end{array}$ & 1 & $\begin{array}{l}(40-) 43-67(- \\
75) ;(\bar{x}=51)\end{array}$ & $6-14$ & $\begin{array}{l}\text { On Taxus } \\
\text { baccata } \text { and } \\
\text { endophytic in } \\
\text { branches of } \\
\text { Quercus robur }\end{array}$ & Netherlands & $\begin{array}{l}\text { Maharachchikumbura } \\
\text { et al. }(2014 \mathrm{~b})\end{array}$ \\
\hline P. scoparia & $\begin{array}{l}(22-) 23.5- \\
29(-31) \times 6- \\
8.5 ;(\bar{x}=26.3 \\
\times 7.4) \\
\end{array}$ & $\begin{array}{l}15.5-19.5 ;(\bar{x}= \\
17)\end{array}$ & $3-5$ & $\begin{array}{l}(20-) 23-35(- \\
42) ;(\bar{x}=29.6)\end{array}$ & $9-25$ & $\begin{array}{l}\text { Chamaecypari } \\
-s \mathrm{sp} .\end{array}$ & Unknown & $\begin{array}{l}\text { Maharachchikumbura } \\
\text { et al. }(2014 \mathrm{~b})\end{array}$ \\
\hline P. unicolor & $\begin{array}{l}20-24.5 \times 4-6 ; \\
(\bar{x}=22.5 \times 1)\end{array}$ & $\begin{array}{l}13-16 ;(\bar{x}= \\
14 \times 7)\end{array}$ & $2-3$ & $\begin{array}{l}11-20 ;(\bar{x}= \\
17.5)\end{array}$ & $4-10$ & $\begin{array}{l}\text { Endophytic on } \\
\text { Rhododendron } \\
\text { sp. }\end{array}$ & $\begin{array}{l}\text { Hunan } \\
\text { Province, } \\
\text { China }\end{array}$ & $\begin{array}{l}\text { Maharachchikumbura } \\
\text { et al. (2012) }\end{array}$ \\
\hline P. verruculosa & $\begin{array}{l}28-35 \times 9-11 \\
(\bar{x}=30.6 \\
\times 10.3)\end{array}$ & $\begin{array}{l}18-26 ;(\bar{x}= \\
21.6)\end{array}$ & $2-6,($ mostly $3-4)$ & $25-40 ;(\bar{x}=34)$ & $8-12$ & $\begin{array}{l}\text { Endophytic on } \\
\text { living leaf of } \\
\text { Rhododendron } \\
\text { sp. }\end{array}$ & $\begin{array}{l}\text { Yunnan } \\
\text { Province, } \\
\text { China }\end{array}$ & $\begin{array}{l}\text { Maharachchikumbura } \\
\text { et al. (2012) }\end{array}$ \\
\hline
\end{tabular}



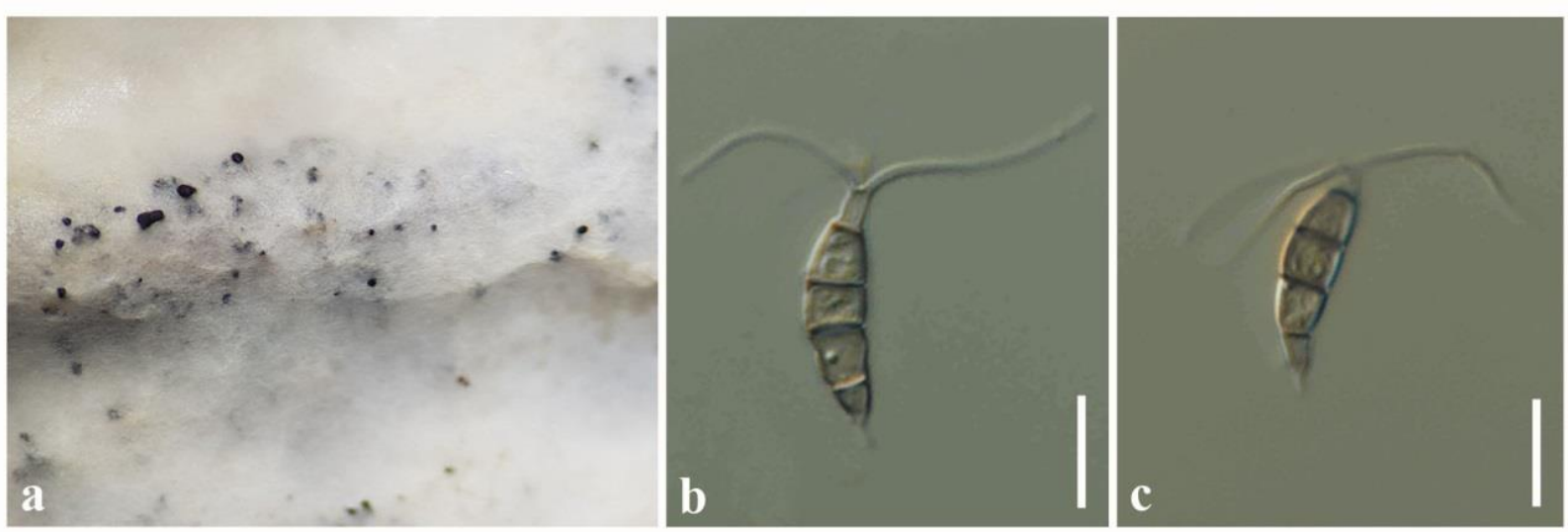

Figure 33 - Pestalotiopsis kenyana (MFLUCC 20-0143, new host record). a Conidial masses on PDA. b, c Conidia. Scale bars: b, c $=10 \mu \mathrm{m}$.

Pestalotiopsis neolitseae Ariyawansa \& K.D. Hyde Mycosphere 9 (5): 1005 (2018)

Fig. 34

Index Fungorum number: IF827598; Facesoffungi number: FoF04938

Endophytic in fresh leaves of Magnolia garrettii. Colonies on PDA slightly raised, white mycelia. Mycelia superficial and immersed composed of septate, branched, 2-3 $\mu \mathrm{m}$ wide, hyaline and brown with smooth and thick-walled hyphae. Sexual morph: Undetermined. Asexual morph: Conidiomata pycnidial on pine needle on PDA, globose, solitary or aggregated, embedded or semiimmersed, exuding black conidial masses. Conidia 17-20 ×4-6 $\mu \mathrm{m}(\bar{x}=18 \times 5 \mu \mathrm{m})$, ellipsoid, fusoid, straight to slightly curved, 4-septate; basal cell 2-3 $\mu \mathrm{m}$ long, hyaline, obconic, smooth- and thin-walled; three median cells $11-13 \times 3-5 \mu \mathrm{m},(\bar{x}=12 \times 4 \mu \mathrm{m})$ light brown, doliiform, (the second cell from base 4-5 $\mu \mathrm{m}$ long, third cell 3-4 $\mu \mathrm{m}$ long, fourth cell 4-5 $\mu \mathrm{m}$ long); apical cell 2$3 \mu \mathrm{m}$ long, cylindrical to subcylindrical, conic to bell-shaped, hyaline, smooth- and thin-walled, with 2-3 tubular apical appendages, 10-15 $\mu \mathrm{m}$ long, arising from the apical crest, filiform, basal appendage $2-3 \mu \mathrm{m}$ long, single, tubular, straight and centric.

Culture characteristics - Colonies on PDA reaching $30 \mathrm{~mm}$ diameter after 7 days at $25^{\circ} \mathrm{C}$, colonies circular, margin undulate, slightly raised, white mycelia, with black, gregarious conidiomata, colony from above: white; reverse: cream.

Material examined - THAILAND, Chiang Mai Province, healthy leaves of Magnolia garrettii (Magnoliaceae), 26 April 2017, N. I. de Silva, GMT1, living culture, MFLUCC 18-0930, GMT2, living culture, MFLUCC 18-0931.

GenBank numbers - (GMT1); ITS: MW263951, tef1: MW273932, (GMT2); ITS: MW263952, tef1: MW273933
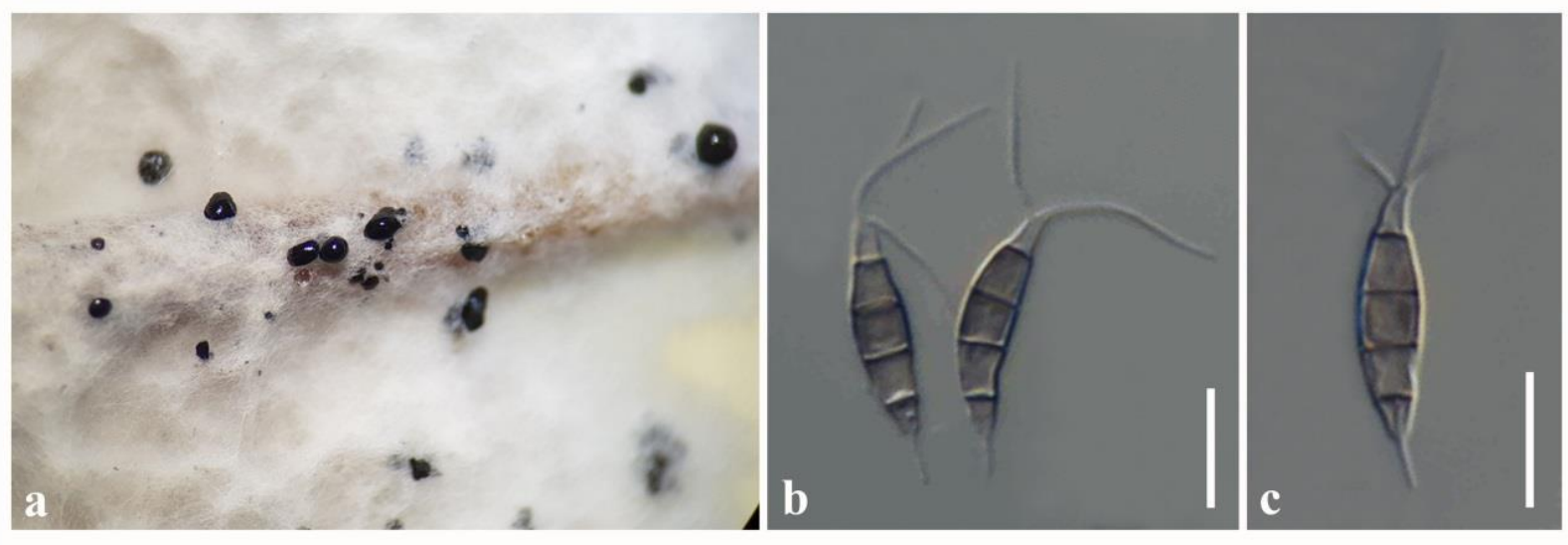

Figure 34 - Pestalotiopsis neolitseae (MFLUCC 18-0930, new host and geographical record). a Conidial masses on pine needles. b, c Conidia. Scale bars: b, c $=10 \mu \mathrm{m}$. 
Notes - As morphological characters examined largely overlap with the type of $P$. neolitseae (NTUH 17-011), we report our collections (GMT 1 and GMT 2) as a new host record from healthy leaves of Magnolia candolli. Both share a similar morphology in having concolourous median cells and 1-3 tubular apical appendages (Ariyawansa \& Hyde 2018). The multi-gene (ITS, tub2 and tef1) phylogeny reported herein, also showed that our collections clusters with the ex-type of $P$. neolitseae (NTUCC 17-011) (Fig. 31). Pestalotiopsis neolitseae have been recorded from leaf spots of Neolitsea villosa as pathogen in Taiwan (Ariyawansa \& Hyde 2018) and this is the first record of $P$. neolitseae associated with healthy leaves of $M$. candolli as an endophyte.

\section{Pseudopestalotiopsis Maharachch., K.D. Hyde \& Crous}

The genus was introduced by Maharachchikumbura et al. (2014b) with the type Pseudopestalotiopsis theae. Pseudopestalotiopsis species are appendage-bearing phenotypically diverse coelomycetes in Sporocadaceae and are commonly found in tropical and subtropical ecosystems (Jaklitsch et al. 2016, Maharachchikumbura et al. 2016a, Jayawardena et al. 2019). Pseudopestalotiopsis is characterized by brown to dark brown or olivaceous median cells (concolourous median cells) and knobbed or not knobbed apical appendages (Maharachchikumbura et al. 2014b, 2016a). Pseudopestalotiopsis species are considered as plant pathogens; P. theae causes grey blight of tea (Maharachchikumbura et al. 2011, 2016a) and $P$. ixorae and $P$. taiwanensis cause a leaf spot (Tsai et al. 2018). Pseudopestalotiopsis species are exhibit saprobic and endophytic life modes. Pseudopestalotiopsis theae isolated as an endophyte from different hosts (Camellia nitidissima, C. sinensis, Holarrhena antidysenterica, Podocarpus macrophyllus, Terminalia arjuna) or as a saprobe (seeds of Diospyros crassiflora) (Maharachchikumbura et al. 2011, 2016a, Jayawardena et al. 2019). There are 22 species epithets are recorded in Index Fungorum (2021). In this study, we report two new host records of endophytic P. ampullacea and $P$. simitheae from Magnolia candolli in China.

Pseudopestalotiopsis ampullacea F. Liu \& L. Cai, Scientific Reports 7 (no. 866): 12 (2017)

Index Fungorum number: IF818922; Facesoffungi number: FoF09445

Fig. 36

Endophytic in fresh leaves of Magnolia candolli. Colonies on PDA flat, white mycelia. Mycelia superficial and immersed composed of septate, branched, 2-3 $\mu \mathrm{m}$ wide, hyaline and brown with smooth and thick-walled hyphae. Sexual morph: Undetermined. Asexual morph: Conidiomata pycnidial on PDA, globose, solitary, embedded or semi-immersed, exuding black conidial masses. Conidia 25-28 $\times 5-7 \mu \mathrm{m}(\bar{x}=26 \times 6 \mu \mathrm{m})$, ellipsoid, fusoid, straight to slightly curved, 4-septate; basal cell 3-4 $\mu \mathrm{m}$ long, hyaline, obconic, smooth- and thin-walled; three median cells 17-19 $\times 5-7$ $\mu \mathrm{m},(\bar{x}=18 \times 6 \mu \mathrm{m})$ light brown, doliiform, (the second cell from base 6-7 $\mu \mathrm{m}$ long, third cell 5-6 $\mu \mathrm{m}$ long, fourth cell 6-7 $\mu \mathrm{m}$ long); apical cell 3-4 $\mu \mathrm{m}$ long, cylindrical to subcylindrical, conic to bell-shaped, hyaline, thin-walled, with 2-3 tubular apical appendages, 24-27 $\mu \mathrm{m}$ long, arising from the apical crest, filiform, basal appendage 2-3 $\mu \mathrm{m}$ long, single, tubular, straight and centric.

Culture characteristics: Colonies on PDA reaching $36 \mathrm{~mm}$ diameter after 7 days at $25^{\circ} \mathrm{C}$, colonies circular, margin entire, flat, fluffy appearance, white mycelia, colony from above: white; reverse: cream.

Material examined - CHINA, Yunnan Province, Xishuangbanna, healthy leaves of Magnolia candolli (Magnoliaceae), 26 April 2017, N. I. de Silva, S9, living culture, MFLUCC 19-0100 = KUMCC 17-0234, S23, living culture, MFLUCC 19-0113 = KUMCC 17-0247.

GenBank numbers - (S9); ITS: MW244024, tub2: MW602385, tef1: MW273928, (S23); ITS: MW244025, tub2: MW602386, tef1: MW273929

Notes -Phylogenetic analysis of combined ITS, tub2 and tef1 sequence data confirmed that our two isolates (S9 and S23) are P. ampullacea with 99\% ML, 98\% MP and 1.00 BYPP support (Fig. 35). The ITS gene region of the ex-type P. ampullacea (LC6618) and two new strains are similar. There are two base pair differences in each tub2 and tefl gene regions of the ex-type $P$. ampullacea (LC6618) and the new strain S9 and S23. Pseudopestalotiopsis ampullacea (HMAS 
247056, holotype) was isolated from on Camellia sinensis in China (Liu et al. 2017). Pseudopestalotiopsis ampullacea was also recorded from plant family Lauraceae (Liu et al. 2017). We hence, identify our collection as a new host record of $P$. ampullacea, isolated from leaves of Magnolia candolli.

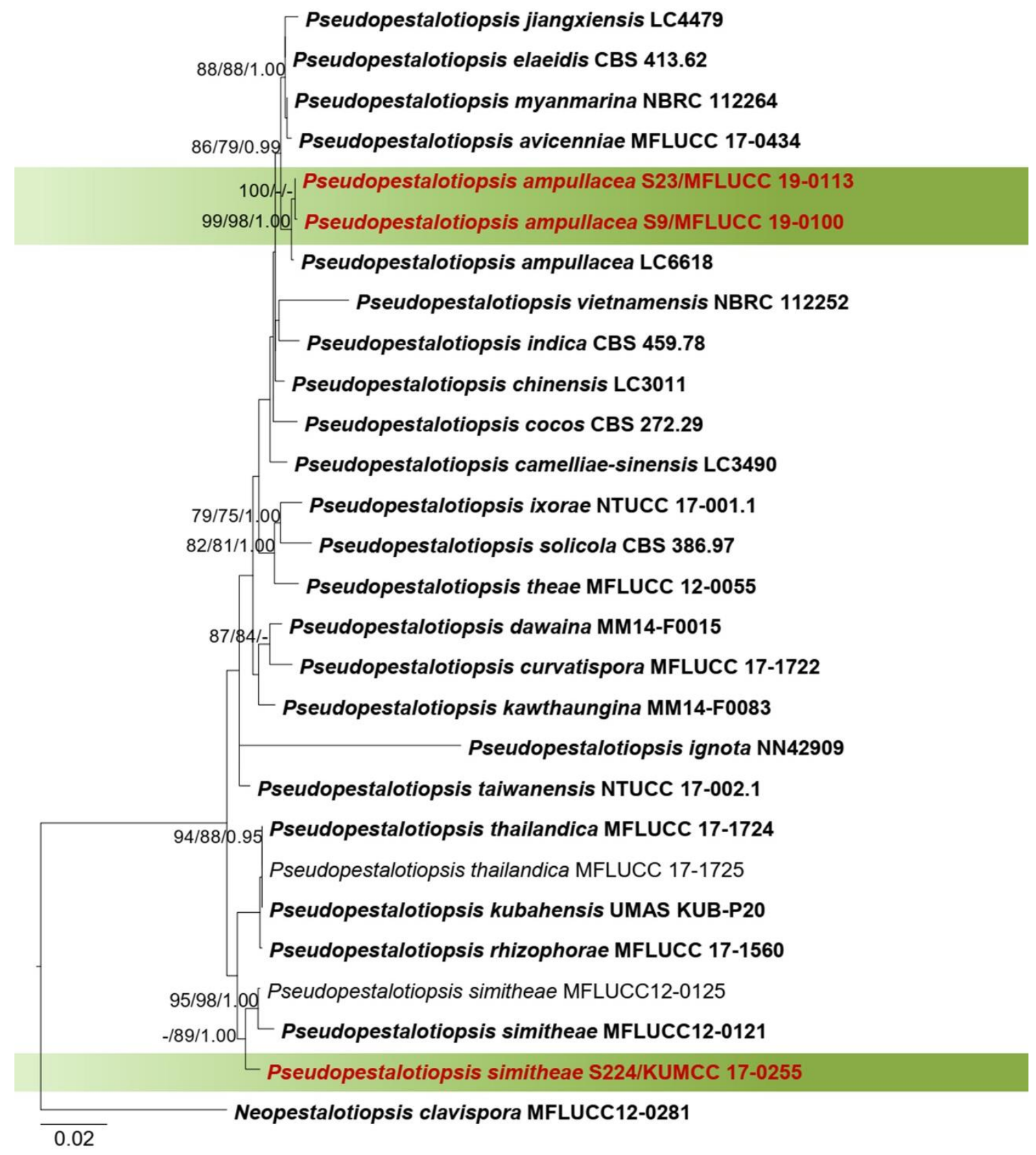

Figure 35 - Phylogram generated from maximum likelihood analysis based on combined ITS, tub2 and tefl sequence data alignment. Twenty eight strains are included in the combined gene analyses comprising 1880 characters after alignment (500 characters for ITS, 440 characters for tub2 and 940 characters for tef1). Neopestalotiopsis clavispora (MFLUCC 12-0281) is used as outgroup taxon. The best RAxML tree with a final likelihood value of -5232.29747 is presented. The matrix had 376 distinct alignment patterns, with $19.27 \%$ undetermined characters or gaps. Estimated base frequencies were as follows: $\mathrm{A}=0.252534, \mathrm{C}=0.258358, \mathrm{G}=0.234842, \mathrm{~T}=0.254266$; substitution rates $\mathrm{AC}=1.785859, \mathrm{AG}=4.601061, \mathrm{AT}=2.011516, \mathrm{CG}=1.468089, \mathrm{CT}=$ 5.532301, GT $=1.000000$; gamma distribution shape parameter $\alpha=0.942725$. Bootstrap values for maximum likelihood and maximum parsimony equal to or greater than $75 \%$ and Bayesian posterior 
probabilities equal or greater than 0.95 are placed above the branches. The newly generated sequences are indicated in red. Type and ex-type strains are in bold.

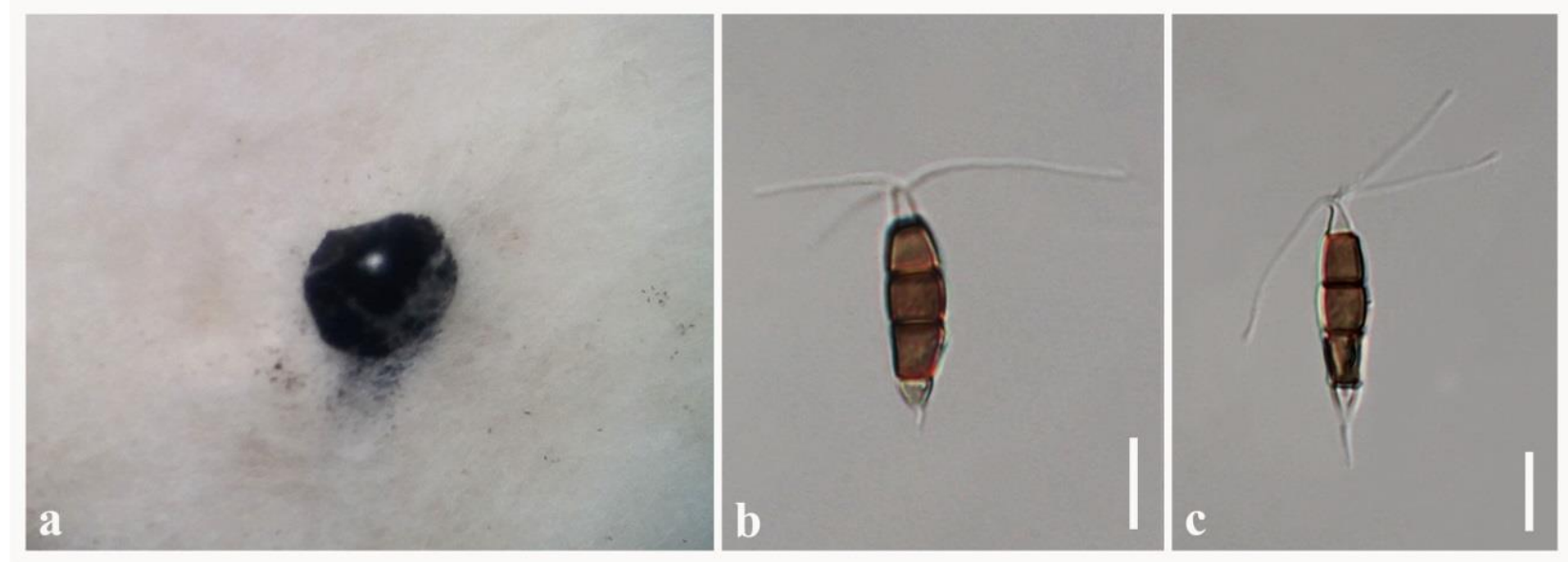

Figure 36 - Pseudopestalotiopsis ampullacea (MFLUCC 19-0100, new host record). a Conidial masses on PDA. b, c Conidia. Scale bars: b, c $=10 \mu \mathrm{m}$.

Pseudopestalotiopsis simitheae (Yu Song, Tangthir., K.D. Hyde \& Y. Wang) Maharachch. \& K.D. Hyde, Mycological Progress 15(no. 22): 5 (2016)

Index Fungorum number: IF551720; Facesoffungi number: FoF01631

Fig. 37

Endophytic in fresh leaves of Magnolia candolli. Colonies on PDA flat, white mycelia. Mycelia superficial and immersed composed of septate, branched, 2-3 $\mu \mathrm{m}$ wide, hyaline and brown with smooth and thick-walled hyphae. Sexual morph: Undetermined. Asexual morph: Conidiomata pycnidial on PDA, globose, solitary or aggregated, embedded or semi-immersed, exuding black conidial masses. Conidia 20-25 × 5-7 $\mu \mathrm{m}(\bar{x}=23 \times 6 \mu \mathrm{m})$, ellipsoid, fusoid, straight to slightly curved, 4-septate; basal cell 3-4 $\mu \mathrm{m}$ long, hyaline, obconic, smooth- and thin-walled; three median cells $15-19 \times 5-7 \mu \mathrm{m}(\bar{x}=16 \times 6 \mu \mathrm{m})$, light brown, doliiform, (the second cell from base 5-6 $\mu \mathrm{m}$ long, third cell 5-6 $\mu \mathrm{m}$ long, fourth cell 5-7 $\mu \mathrm{m}$ long); apical cell 3-4 $\mu \mathrm{m}$ long, cylindrical to subcylindrical, conic to bell-shaped, hyaline, thin-walled, with 3 tubular apical appendages, 22-27 $\mu \mathrm{m}$ long, arising from the apical crest, filiform, basal appendage $2-3 \mu \mathrm{m}$ long, single, tubular, straight and centric.

Culture characteristics - Colonies on PDA reaching $36 \mathrm{~mm}$ diameter after 7 days at $25^{\circ} \mathrm{C}$, colonies circular, margin entire, flat, fluffy appearance, white mycelia, colony from above: white; reverse: cream.

Material examined - CHINA, Yunnan Province, Xishuangbanna, healthy leaves of Magnolia candolli (Magnoliaceae), 26 April 2017, N. I. de Silva, S224 (MFLU 20-0603, dried culture); living culture, KUMCC 17-0255.

GenBank numbers - ITS: MW244023, tub2: MW602387, tef1: MW273930

Notes - Phylogenetic analyses of concatenated ITS, tub2 and tefl sequence dataset indicated that our isolate has a close affinity with Pseudopestalotiopsis simitheae with $67 \%$ ML, 89\% MP, 1.00 BYPP support (Fig. 35). Comparisons of ITS and $t u b 2$ gene regions revealed one base pair difference in each gene region between the ex-type $P$. simitheae (MFLUCC 12-0121) and new isolate S224. There are 10 base pair differences (substitutions) in tefl gene regions between the extype P. simitheae (MFLUCC 12-0121) and the new strain S224 without gaps. Furthermore, the new isolate (S224) shares a size range of conidia $(26-30 \times 5-7 \mu \mathrm{m})$ conidial characters with the holotype $P$. simitheae (MFLU 13-0305) $(22-30 \times 5-6.5 \mu \mathrm{m})$. Pseudopestalotiopsis simitheae was collected from dead and living leaves of Pandanus odoratissimus in Thailand (Song et al. 2014b). Based on similar morphology and molecular data, here, we report our isolate as a new host and geographical record of $P$. simitheae associate with healthy leaves of Magnolia candolli in China. 


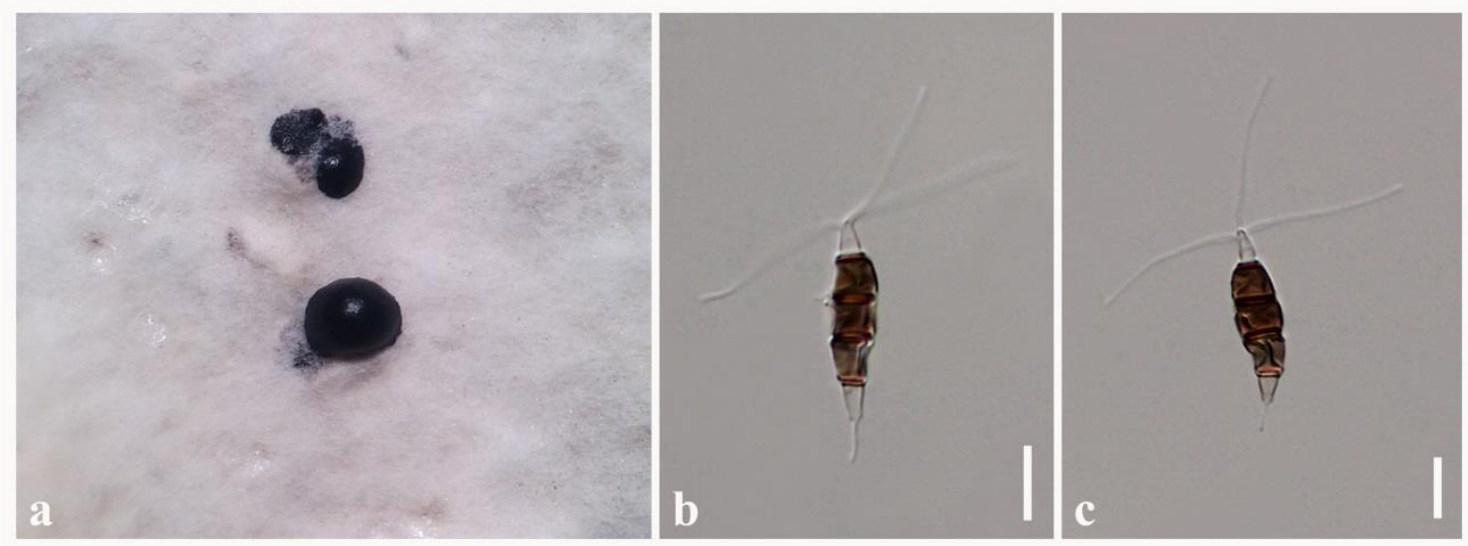

Figure 37 - Pseudopestalotiopsis simitheae (KUMCC 17-0255, new host and geographical record). a Conidial masses on PDA. b, c Conidia. Scale bars: b, c $=10 \mu \mathrm{m}$.

Xylariales Nannf.

Apiosporaceae K.D. Hyde et al.

Hyde et al. (1998) established Apiosporaceae with the type genus Apiospora. Species of this family are saprobes, pathogens, endophytes of plants and occasionally infecting humans (Wang et al. 2017b, Raza et al. 2019, Hyde et al. 2020b, c). Maharachchikumbura et al. (2016b) accepted six genera in Apiosporaceae. Hyde et al. (2020b) accommodated five genera, namely, Appendicospora, Arthrinium, Dictyoarthrinium, Endocalyx and Nigrospora. Asexual morph of this family are considered as coelomycetous or hyphomycetous comprising sporodochial conidiomata, smooth to finely verruculose conidiogenous cells, unicellular or guttulate to granular conidia (Maharachchikumbura et al. 2016b, Raza et al. 2019, Hyde et al. 2020c). The sexual morphs are characterized by perithecial ascomata immersed in pseudostromata, unitunicate or short-pedicellate asci, smooth-walled ascospores (Maharachchikumbura et al. 2016b, Raza et al. 2019).

\section{Nigrospora Zimm.}

Nigrospora species have been isolated as endophytes from leaves and stems of various plants, or as saprobes from detritus, dead larvae or leaf litter (Mason 1927, Uzor et al. 2015, Wang et al. 2017b). Nigrospora is also known as plant pathogen causing leaf spots, leaf blight and squirter disease in many important economic crops, fruits and ornamentals (Wang et al. 2017b) while these fungi cause onychomycosis, hay fever, respiratory and allergic diseases in humans (Raza et al. 2019). Nigrospora has a cosmopolitan distribution and a wide host range (Wang et al. 2017b). Asexual morph is characterized by branched micronematous or semimacronematous conidiophores, monoblastic conidiogenous cells and black, shiny, aseptate conidia and sexual morph comprises perithecial ascomata, short-stalked asci with biseriate ascospores (Webster 1952, Wang et al. 2017b, Raza et al. 2019). There are 34 Nigrospora epithets in Index Fungorum (2021).

Nigrospora camelliae-sinensis Mei Wang \& L. Cai, Persoonia 39: 127 (2017)

Fig. 39

Index Fungorum number: IF820731; Facesoffungi number: FoF09396

Endophytic in fresh leaves of Magnolia candolli. Colonies on PDA cream, flat, fluffy appearance with abundant aerial mycelia. Mycelia superficial and immersed composed of septate, branched, 2-3 $\mu \mathrm{m}$ wide, hyaline and brown with smooth and thick-walled hyphae. Sexual morph: Undetermined. Asexual morph: hyphomycetous, conidial masses with mycelia in culture on PDA. Conidiogenous cells 4-5×3-4 $\mu \mathrm{m}$, hyaline, monoblastic, discrete, solitary, determinate, doliiform to ampulliform. Conidia 8-10 $\times 8-9 \mu \mathrm{m}$, hyaline, solitary, globose, subglobose and smooth-walled.

Culture characteristics - Colonies on PDA reaching $36 \mathrm{~mm}$ diameter after 7 days at $25^{\circ} \mathrm{C}$, colonies circular, margin entire, flat, fluffy appearance, white mycelia, colony from above: white; reverse: cream. 


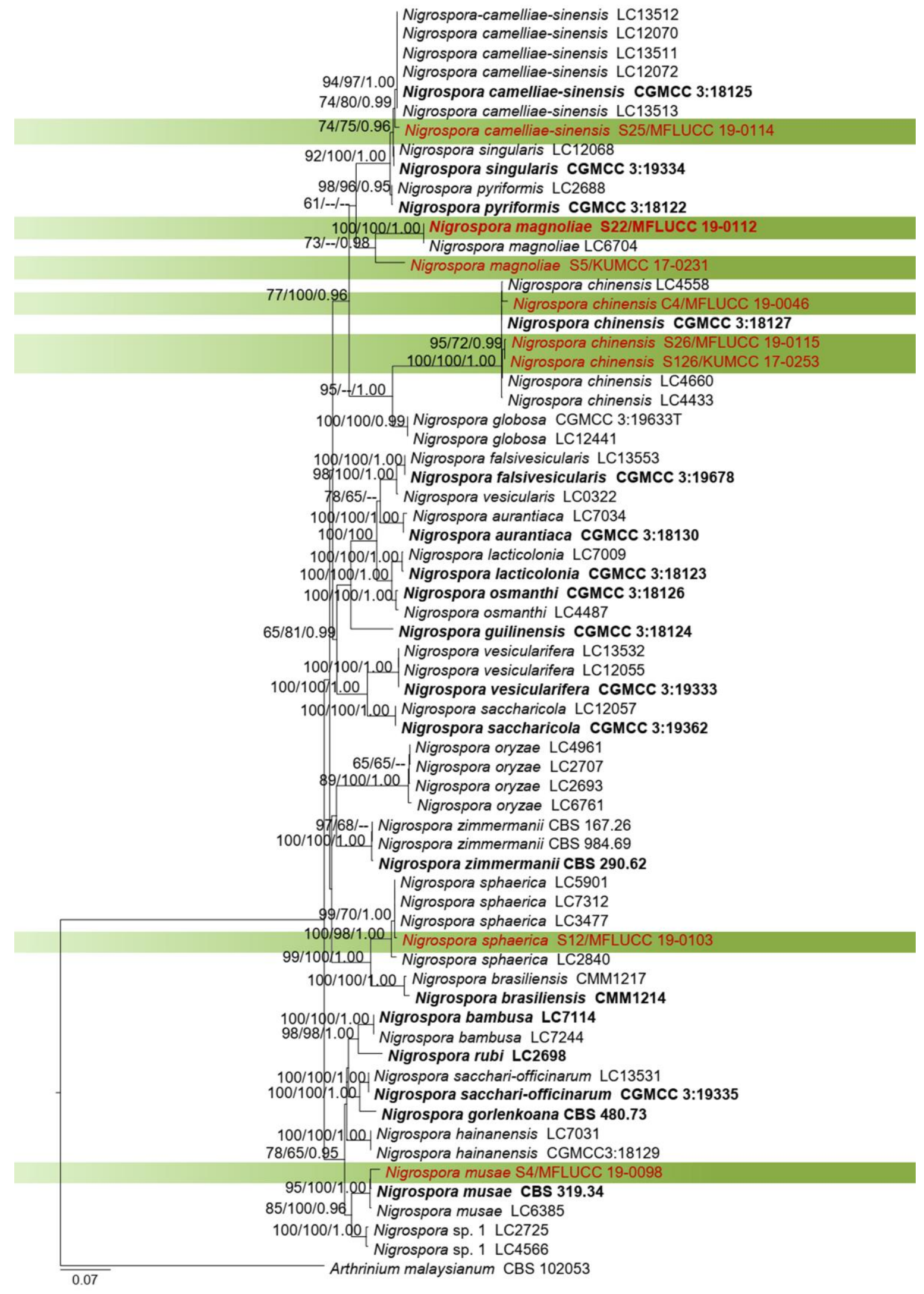

Figure 38 - Phylogram generated from maximum likelihood analysis based on combined ITS, tub2 and tefl sequence data. Related sequences of Nigrospora were obtained from Raza et al. (2019). Sixty six strains are included in the combined gene analyses comprising 1360 characters after alignment (600 characters for ITS, 430 characters for $t u b 2$ and 330 characters for tef1). Arthrinium malaysianum (CBS 102053) is used as outgroup taxon. The best RAxML tree with a final likelihood value of -9137.301167 is presented. The matrix had 657 distinct alignment patterns, with 
$16.46 \%$ undetermined characters or gaps. Estimated base frequencies were as follows: $\mathrm{A}=$ $0.212749, \mathrm{C}=0.307101, \mathrm{G}=0.241426, \mathrm{~T}=0.238724$; substitution rates $\mathrm{AC}=0.995728, \mathrm{AG}=$ 2.485554, $\mathrm{AT}=0.913276, \mathrm{CG}=0.873873, \mathrm{CT}=4.084712, \mathrm{GT}=1.000000$; gamma distribution shape parameter $\alpha=0.714119$. Bootstrap values for maximum likelihood and maximum parsimony equal to or greater than $75 \%$ and Bayesian posterior probabilities equal or greater than 0.95 are placed above the branches. The newly generated sequences are indicated in red. Type and ex-type strains are in bold.

Material examined - CHINA, Yunnan Province, Xishuangbanna, healthy leaves of Magnolia candolli (Magnoliaceae), 26 April 2017, N. I. de Silva, S25 (MFLU 20-0599, dried culture); living culture, MFLUCC 19-0114 = KUMCC 17-0248.

GenBank numbers - ITS: MW285155, tub2: MW346467, tef1: MW296112.

Notes - The combined ITS, tub2 and tefl phylogeny herein, showed that the new isolate (S25) clustered closely related to the ex-type Nigrospora camelliae-sinensis (CGMCC3.18125) and five strains of $N$. camelliae-sinensis with 74\% ML, 75\% MP and 0.96 BYPP support (Fig. 38). Conidia of the type $N$. camelliae-sinensis are spherical or slightly ellipsoidal (Wang et al. 2017b) while conidia of new isolate are spherical. Spherical conidia of new isolate $(\mathrm{S} 25)(8-10 \times 8-9 \mu \mathrm{m})$ are smaller than the type $N$. camelliae-sinensis (13-18 $\mu \mathrm{m}$ diam.) (Wang et al. 2017b).

There are 7 base pair differences $(7 / 220=3.18 \%)$ between the ex-type $N$. camelliae-sinensis and new isolate (S25) in tef1 sequence data. A base pair comparison of ITS and tub2 sequence data between the ex-type N. camelliae-sinensis and S25 revealed 100\% similarity.

Nigrospora camelliae-sinensis was introduced by Wang et al. (2017b), which was collected from Guangxi Province, China, on Camellia sinensis. In addition to that N. camelliae-sinensis was recorded from leaves and roots of Saccharum officinarum in China (Raza et al. 2019). The new isolate (S25) was isolated from healthy leaves of Magnolia candolli in Yunnan Province, China. We consider the new isolate as $N$. camelliae-sinensis and the first report of $N$. camelliae-sinensis from leaves of Magnolia candolli.
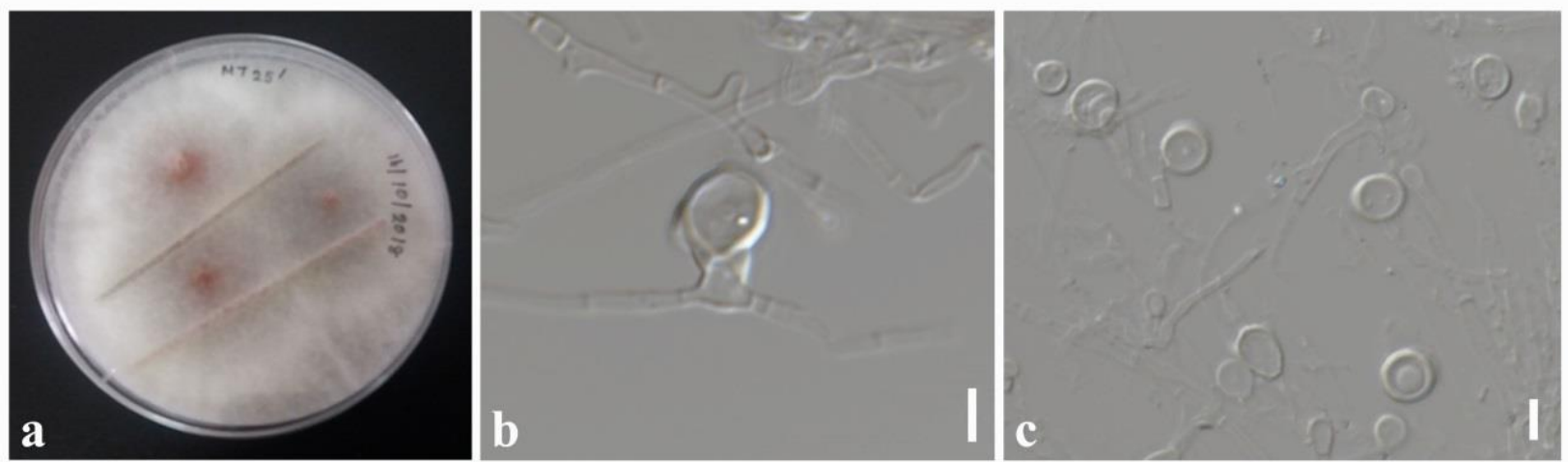

Figure 39 - Nigrospora camelliae-sinensis (MFLUCC 19-0114, new host record). a Colonies on PDA. b Conidiogenous cell with conidia. c Mycelia and conidia. Scale bars: b, c $=5 \mu \mathrm{m}$.

Nigrospora chinensis Mei Wang \& L. Cai, Persoonia 39: 129 (2017)

Fig. 40 Index Fungorum number: IF820732; Facesoffungi number: FoF09446

Endophytic in fresh leaves of Magnolia candolli. Colonies on PDA cream, slightly raised, wooly appearance, with aerial mycelia. Mycelia superficial and immersed composed of septate, branched, 2-3 $\mu \mathrm{m}$ wide, hyaline and brown with smooth and thick-walled hyphae. Sexual morph: Undetermined. Asexual morph: hyphomycetous, conidial masses with mycelia in culture on PDA. Conidiogenous cells 8-10× 4-5 $\mu \mathrm{m}$, hyaline, monoblastic, discrete, solitary, determinate, doliiform to ampulliform. Conidia 10-12 × 12-14 $\mu \mathrm{m}$, hyaline, dark brown, solitary, globose or subglobose and smooth-walled. 
Culture characteristics - Colonies on PDA reaching $30 \mathrm{~mm}$ diameter after 7 days at $25^{\circ} \mathrm{C}$, colonies circular, margin entire, slightly raised, wooly appearance, white aerial mycelia, colony from above: white; reverse: cream.

Material examined - CHINA, Yunnan Province, Xishuangbanna, healthy leaves of Magnolia candolli (Magnoliaceae), 26 April 2017, N. I. de Silva, S26 (MFLU 20-0600, dried culture); living culture, MFLUCC 19-0115 = KUMCC 17-0249, S126, living culture, KUMCC 17-0253, MT 4, living culture, KUMCC 17-0210 = MFLUCC 19-0046.

GenBank numbers - (S26); ITS: MW285153, tub2: MW620879, tef1: MW296113, (S126); ITS: MW285154, tub2: MW620880, (MT4); ITS: MW285152, tub2: MW620881.

Notes - Three new strains clustered in a well-supported clade with the ex-type Nigrospora chinensis (CGMCC3.18127). Nigrospora chinensis has recorded from various host plants, i.e. Aucuba japonica, Camellia sinensis, Castanopsis sp., Lindera aggregate, Machilus duthiei, Musa paradisiaca, Osmanthus sp. and Smilax ocreata in China (Wang et al. 2017b). Therefore, we report our new collection as endophytic lifestyle of $N$. chinensis, which was isolated from healthy leaves of Magnolia candolli in Yunnan, China for the first time.

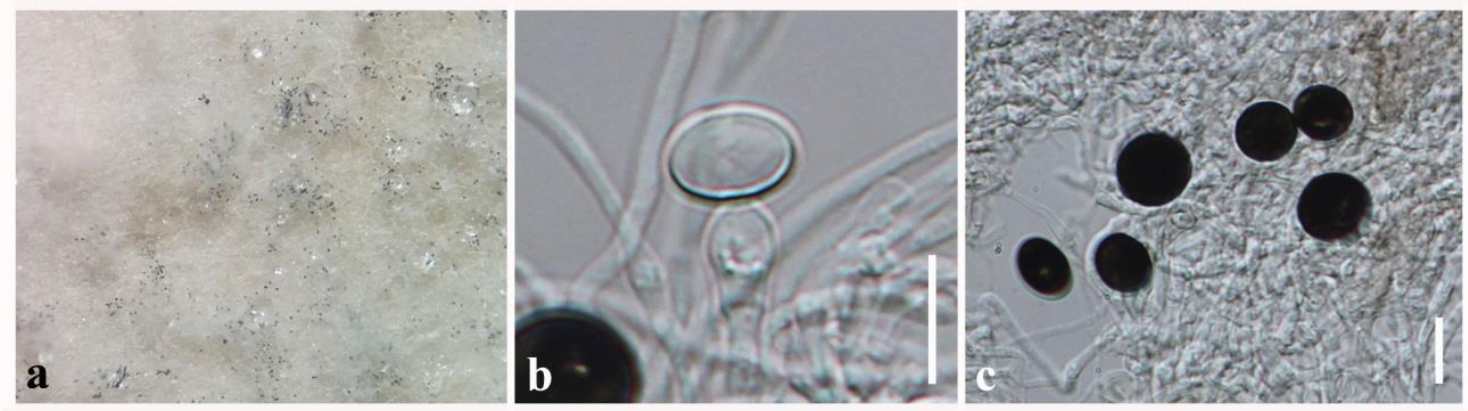

Figure 40 - Nigrospora chinensis (MFLUCC 19-0115, new host record). a Colony on PDA producing conidia masses. $\mathrm{b}$ Conidiogenous cell with immature conidium. c Mycelia and conidia. Scale bars: $b, c=10 \mu \mathrm{m}$.

Nigrospora magnoliae N.I. de Silva, Lumyong \& K.D. Hyde, sp. nov. Fig. 41

Index Fungorum number: IF556382; Facesoffungi number: FoF09497 isolated.

Etymology - Name reflects the host genus Magnolia, from which the new species was

Holotype - MFLU 20-0597

Endophytic in fresh leaves of Magnolia candolli. Colonies on PDA brown, flat, spreading, with abundant aerial mycelia. Mycelia superficial and immersed composed of septate, branched, 2$4 \mu \mathrm{m}$ wide, hyaline and brown with smooth and thick-walled hyphae. Sexual morph: Undetermined. Asexual morph: hyphomycetous, conidial masses with mycelia in culture on PDA. Conidiophores 2-4 $\mu \mathrm{m}$ diam., hyaline, micronematous or semi-macronematous, flexuous or

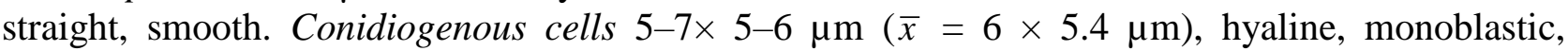
discrete, solitary, determinate, doliiform to ampulliform. Conidia 10-14 $\times 10-13 \mu \mathrm{m}(\bar{x}=12 \times 11$ $\mu \mathrm{m})$, dark brown, solitary, globose or subglobose and smooth-walled.

Culture characteristics - Colonies on PDA reaching $30 \mathrm{~mm}$ diameter after 7 days at $25^{\circ} \mathrm{C}$, colonies circular, margin entire, flat, initially white and becoming dark brown, some white aerial mycelia, colony from above: brown; reverse: dark brown.

Material examined - CHINA, Yunnan Province, Xishuangbanna, healthy leaves of Magnolia candolli L. (Magnoliaceae), 26 April 2017, N. I. de Silva, S22 (MFLU 20-0597, holotype, dried culture); ex-type living culture, MFLUCC 19-0112 = KUMCC 17-0246.

Additional material - CHINA, Yunnan Province, Xishuangbanna, healthy leaves of Magnolia candolli L. (Magnoliaceae), 26 April 2017, N. I. de Silva, S5, living culture, KUMCC 17-0231. 
GenBank numbers - (S22); ITS: MW285092, tub2: MW438334, (S5); ITS: MW699933, tub2: MW727265.

Notes - Phylogenetic results indicated that Nigrospora magnoliae (S22) clustered with other Nigrospora species and in particular, and formed a distinct clade sister to $N$. camelliae-sinensis, $N$. singularis and N. pyriformis with $61 \% \mathrm{ML}, 50 \% \mathrm{MP}$ and $0.75 \mathrm{BYPP}$ support (Fig. 38). Nigrospora magnoliae has dark brown, globose or subglobose $(10-14 \times 10-13 \mu \mathrm{m})$ conidia that are slightly smaller than $N$. camelliae-sinensis $(13-18 \mu \mathrm{m}$ diam. spherical and $12-18 \times 9-14.5 \mu \mathrm{m}$ ellipsoidal conidia) $N$. pyriformis $(12.5-16.5 \mu \mathrm{m}$ globose to subglobose and $17.5-27.5 \times 10-18.5 \mu \mathrm{m}$ pyriform conidia) (Wang et al. 2017b) and $N$. singularis $(9.5-13 \times 11-15 \mu \mathrm{m}$ ellipsoid to subglobose conidia) (Raza et al. 2019). Nigrospora sp. 2 (LC6702) clustered with N. magnoliae in our combined multi-gene phylogenetic analysis. Wang et al. (2017b) recorded Nigrospora sp. 2 (LC6702) in their phylogenetic analyses without morphological description, which was isolated from Camellia sinensis in China. Therefore, based on phylogenetic analyses and morphology, $N$. magnoliae identified as a novel endophytic species in this study.

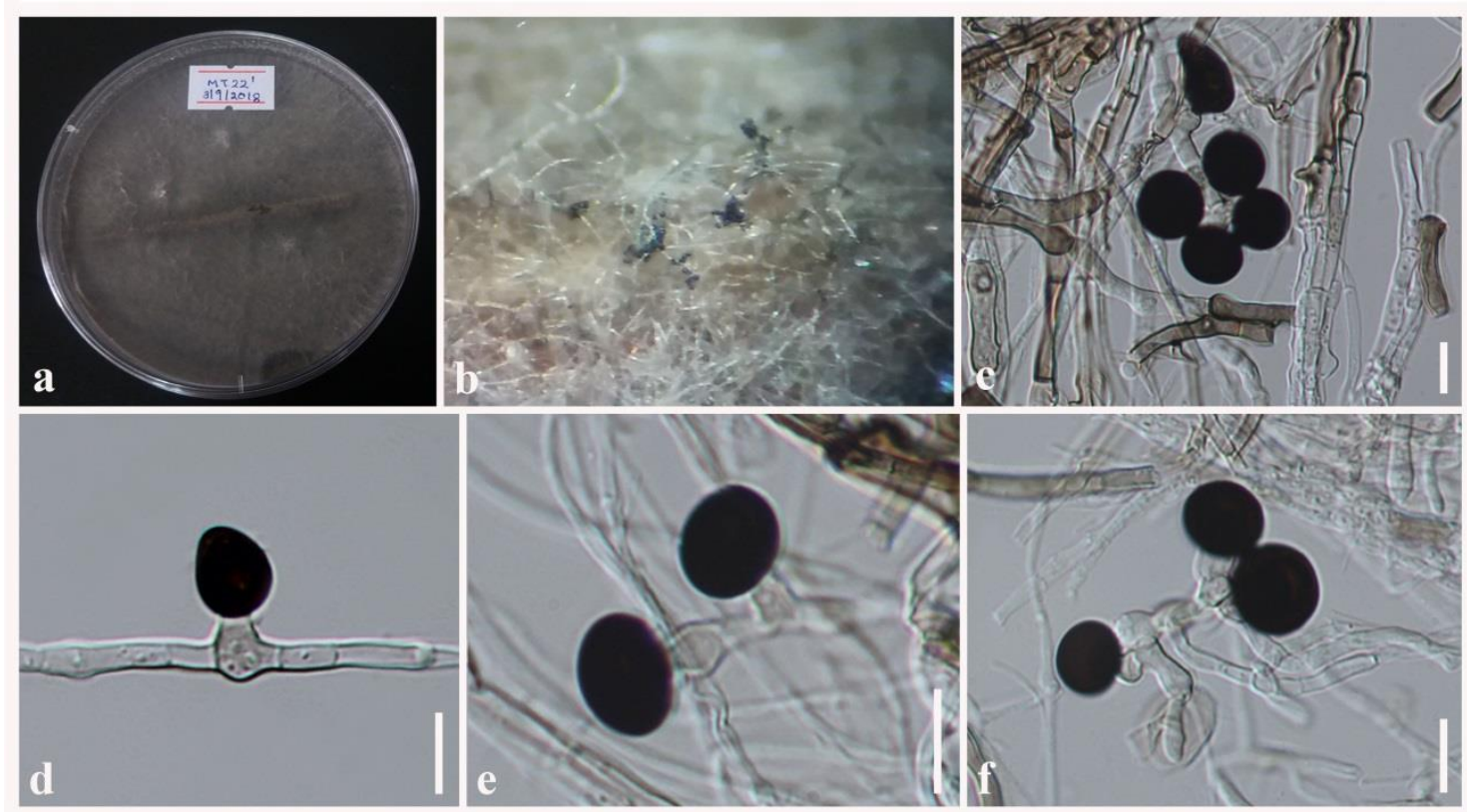

Figure 41 - Nigrospora magnoliae (MFLU 20-0597, holotype). a Colonies on PDA. b Colony on PDA producing conidia masses. c Mycelia and conidia d, e Conidiogenus cells with conidia. f Mycelia and conidia. Scale bars: $\mathrm{c}-\mathrm{f}=10 \mu \mathrm{m}$.

Nigrospora musae McLennan \& Hoëtte, Australian Institute of Science and Industry Reserch Bulletin 75: 15 (1933)

Index Fungorum number: IF271866; Facesoffungi number: FoF09447

Fig. 42

Endophytic in fresh leaves of Magnolia candolli. Colonies on PDA white, slightly raised, wooly appearance, with abundant aerial mycelia. Mycelia superficial and immersed composed of septate, branched, 2-3 $\mu \mathrm{m}$ wide, hyaline and brown with smooth and thick-walled hyphae. Sexual morph: Undetermined. Asexual morph: hyphomycetous, developing conidia with mycelia in culture on PDA. Conidiophores 15-20 $\mu \mathrm{m}$ diam., hyaline, micronematous or semi-macronematous, flexuous or straight, smooth. Conidiogenous cells 10-12×7-8 $\mu \mathrm{m}$, hyaline, monoblastic, discrete, solitary, determinate, doliiform to ampulliform. Conidia 13-15 $\times 10-12 \mu \mathrm{m}$, hyaline, solitary, obpyriform or ovoid and smooth.

Culture characteristics - Colonies on PDA reaching $35 \mathrm{~mm}$ diameter after 7 days at $25^{\circ} \mathrm{C}$, colonies circular, margin entire, slightly raised, woolly appearance, white and brown mycelia, colony from above: brown and white; reverse: brown. 
Material examined - CHINA, Yunnan Province, Xishuangbanna, healthy leaves of Magnolia candolli (Magnoliaceae), 26 April 2017, N. I. de Silva, S4 (MFLU 20-0585, dried culture); living culture, MFLUCC 19-0098 = KUMCC 17-0230.

GenBank numbers - ITS: MW285148, tub2: MW346468, tef1: MW296114.

Notes - Phylogram generated from a combined ITS, tub2 and tefl sequence dataset indicated that our strain is Nigrospora musae and it formed a well-supported clade with $95 \% \mathrm{ML}, 100 \% \mathrm{MP}$, 1.00 BYPP support (Fig. 38). McLennan \& Hoëtte (1993) originally described N. musae from fruits of Musa sapientum in Australia. The ex-type strain (CBS 319.34) was sterile and therefore, Wang et al. (2017b) emended taxonomic description based on a freshly collected strain from Camellia sinensis in China. This species has not been reported from the plant family Magnoliaceae (Farr \& Rossman 2021). Herein, we provide the new host record for $N$. musae from healthy leaves of Magnolia candolli.
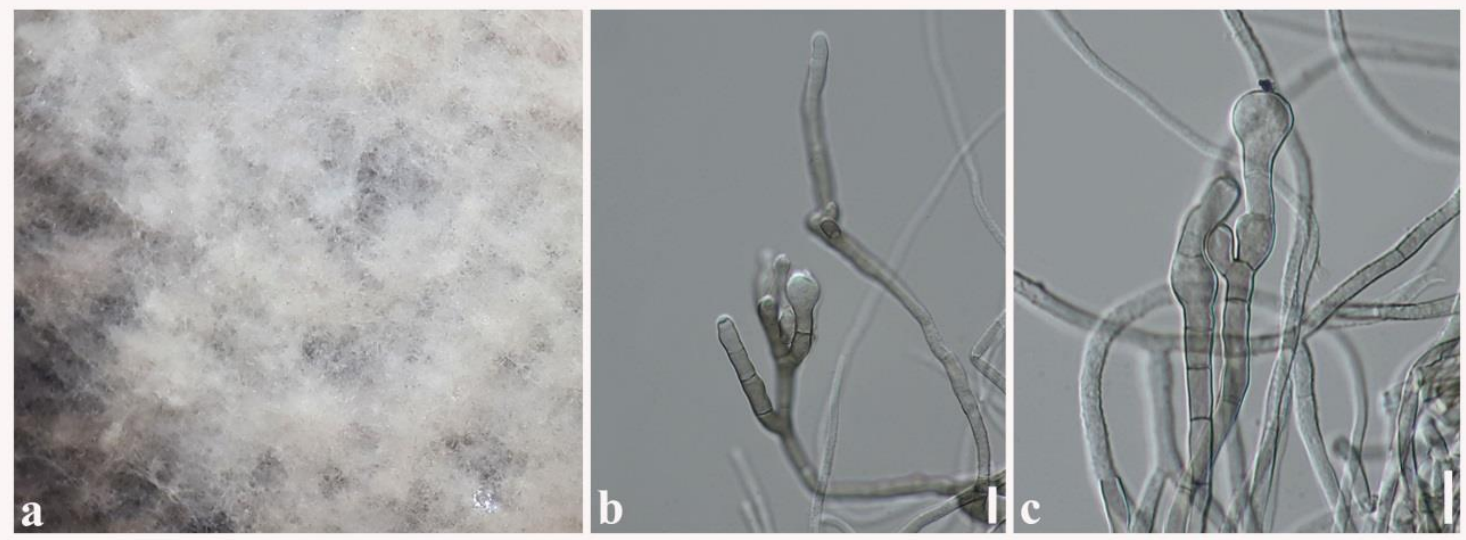

Figure 42 - Nigrospora musae (MFLUCC 19-0098, new host record). a Colonies on PDA producing conidia. $\mathrm{b}, \mathrm{c}$ Mycelia and young developing conidia. Scale bars: $\mathrm{b}, \mathrm{c}=10 \mu \mathrm{m}$.

Nigrospora sphaerica (Sacc.) E.W. Mason, Transactions of the British Mycological Society 12(23): 158 (1927)

Index Fungorum number: IF254776; Facesoffungi number: FoF06599

Fig. 43

Endophytic in fresh leaves of Magnolia candolli. Colonies on PDA white, slightly raised, woolly appearance, with abundant aerial mycelia. Mycelia superficial and immersed composed of septate, branched, 2-3 $\mu \mathrm{m}$ wide, hyaline and brown with smooth and thick-walled hyphae. Sexual morph: Undetermined. Asexual morph: hyphomycetous, conidial masses with mycelia in culture on PDA. Conidiophores 25-30 $\mu \mathrm{m}$ diam., hyaline, micronematous or semi-macronematous, flexuous or straight, smooth. Conidiogenous cells 8-10 × 6-8 $\mu \mathrm{m}$, hyaline, monoblastic, discrete, solitary, determinate, doliiform to ampulliform. Conidia 12-14 × 14-16 $\mu \mathrm{m}$, hyaline, dark brown, solitary, globose or subglobose and smooth.

Culture characteristics - Colonies on PDA reaching $35 \mathrm{~mm}$ diameter after 7 days at $25^{\circ} \mathrm{C}$, colonies circular, margin entire, slightly raised, woolly appearance, white mycelia, colony from above: white; reverse: light brown.

Material examined - CHINA, Yunnan Province, Xishuangbanna, healthy leaves of Magnolia candolli (Magnoliaceae), 26 April 2017, N. I. de Silva, S12 (MFLU 20-0589, dried culture); living culture, MFLUCC 19-0103 = KUMCC 17-0237.

GenBank numbers - ITS: MW285149, tef1: MW296115.

Notes - Based on combined multi-gene phylogenetic analysis, the new strain S12 nested with other strains of Nigrospora sphaerica with 100\% ML, 98\% MP, 0.99 BYPP support (Fig. 38). Nigrospora sphaerica has a wide host range in China (i.e. on Camellia sinensis, Cleyera japonica, Deutzia sp., Harpullia longipetala, Musa paradisiacal, Nelumbo sp., Rhododendron arboretum, Rosa sp., Saccharum officinarum and submerged wood) (Wang et al. 2017b, Raza et al. 2019). Nigrospora sphaerica is a well-known pathogen associated with leaf blight on Camellia sinensis in 
China (Liu et al. 2015b), leaf spots and twig and shoot blight on blueberries (Vaccinium corymbosum) (Wright et al. 2008). Nigrospora sphaerica is also considered as an opportunistic pathogen causing onychomycosis in humans (de Hoog et al. 2000, Fan et al. 2009) and a corneal ulcer (Kindo et al. 2014). The endophytic lifestyle of $N$. sphaerica was recorded from different plant species i.e. Vinca rosea (Apocynaceae) (Metwaly et al. 2014), roots of Smallanthus sonchifolius (Asteraceae) (Lopes \& Pupo 2011), leaves of Eupatorium adenophorum (Asteraceae) (Chen et al. 2016). Nigrospora sphaerica was isolated from healthy leaves of Magnolia candolli (Magnoliaceae) is regarded as a new host record.

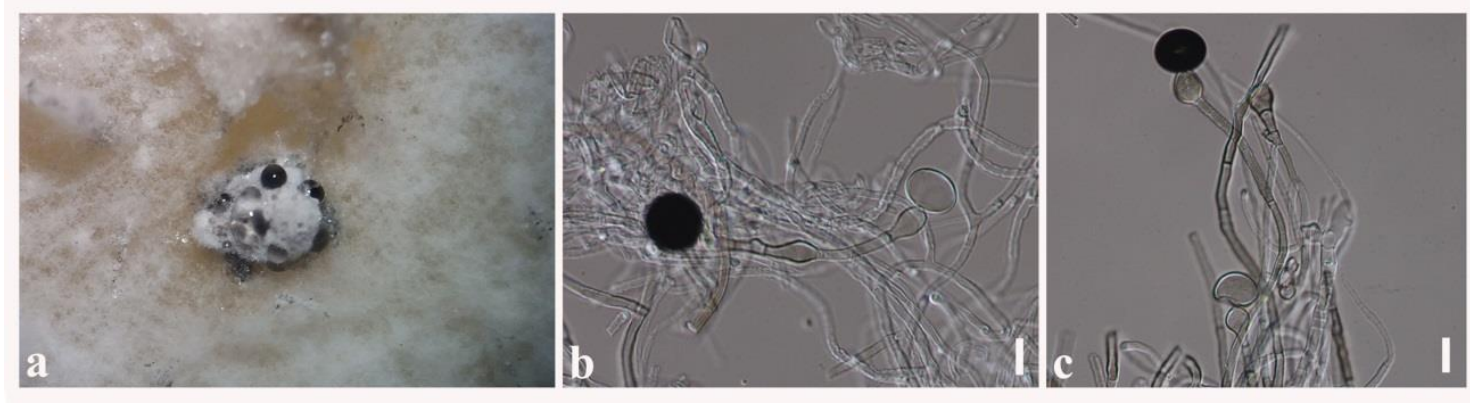

Figure 43 - Nigrospora sphaerica (MFLUCC 19-0103, new host record). a Colony on PDA producing conidia masses. b, c Mycelia and developing conidia. Scale bars: $b, c=10 \mu \mathrm{m}$.

Phylum Basidiomycota Whittaker ex R.T. Moore

Class Agaricomycetes Doweld

Agaricales Underw

Psathyrellaceae Vilgalys, Moncalvo \& Redhead

Deliquescent type mushroom fruiting bodies are found in this family that they have a special autodigestive phase of ontogeny (hence, the name "deliquescent") (Nagy et al. 2011, 2013). The type genus of the family is Psathyrella and the members of this genus are mainly decomposers of leaf-litter or wood, more rarely living on dung, or parasitizing other fungi (Nagy et al. 2013). Traditionally, the family contained two large genera, Coprinus and Psathyrella (Nagy et al. 2013). Ozonium and Hormographiella are the conidial anamorphic taxa in the family that recently reclassified as Coprinellus (Nagy et al. 2013). Nagy et al. (2013) revised the taxonomy of the family using ITS sequences data and distinguished 14 major clades within Psathyrellaceae.

\section{Coprinellus P. Karst.}

Coprinellus is one of the most species-rich, coprinoid mushroom genera in Psathyrellaceae that include approximately 80 species (Gomes \& Wartchow 2014, Hussain et al. 2018) while Index Fungorum (2021) lists 94 species epithets. Species-level identification of Coprinellus is based mainly on the presence or absence and the structure of veil and cystidia on the pileus, of cystidia on the lamellae and on basidiospore morphology and phylogenetic analyses of ITS sequence data (Hussain et al. 2018). Coprinellus species are common saprotroph of wood chips, leaf-litter and herbivore dung (Hussain et al. 2018).

Coprinellus magnoliae N.I. de Silva, Lumyong \& K.D. Hyde, sp. nov.

Fig. 45 Index Fungorum number: IF556385; Facesoffungi number: FoF09498 isolated.

Etymology - Name reflects the host genus Magnolia, from which the new species was

Holotype - MFLU 20-0605

Endophytic in fresh leaves of Magnolia candolli. Colonies on PDA white aerial mycelia. Mycelia superficial and immersed composed of septate, branched, 1-2 $\mu \mathrm{m}$ wide, hyaline and light brown, with smooth and thick-walled hyphae. Spores $2-3.5 \times 1-2 \mu \mathrm{m}(\bar{x}=3 \times 1.4 \mu \mathrm{m})$, hyaline, sub-globose to fusiform with smooth-walled. 


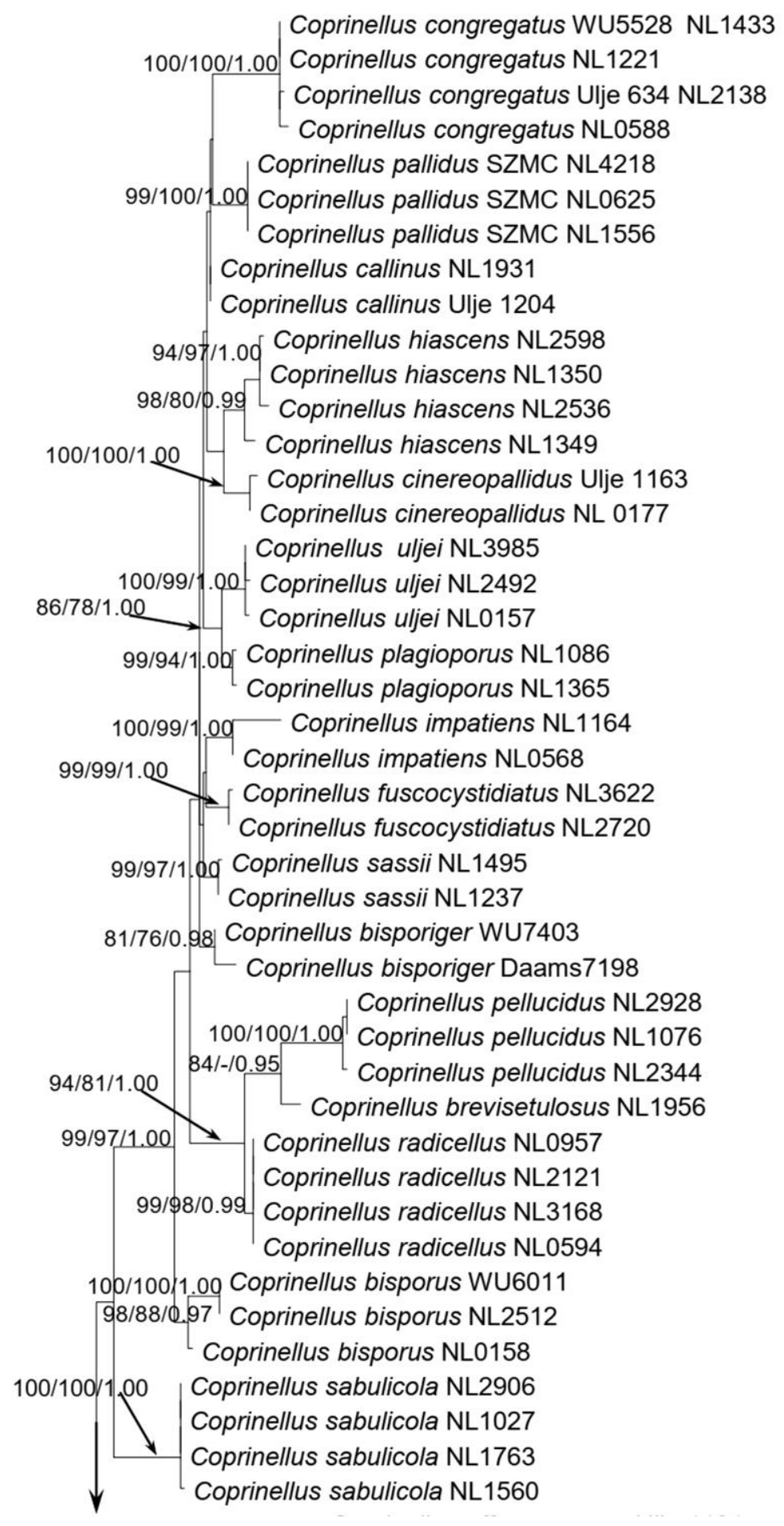

Figure 44 - Phylogram generated from maximum likelihood analysis based on ITS sequence data. Related sequences representing Coprinellus species were obtained from Hussain et al. (2018). Nighty eight strains are included in the phylogenetic analyses comprising 700 characters after ITS alignment Psathyrella candolleana (CBS 300.47) is used as the outgroup taxon. The best RAxML tree with a final likelihood value of -5818.670832 is presented. The matrix had 462 distinct alignment patterns, with $17.55 \%$ undetermined characters or gaps. Estimated base frequencies were as follows: $\mathrm{A}=0.244768, \mathrm{C}=0.236272, \mathrm{G}=0.230683, \mathrm{~T}=0.288278$; substitution rates $\mathrm{AC}=$ 2.005058, $\mathrm{AG}=2.692844, \mathrm{AT}=2.306751, \mathrm{CG}=1.041461, \mathrm{CT}=5.240997, \mathrm{GT}=1.000000$; gamma distribution shape parameter $\alpha=0.548187$. Bootstrap values for maximum likelihood and maximum parsimony equal to or greater than $75 \%$ and Bayesian posterior probabilities equal or 
greater than 0.95 are placed above the branches. The newly generated sequence is indicated in red. Type and ex-type strains are in bold.

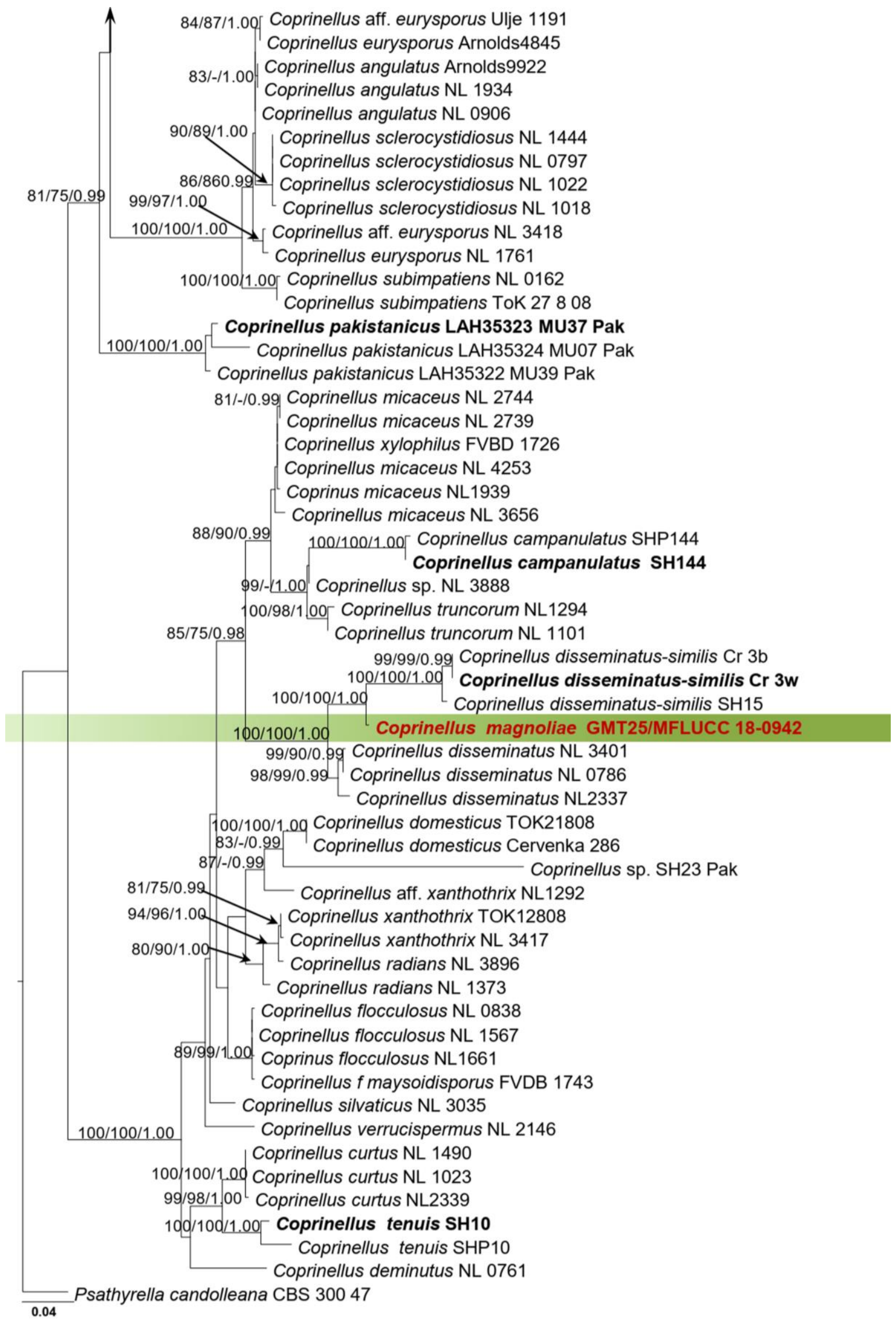

Figure 44 - Continued. 
Culture characteristics - Colonies on PDA reaching $30 \mathrm{~mm}$ diameter after 7 days at $25^{\circ} \mathrm{C}$, colonies circular, margin entire, flat, white, some white aerial mycelia, colony from above: white; reverse: cream.

Material examined - THAILAND, Chiang Mai Province, Mueang Chiang Mai District, healthy leaves of Magnolia garrettii (Magnoliaceae), 14 August 2017, N. I. de Silva, GMT25 (MFLU 20-0605, holotype, dried culture); ex-type living culture, MFLUCC 18-0942.

GenBank numbers - ITS: MW244022.

Notes - Phylogenetic analyses of ITS sequence data revealed that Coprinellus magnoliae forms a sister lineage with $C$. disseminates-similis and distinctly separate from $C$. disseminatessimilis with 100\% ML, 100\% MP, 1.00 BYPP support (Fig. 44). A comparison of ITS sequence shows that $C$. magnolia differs from $C$. disseminates-similis $(\mathrm{Cr} 3 \mathrm{w})$ in 28 base pair positions $(28 / 600=4.67 \%)$. The important characteristics of $C$. disseminatus-similis are pileus parabolic to campanulate, greyish-brown, with umbonate centre; surface pruinose to pulverulent, with sparse micaceous-glistening veil, bright white, deeply plicate from centre to margin (Hussain et al. 2018). Basidiopores of $C$. disseminates-similis are on average $8.5 \times 5.2 \times 4.9 \mu \mathrm{m}$, ellipsoid to cylindrical or obovoid in face view; ellipsoid to amygdaliform in side view (Hussain et al. 2018). However, $C$. magnoliae formed hyaline, sub-globose to fusiform, $(2-3.5 \times 1-2 \mu \mathrm{m})$, sized spores on PDA media. C. disseminates-similis was found on leaf litter under Populus alba and Morus alba, in lowland northern Pakistan (Hussain et al. 2018). Coprinellus magnoliae was isolated from healthy leaves of Magnolia garrettii in Chiang Mai Province, Thailand. We introduce $C$. magnoliae as a new species based on phylogeny and morphology.

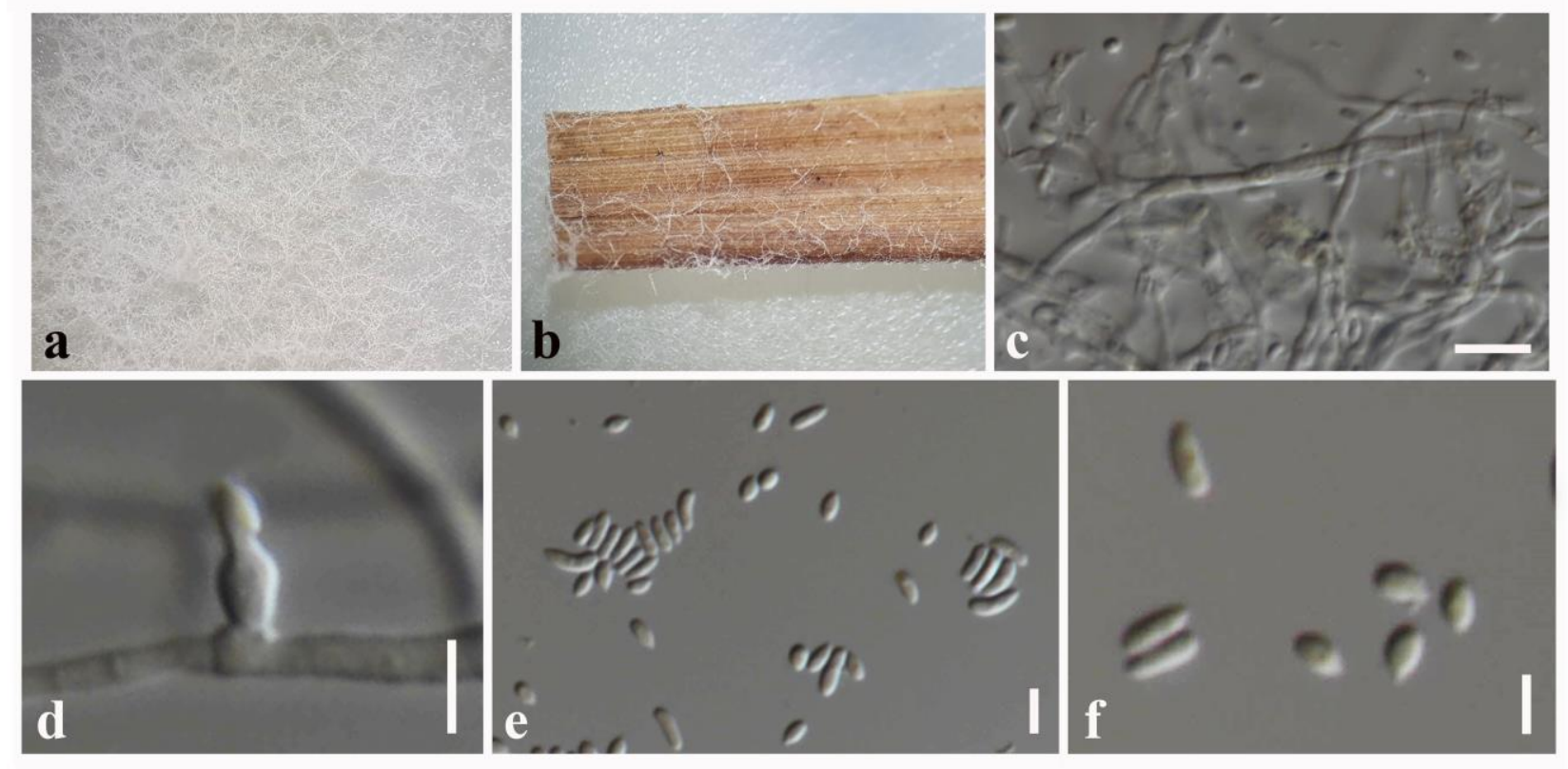

Figure 45 - Coprinellus magnoliae (MFLU 20-0605, holotype). a Mycelia on PDA. b Mycelia on a rice straw. c Mycelia masses. $d$ Developing spores from mycelia. e, f Spores. Scale bars: $c=10$ $\mu \mathrm{m}, \mathrm{d}, \mathrm{f}=5 \mu \mathrm{m}, \mathrm{f}=2 \mu \mathrm{m}$.

\section{Polyporales Gäum.}

Phanerochaetaceae Jülich

Taxa of this family are mainly saprobic and some species may also occur as parasites and were recorded worldwide from different dead plants (Larsson 2007, Miettinen et al. 2016). Larsson (2007) suggested accommodating corticioid fungi within Phanerochaete in Phanerochaetaceae. Binder et al. (2013) included the polypore genus Bjerkandera in Phanerochaetaceae. The recent taxonomic revision of Miettinen et al. (2016) accepted 14 genera of corticioid and poroid species in Phanerochaetaceae. 


\section{Phanerina Miettinen}

The polypore genus Phanerina belongs to Phanerochaete clade in Phanerochaetaceae according to phylogenetic analyses (Miettinen et al. 2016). Members of genus Phanerina grow on dead dicot trees (Miettinen et al. 2016). Phanerina is a monotypic genus closely related to Riopa by both morphology and phylogeny (Miettinen et al. 2016).

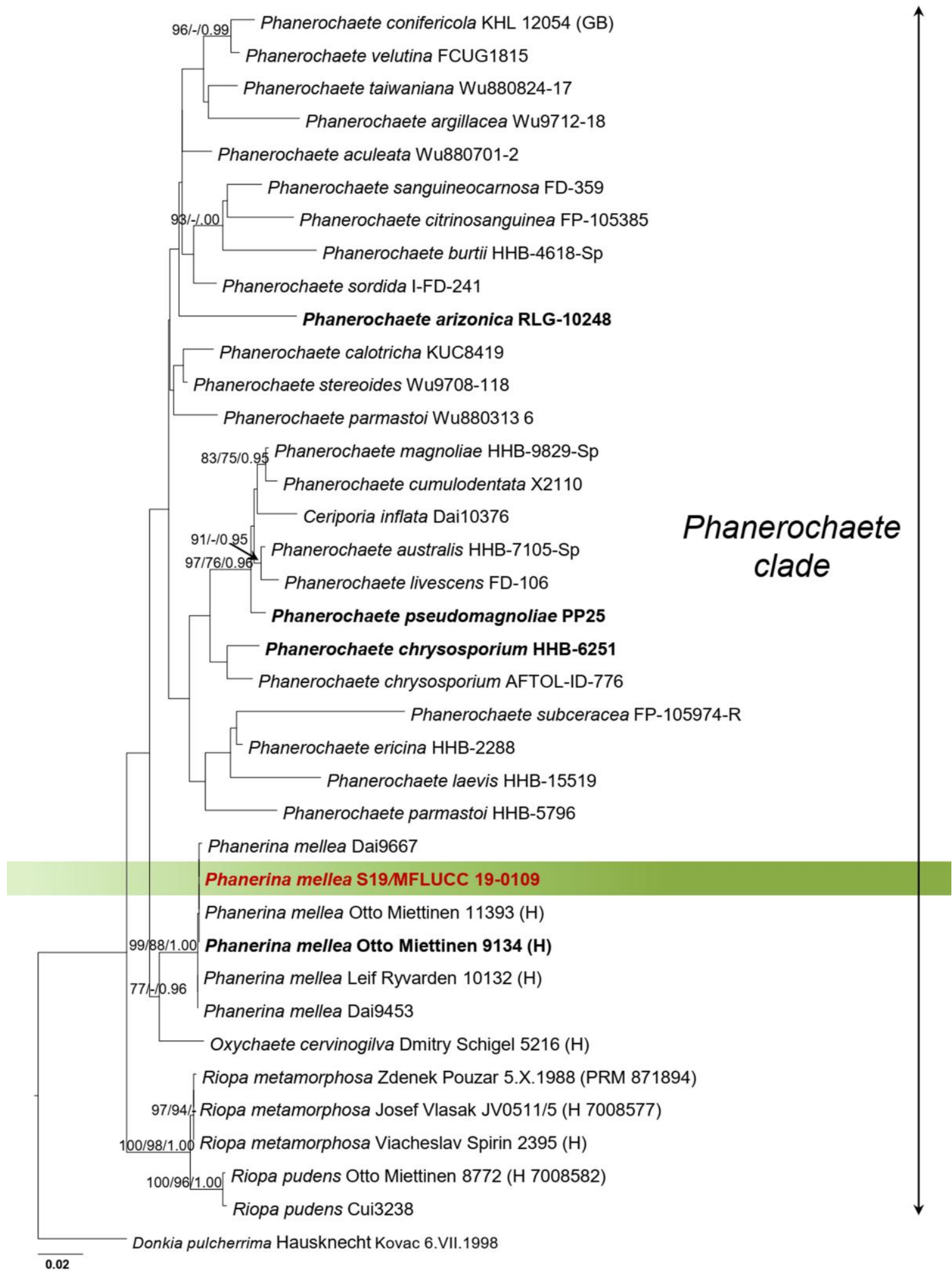

Figure 46 - Phylogram generated from maximum likelihood analysis based on combined ITS and LSU sequence data. Related sequences representing Phanerochaete clade in Phanerochaetaceae 
were obtained from Miettinen et al. (2016). Thirty eight strains are included in the combined gene analyses comprising 1750 characters after alignment (750 characters for ITS and 1000 characters for LSU). Donkia pulcherrima (Hausknecht Kovac 6.VII.1998) is used as the outgroup taxon. The best RAxML tree with a final likelihood value of -6571.270371 is presented. The matrix had 471 distinct alignment patterns, with $56.37 \%$ undetermined characters or gaps. Estimated base frequencies were as follows: $\mathrm{A}=0.250421, \mathrm{C}=0.215000, \mathrm{G}=0.265827, \mathrm{~T}=0.268752$; substitution rates $\mathrm{AC}=1.280665, \mathrm{AG}=3.466017, \mathrm{AT}=1.741286, \mathrm{CG}=0.529488, \mathrm{CT}=$ 5.989708, GT = 1.000000; gamma distribution shape parameter $\alpha=0.567128$. Bootstrap values for maximum likelihood and maximum parsimony equal to or greater than $75 \%$ and Bayesian posterior probabilities equal to or greater than 0.95 are placed above the branches. The newly generated sequence is indicated in red. Type and ex-type strains are in bold.

Phanerina mellea (Berk. \& Broome) Miettinen, MycoKeys 17: 22 (2016)

Fig. 47

Index Fungorum number: IF811537; Facesoffungi number: FoF09448

Endophytic in fresh leaves of Magnolia candolli. Colonies on PDA white aerial mycelia and brown spore masses. Mycelia superficial and immersed composed of septate, branched, 1-2 $\mu \mathrm{m}$ wide, hyaline and light brown, with smooth and thick-walled hyphae. Spores 2-3 $\mu \mathrm{m}$ diameter, initially hyaline, becoming brown at maturity, globose, smooth-walled.

Culture characteristics - Colonies on PDA reaching $24 \mathrm{~mm}$ diameter after 7 days at $25^{\circ} \mathrm{C}$, colonies circular, margin entire, flat, fluffy appearance, white mycelia, colony from above: white; reverse: cream.

Material examined - CHINA, Yunnan Province, Xishuangbanna, healthy leaves of Magnolia candolli (Magnoliaceae), 26 April 2017, N. I. de Silva, S19 (MFLU 20-0594, dried culture); living culture, MFLUCC 19-0109 = KUMCC 17-0244.

GenBank numbers - ITS: MW244021, LSU: MW244026.

Notes - Polyporus melleus was synonymized as Phanerina mellea by Miettinen et al. (2016) based on phylogenetic analyses and morphological studies. The type was described from dead wood in Sri Lanka (Miettinen et al. 2016). Phanerina mellea was also recorded from East Africa (Tanzania, Kenya), Japan (Okinawa), and Indonesia (New Guinea) (Miettinen et al. 2016). Phanerina mellea grows on dead dicot trees, both standing and fallen, often in sun-exposed habitats (Miettinen et al. 2016). According to the combined ITS and LSU analyses, our endophytic isolate clustered with other isolates of P. mellea with 99\% ML, 88 MP, 1.00 BYPP support (Fig. 46). Therefore, this study is the first report of $P$. mellea as an endophyte occurring on Magnolia candolli in Yunnan Province, China.
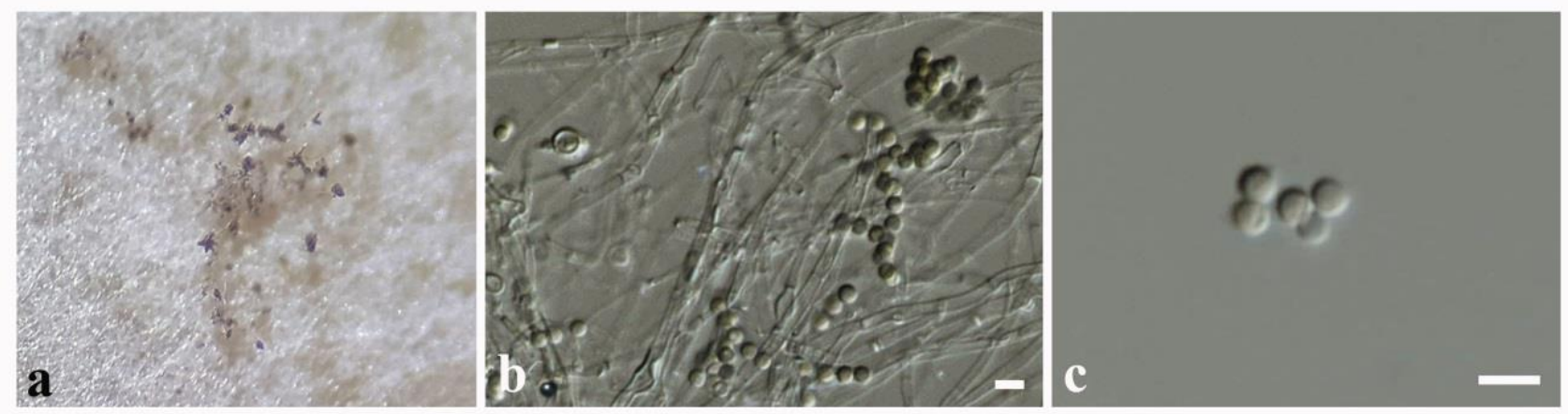

Figure 47 - Phanerina mellea (MFLUCC 19-0109, new host record). a Colonies on PDA with mycelia. $\mathrm{b}$ Mycelia masses and spores. $\mathrm{c}=$ Spores. Scale bars: $\mathrm{b}, \mathrm{c}=5 \mu \mathrm{m}$.

\section{Discussion}

This study investigated fungal endophytes associated with healthy leaves of Magnolia candolli in Yunnan Province, China and M. garrettii in Chiang Mai Province, Thailand. The present collection of fungal endophytes comprises both Ascomycota and Basidiomycota. A total of 
56 fungal endophyte isolates were obtained. Among them, two isolates were Basidiomycota and 54 isolates were Ascomycota. Considering the endophytic nature of isolates, higher numbers of samples were Ascomycetes, comprising eight isolates of Dothideomycetes and 46 isolates of Sordariomycetes. The current collection consists of eight new species and 23 new host and or geographical records. In addition, de Silva et al. (2019b) introduced Lasiodiplodia endophytica from Magnolia candolli in Yunnan Province, China and two host records of endophytic Lasiodiplodia thailandica and L. pseudotheobromae from Magnolia candolli.

Promputtha et al. (2005) studied endophytes of leaves of Magnolia liliifera, a commonly found tree in Doi Suthep-Pui National Park, Thailand. They isolated different endophytic fungal species such as Bionectria sp., Colletotrichum sp., Diaporthe sp., Hypoxylon sp., Massarina sp. and Xylaria sp. Promputtha et al. (2007) examined the relationships of fungal saprotrophs and endophytes isolated from Magnolia liliifera in Chiang Mai, Thailand. They identified endophytic Colletotrichum gloeosporioides, Colletotrichum sp., Corynespora cassiicola, Diaporthe sp., Fusarium oxysporum, Fusarium sp., Guignardia mangiferae and Leptosphaeria sp. In the current study, we identified Colletotrichum gloeosporioides and Corynespora cassiicola, similar to the study of Promputtha et al. (2007).

Colletotrichum and Diaporthe were found asymptomatic in plant leaves in the current study of Magnolia garrettii in Thailand as well as the previous studies of Promputtha et al. $(2005,2007)$ on Magnolia liliifera in Thailand. Nonetheless, our collection comprised genera including Cladosporium, Coprinellus, Epicoccum, Leptosphaerulina, Letendraea, Neopestalotiopsis, Nigrospora, Pestalotiopsis, Pseudopestalotiopsis and Phanerina (isolated from Magnolia garrettii in Thailand) that differ from the previous studies of Promputtha et al. $(2005,2007)$. In the current collection, we identified common occurrence of endophytic Colletotrichum and Diaporthe on Magnolia garrettii in Chiang Mai, Thailand and Magnolia candolli in Yunnan Province, China. Apart from that different endophytic fungal genera were recorded between Thailand and China from Magnolia garrettii and M. candolli. Endophytic species were found in Magnolia garrettii in Chiang Mai, Thailand, such as Coprinellus and Pestalotiopsis and some species were found in Magnolia candolli in Yunnan Province, China, such as Cladosporium, Corynespora, Epicoccum, Leptosphaerulina, Letendraea, Neopestalotiopsis, Nigrospora, Phanerina and Pseudopestalotiopsis. These data suggest that two Magnolia hosts in Thailand and China are inhabited by different fungal species while few fungal species common in both hosts. Moreover, fungal species of Magnolia liliifera from previous studies (Promputtha et al. 2005, 2007) and M. garrettii in the current study in Chiang Mai, Thailand are different and only a few fungal species are found common to two host plants.

An endophytic community typically comprises common (generalist) and rare species (host specificity and geographic structure are difficult to assess) (Arnold 2007). According to the current study and previous studies of Magnolia host plants (Promputtha et al. 2005, 2007), common endophytic genera are Colletotrichum, Corynespora and Diaporthe whereas rare species containing genera are Coprinellus, Epicoccum and Letendraea when considering the current investigation and previous studies by Promputtha et al. $(2005,2007)$. It is hypothesized that each tree species in each locality has a signature community of endophytic symbionts (Hoffman \& Arnold 2008). The abundance, diversity, and species composition of endophytic assemblage can be influenced by host plants species, the geographic region, microhabitat and microclimatic conditions (Arnold 2007). Leaves are one of the biologically active tissues in plants and they have the most dynamic interfaces between plants and their environment (Arnold 2007). Different studies agree that endophytic colonization of leaves might vary from one host individual to another (Rashmi et al. 2019). For example, Rodrigues (1994) reported only 30\% of leaf colonization in Amazonian palms (Arnold et al. 2003) while it was found up to $73.9 \%$ of leaf colonization in Manilkara bidentata. The surface area of the host leaf and the age of the leaf are also important factors that shape the endophytic assemblage (Arnold et al. 2000, Rashmi et al. 2019). Fungal endophytic colonization involves penetration and persistence within host plant tissues and might be influenced by the host plant (Arnold 2007). This is explained by the hypothesis of 'balanced antagonism' between 
endophyte and their host (Schulz et al. 2015, de Silva et al. 2019a). In general, fungi (fungal virulence factors) can control activation of the host defenses and activate resistance against toxic metabolites of the host. Some fungal endophytes secrete secondary metabolites at low concentrations in the presence of elicitors or substrates of the host plants (Suryanarayanan et al. 2016). If the plant defense withstands fungal virulence, the fungus is unable to colonize plant tissues (Suryanarayanan et al. 2016). If the fungal virulence can act against plant defense, endophytes switch to pathogenic lifestyle and lead to plant diseases (Lo Presti et al. 2015, Suryanarayanan et al. 2016). This implies that the interaction of host plants and endophytic fungi can restrict fungal colonization for specific fungal groups that successfully inhabit host plant tissues without causing visible manifestations of infection.

Previous studies have indicated that incidence, diversity and composition of endophytic fungi from taxonomically related hosts vary related to the biogeographic areas (Arnold et al. 2003, Arnold 2007, U'Ren et al. 2012, Fang et al. 2019). In a general view, it is stated that diversity of endophytes is rich in seasonally wet tropics and decreases with increasing latitude, and relatively few endophyte taxa might be shared among closely related hosts in different biogeographic areas (Arnold \& Lutzoni 2007, U'Ren et al. 2012). Fang et al. (2019) studied endophytic fungi from different plant tissues (roots, stems, mature healthy leaves) of Ageratina adenophora in three groups of latitudes (ranging from latitudes 22.63 to 23.22 and elevation 1171-2128 m). Their study revealed that diversity and abundance of endophytic fungi change across different geographic sites. Further, they indicated that latitude is an important factor determining the composition of the endophytic community in plant leaves. They also revealed that the latitude positively correlates with the diversity of the leaf endophytic fungi but negatively correlates with the abundance of the leaf fungi. Different patterns of endophytic assembly are related to the surrounding environment of the biogeographic areas (Fang et al. 2019). Leaves might face fluctuations against climatic changes, including soil and canopy air temperature variations (Fang et al. 2019). Kazenel et al. (2019) indicated that endophytic leaf fungal assemblage varies with altitude. Their study was further detailed that climatic variables such as $\mathrm{pH}$, or soil nutrients might alter some fungal responses, which ultimately change fungal symbiont abundance and composition along with the altitudinal changes. The above explanations justify the variations in fungal communities between Magnolia liliifera from previous studies (Promputtha et al. 2005, 2007) and $M$. garrettii in the current study in Chiang Mai, Thailand. It also explains the difference in endophytic fungal species in different Magnolia host plants in Thailand and China (in the current study).

Previous studies reported that endophytic fungi of different plant hosts include Ascomycota, Basidiomycota, Chytridiomycota, Mucoromycota and Zygomycota (Carvalho et al. 2012, Rashmi et al. 2019). The majority of endophytic fungi belong to the division Ascomycota while major orders that fall within Ascomycota are Botryosphaeriales, Eurotiales, Hypocreales, Pleosporales, Sordariales and Xylariales (Rashmi et al. 2019). The most frequently recorded taxa of Basidiomycota belong to orders Agaricales, Cantharellales and Polyporales (Rashmi et al. 2019). When considering Ascomycota, most taxa reported being Sordariomycetes followed by Dothideomycetes (Arnold 2007, 2008) and Leotiomycetes mostly in temperate and tropical plants (Arnold 2008, Rashmi et al. 2019). However, Dothideomycetes were reported as dominant members in boreal and Arctic plants followed by Sordariomycetes and Leotiomycetes (Arnold 2007, Rungjindamai et al. 2008). It has not yet been provided robust evidence or explanations for the abundance in Ascomycota species within endophytic community. But there are few possible reasons why the endophytic community is rich in Ascomycota than in Basidiomycota. This might be due to the better adaptations of Ascomycota to colonize the internal tissues of plants than Basidiomycota (Rashmi et al. 2019). Asexual morphs of Ascomycota such as hyphomycetous and coelomycetous would help the endophytic fungi for the successful asymptomatic colonization as well as subsequent saprophytic and pathogenic infections when environmental conditions become unfavorable to the host (Rashmi et al. 2019). Ascomycota species can also produce microscopic fruit bodies or asci directly arising from the hyphae when they switch lifestyle from endophytes either saprophytes or pathogens (Rashmi et al. 2019). The above reasons might increase the 
colonization of Ascomycota taxa than Basidiomycota taxa within a particular endophytic community. However, the detection of the abundance of endophytic taxa depends on isolation methods and identification techniques of endophytes (Rashmi et al. 2019). This will be the next important aspect to discuss further that affects the diversity of endophytes.

Studying endophytes is challenging because of their cryptic presence within the healthy host tissues (Rashmi et al. 2019). It is challenging to observe fungal reproductive structures within the host tissues (Rashmi et al. 2019). Fungal hyphae of endophytes can rarely be observed inside and lack any identifying characteristics (Arnold 2008). Therefore, most of the studies depend on in vitro isolations of the emerging endophytes from the sterilized tissues of the hosts on suitable growth media (Rashmi et al. 2019). However, some fungal species are unable to grow on synthetic media (Tao et al. 2008), or some may get overlooked by fast-growing fungi due to their slow growth (Zhu et al. 2008), or require specific nutrients (Jeewon \& Hyde 2007, Rashmi et al. 2019). Macro- and micro-morphological characteristics such as culture characteristics, sexual and asexual morph characteristics are considered as main criteria to distinguish different endophytic taxa (Zheng et al. 2016). However, most endophytic isolates cannot sporulate in cultures and are considered as mycelia sterilia (Jeewon et al. 2017). The most reliable alternative option for this problem can be the use of DNA sequence data and molecular phylogenetic analysis (Jeewon et al. 2017). Further, concatenated sequence data were used to determine the phylogenetic relationships of fungal taxa and introduce novel taxa (Zheng et al. 2016). And also, taxonomists mostly use culture-independent molecular approaches, such as PCR-based ITS gene clone libraries, 18S rDNA, and denaturing gradient gel electrophoresis (DGGE), to reveal the complex fungal endophyte communities (Zheng et al. 2016). However, these techniques have limitations and may prevent the identification of heterogeneous species (Zheng et al. 2016). Therefore, a combination of morphological studies and molecular analyses are suggested to identify fungal taxa (Zheng et al. 2016, Jeewon et al. 2017).

Generally, it is considered that most of the endophytes that reside in internal plant tissues are able to switch their lifestyle to be either saprophytic or latent pathogens (Promputtha et al. 2005, Delaye et al. 2013, de Silva et al. 2016, 2019a, Rashmi et al. 2019). Promputtha et al. (2007) provided phylogenetic evidence of exhibiting Corynespora cassiicola as endophytes and saprobes in Magnolia liliifera in Thailand. Further, they revealed endophytic isolates of Colletotrichum, Fusarium, Guignardia, and Phomopsis have high sequence similarity with saprobic isolates of Colletotrichum, Diaporthe, Fusarium and Phylosticta from dead leaves of M. liliifera. In addition to that, two saprobic isolates of Lasiodiplodia pseudotheobromae from dead twigs and an endophytic isolate from fresh leaves of Magnolia candolii were recorded for the first time from China (de Silva et al. 2019b). Moreover, a saprobic isolate of Neopestalotiopsis saprophytica from dead leaves and two endophytic isolates from fresh leaves were identified as endophytic and saprobic lifestyle switching for the first time from Magnolia candolii in China (unpublished data). This confirms Lasiodiplodia pseudotheobromae and Neopestalotiopsis saprophytica species exhibit endophytic and saprobic lifestyles in the same host plant. This situation might be possible because endophytes switch their nutritional mode to saprobic when environmental conditions become unfavorable to the host or during host senescence (de Errasti et al. 2014, de Silva et al. 2019b). In an ecological context switching lifestyle of endophytes to saprobes might be important as saprobes can decay the plant part when the host dies (de Errasti et al. 2014, de Silva et al. 2019b).

Endophytes have attracted increasing attention for novel biological resources for exploitation in the pharmaceutical, industry and agriculture (Zheng et al. 2016). These novel compounds isolated from endophytic fungi show antimicrobial, anti-insect, antioxidant, anticancer, antineoplastic, cytotoxicity and other important biological activities (Zheng et al. 2016). Screening of novel bioactive compounds from endophytic fungi has become a research hotspot. It might be possible to explore novel fungal endophytes from a variety of host plants in different environments in the future. This requires advances in detection methods in both morphological and phylogenetic techniques to identify and introduce taxonomic novelties of unexplored endophytes. 


\section{Acknowledgements}

This work was supported by grants from Chiang Mai University and TRF Research-Team Association Grant (RTA5880006). Kevin D. Hyde thanks Chiang Mai University for the award of Visiting Professor. Kevin D. Hyde thanks the grant Impact of climate change on fungal diversity and biogeography in the Greater Mekong Subregion (grant no: RDG6130001). Samantha C. Karunarathna would like to thank the CAS President's International Fellowship Initiative (PIFI) young staff under the grant number: 2020FYC0002 and the National Science Foundation of China (NSFC) under the project code 31851110759 for funding. We wish to thank the Key Research Program of Frontier Sciences, CAS (grant no. QYZDY-SSWSMC014 and 973 key projects of the National Natural Science Foundation of China (grant no. 2014CB954101). Rungtiwa Phookamsak thanks CAS President's International Fellowship Initiative (PIFI) for young staff (grant no. Y9215811Q1), the National Science Foundation of China (NSFC) project code 31850410489 (grant no. Y81I982211), Chiang Mai University and Key Research Project "Agroforestry Systems for restoration and bio-industry technology development (grant no. 2017YFC0505101)" for partial support of this research work. Germplasm Bank of Wild Species in Southwest China, Kunming Institute of Botany, Chinese Academy of Science, Kunming is thanked for supporting molecular phylogenetic experiments of this study. Dr. Shaun Pennycook is thanked for nomenclatural clarification of the new species. The author would like to thank Mushroom Research Foundation (MRF), Chiang Rai Province, Thailand. R.S. Jayawardena thanks the National Research Council of Thailand, a grant for the new researcher NRCT5-TRG630010-01, entitled Biodiversity, taxonomy, phylogeny and evolution of Colletotrichum in northern Thailand. Nimali I. de Silva also thanks to

Asha Dissanayake, Santhiti Vadthanarat, Saowaluck Tibpromma, Chathumini Jayasiri and Thatsanee Luangharn for their valuable suggestions and help.

\section{References}

Ariyawansa HA, Tanaka K, Thambugala KM, Phookamsak R et al. 2014 - A molecular phylogenetic reappraisal of the Didymosphaeriaceae (= Montagnulaceae). Fungal Diversity $68,69-104$.

Ariyawansa HA, Hyde KD. 2018 - Additions to Pestalotiopsis in Taiwan. Mycosphere 9, 9991013.

Arnold AE. 2007 - Understanding the diversity of foliar endophytic fungi, progress, challenges, and frontiers. Fungal Biology Reviews 21, 51-66.

Arnold AE. 2008 - Endophytic fungi, hidden components of tropical community ecology. Tropical Forest Community Ecology 178-188.

Arnold AE, Lutzoni F. 2007 - Diversity and host range of foliar fungal endophytes: Are tropical leaves biodiversity hotspots? Ecology 88, $541-549$.

Arnold AE, Maynard Z, Gilbert GS, Coley PD et al. 2000 - Are tropical fungal endophytes hyperdiverse?. Ecology letters 3, 267-274.

Arnold AE, Mejía LC, Kyllo D, Rojas EI et al. 2003 - Fungal endophytes limit pathogen damage in a tropical tree. Proceedings of the National Academy of Sciences 100, 15649-15654.

Aveskamp MM, de Gruyter J, Woudenberg JHC, Verkley GJ et al. 2010 - Highlights of the Didymellaceae: a polyphasic approach to characterise Phoma and related pleosporalean genera. Studies in Mycology 65, 1-60.

Bamisile BS, Dash CK, Akutse KS, Keppanan R et al. 2018 - Fungal endophytes: beyond herbivore management. Frontiers in Microbiology 9, 544-555.

Barr ME. 2001 - Montagnulaceae, a new family in the Pleosporales and lectotypification of Didymosphaerella. Mycotaxon 77, 193-200.

Bensch K, Groenewald JZ, Starink-Willemse M, Andersen B et al. 2010 - Species and ecological diversity within the Cladosporium cladosporioides complex (Davidiellaceae, Capnodiales). Studies in Mycology 67, 1-94. 
Bensch K, Braun U, Groenewald JZ, Crous PW. 2012 - The genus Cladosporium. Studies in Mycology 72, 1-401.

Bensch K, Groenewald JZ, Braun U, Dijksterhuis J et al. 2015 - Common but different: The expanding realm of Cladosporium. Studies in Mycology 82, 23-74.

Bensch K, Groenewald JZ, Meijer M, Dijksterhuis J et al. 2018 - Cladosporium species in indoor environments. Studies in Mycology 89, 177-301.

Binder M, Justo A, Riley R, Salamov A et al. 2013 - Phylogenetic and phylogenomic overview of the Polyporales. Mycologia 105, 1350-1373.

Cannon PF, Damm U, Johnston PR, Weir BS. 2012 - Colletotrichum current status and future directions. Studies in Mycology 73, 181-213.

Carbone I, Kohn LM. 1999 - A method for designing primer sets for speciation studies in filamentous ascomycetes. Mycologia, 553-556.

Carvalho CR, Gonçalves VN, Pereira CB, Johann S et al. 2012 - The diversity, antimicrobial and anticancer activity of endophytic fungi associated with the medicinal plant Stryphnodendron adstringens (Mart.) Coville (Fabaceae) from the Brazilian savannah. Symbiosis 57, 95-107.

Castlebury LA, Rossman AY, Jaklitsch WJ, Vasilyeva LN. 2002 - A phylogeny overview of the Diaporthales based on large subunit nuclear ribosomal DNA sequences. Mycologia 94, 10171031.

Chen Q, Jiang JR, Zhang GZ, Cai L et al. 2015 - Resolving the Phoma enigma. Studies in Mycology 82, 137-217.

Chen Z, Dong Z, Wen J, Feng T et al. 2016 - A New Sesquiterpene from the endophytic fungus Nigrospora sphaerica 003. Records of Natural Products 10, 307-310.

Chen Q, Hou LW, Duan WJ, Crous PW et al. 2017 - Didymellaceae revisited. Studies in Mycology $87,105-159$.

Corda ACJ. 1842 - Icones fungorum hucusque cognitorum. 5, 1-92.

Chowdhary LK, Kaushik N. 2015 - Fungal endophyte diversity and bioactivity in the Indian medicinal plant Ocimum sanctum Linn. PLoS One 10, 1-25.

Crous PW, Luangsa-Ard JJ, Wingfield MJ, Carnegie AJ et al. 2018 - Fungal Planet description sheets: 785-867. Persoonia: Molecular Phylogeny and Evolution of Fungi 41, 238-417.

Crous PW, Shivas RG, Quaedvlieg W, Van der Bank M et al. 2014 - Fungal Planet description sheets: 214-280. Persoonia 32, 184-306.

Crous PW, Wingfield MJ, Le Roux JJ, Richardson DM et al. 2015 - Fungal Planet description sheets: 371-399. Persoonia: Molecular Phylogeny and Evolution of Fungi 35, 264-327.

Damm U, Cannon PF, Woudenberg JHC, Johnston PR et al. 2012 - The Colletotrichum boninense species complex. Studies in Mycology 73, 1-36.

De Bary A. 1886 - Ueber einige Sclerotinien und Sclero. Botanische Zeitung 44, 377-474.

de Errasti A, Novas MV, Carmarán CC. 2014 - Plant-fungal association in trees: Insights into changes in ecological strategies of Peroneutypa scoparia (Diatrypaceae). Flora-Morphology, Distribution, Functional Ecology of Plants 209, 704-710.

de Gruyter J, Aveskamp MM, Woudenberg JH, Verkley GJ et al. 2009 - Molecular phylogeny of Phoma and allied anamorph genera: towards a reclassification of the Phoma complex. Mycological Research 113, 508-519.

de Hoog GS, Guarro J, Gene J, Figueras MJ. 2000 - Atlas of clinical fungi: 708-711. Centraalbureau voor Schimmelcultures, Utrecht, The Netherlands and Universitat Rovira i Virgili. Reus, Spain. 708-711.

de Hoog GS, Guarro J, Gene J, Figueras MJ. 2011 - Atlas of clinical fungi. CD-ROM v. 3.1. Westerdijk Fungal Biodiversity Institute, Utrecht, The Netherlands.

de Silva NI, Brooks S, Lumyong S, Hyde KD. 2019a - Use of endophytes as biocontrol agents. Fungal Biology Reviews 33, 133-148.

de Silva NI, Lumyong S, Hyde KD, Bulgakov T et al. 2016 - Mycosphere essays 9: defining biotrophs and hemibiotrophs. Mycosphere 7, 545-559. 
de Silva NI, Phillips AJL, Liu JK, Lumyong S, Hyde KD. 2019b - Phylogeny and morphology of Lasiodiplodia species associated with Magnolia forest plants. Scientific Reports 9, 1-11.

Delaye L, Guzman GG, Heil M. 2013 - Endophytes versus biotrophic and necrotrophic pathogens are fungal life-styles evolutionarily stable traits? Fungal Diversity 60, 125-135.

Dissanayake AJ, Bhunjun CS, Maharachchikumbura SSN, Liu JK. 2020 - Applied aspects of methods to infer phylogenetic relationships amongst fungi. Mycosphere 11, 2652-2676.

Dissanayake AJ, Camporesi E, Hyde KD, Wei Z et al. 2017a - Molecular phylogenetic analysis reveals seven new Diaporthe species from Italy. Mycosphere 8, 853-877.

Dissanayake AJ, Phillips AJL, Hyde KD, Yan JY et al. 2017b -The current status of species in Diaporthe. Mycosphere 8, 1106-1156.

Doilom M, Manawasinghe IS, Jeewon R, Jayawardena RS et al. 2017 - Can ITS sequence data identify fungal endophytes from cultures? A case study from Rhizophora apiculata. Mycosphere 8(10), 1869-1892.

Dzoyem JP, Melong R, Tsamo AT, Maffo T et al. 2017 - Cytotoxicity, antioxidant and antibacterial activity of four compounds produced by an endophytic fungus Epicoccum nigrum associated with Entada abyssinica. Revista Brasileira de Farmacognosia, 27, 251253.

Ek-Ramos MJ, Zhou W, Valencia CU, Antwi JB et al. 2013 - Spatial and temporal variation in fungal endophyte communities isolated from cultivated cotton (Gossypium hirsutum). PLoS One 8, 1-13.

Fan YM, Huang WM, Li W, Zhang GX. 2009 - Onychomycosis caused by Nigrospora sphaerica in an immunocompetent man. Archives of Dermatology 145, 611-612.

Fang K, Miao YF, Chen L, Zhou J et al. 2019 - Tissue-specific and geographical variation in endophytic fungi of Ageratina adenophora and fungal associations with the environment. Frontiers in Microbiology 10, 2919.

Farr DF, Rossman AY. 2021 - Fungal Databases, U.S. National Fungus Collections, ARS, USDA. From https://nt.ars-grin.gov/fungaldatabases/ (Retrieved on February 25, 2021)

Favaro LC de L, Sebastianes FL de S, Araújo WL. 2012 - Epicoccum nigrum P16, a sugarcane endophyte, produces antifungal compounds and induces root growth. PloS one 7(6), 36826.

Gao Y, Liu F, Cai L. 2016 - Unravelling Diaporthe species associated with Camellia. Systematics and Biodiversity 14, 102-117.

Gao Y, Liu F, Duan W, Crous PW et al. 2017 - Diaporthe is paraphyletic. IMA fungus 8, 153-187.

Gao YH, Sun W, Su YY, Cai L. 2014 - Three new species of Phomopsis in Gutianshan nature reserve in China. Mycological Progress 13, 111-121.

Gautam AK. 2014 - Colletotrichum gloeosporioides: biology, pathogenicity and management in India. Journal of Plant Physiology and Pathology 2, 2-11.

Glass NL, Donaldson GC 1995 - Development of primer sets designed for use with the PCR to amplify conserved genes from filamentous ascomycetes. Applied and Environmental Microbiology 61, 1323-1330.

Gomes R, Glienke C, Videira S, Lombard L et al. 2013 - Diaporthe: a genus of endophytic, saprobic and plant pathogenic fungi. Persoonia 31, 1-41.

Gomes ARP, Wartchow F. 2014 - Coprinellus arenicola, a new species from Paraíba, Brazil. Sydowia 66, 249-256.

Gouda S, Das G, Sen SK, Shin HS et al. 2016. Endophytes: a treasure house of bioactive compounds of medicinal importance. Frontiers in Microbiology 7, 1538.

Hall TA. 1999 - BioEdit: a user-friendly biological sequence alignment editor and analysis program for Windows 95/98/NT. Nucleic Acids Symposium Series 41, 95-98.

Hardoim PR, Van Overbeek LS, Berg G, Pirttilä AM et al. 2015 - The hidden world within plants: ecological and evolutionary considerations for defining functioning of microbial endophytes. Microbiology and Molecular Biology Reviews 79, 293-320.

Hawksworth DL. 2000 - The magnitude of fungal diversity: the 1.5 million species estimate revisited, Paper presented at the Asian Mycological Congress 2000 (AMC 2000), 
incorporating the 2nd Asia-Pacific Mycological Congress on Biodiversity and Biotechnology, and held at the University of Hong Kong on 9-13 July 2000. Mycological Research 105, $1422-1432$.

Hawksworth DL, Lucking R. 2017 - Fungal Diversity Revisited: 2.2 to 3.8 Million Species. Microbiol Spectrum 5(4): FUNK-0052-2016.

Hoffman MT, Arnold AE. 2008 - Geographic locality and host identity shape fungal endophyte communities in cupressaceous trees. Mycological Research 112, 331-344.

Hongsanan S, Hyde KD, Phookamsak R, Wanasinghe DN et al. 2020 - Refined families of Dothideomycetes: Dothideomycetidae and Pleosporomycetidae. Mycosphere 11, 1553-2107.

Hou LW, Groenewald JZ, Pfenning LH, Yarden O et al. 2020 - The phoma-like dilemma. Studies in Mycology 96, 309-396.

Huang WY, Cai Y, Surveswaran S, Hyde KD et al. 2009 - Molecular phylogenetic identification of endophytic fungi isolated from three Artemisia species. Fungal Diversity 36, 69-88.

Huang F, Udayanga D, Wang X, Hou X et al. 2015 - Endophytic Diaporthe associated with Citrus: A phylogenetic reassessment with seven new species from China. Fungal Biology 119, 331347.

Huang R, Xu Y, Ye B, Ding W et al. 2019 - Letenketals A and B, two novel spirocyclic polyketides from a marine crab-derived Letendraea sp. fungus. Phytochemistry Letters 30, $165-168$.

Huelsenbeck JP, Ronqvist F. 2001 - MRBAYES: Bayesian inference of phylogenetic trees. Bioinformatics 17, 754-755.

Huson DH. 1998 - Splits Tree: analyzing and visualizing evolutionary data. Bioinformatics 14, 6873.

Huson DH, Bryant D. 2006 - Application of phylogenetic networks in evolutionary studies. Molecular Biology and Evolution 23, 254-267.

Hussain S, Usman M, Najam-ul-Sehar AHA, Junaid-Khan ANK. 2018 - The genus Coprinellus (Basidiomycota; Agaricales) in Pakistan with the description of four new species. MycoKeys 39, 41-61.

Hyde KD, Chaiwan N, Norphanphoun C, Boonmee S et al. 2018 - Mycosphere notes 169-224. Mycosphere 9, 271-430.

Hyde KD, de Silva NI, Jeewon R, Bhat DJ et al. 2020c - AJOM new records and collections of fungi: 1-100. Asian Jornal of Mycology 3, 22-294.

Hyde KD, Fröhlich J, Taylor JE. 1998 - Fungi from palms. XXXVI. Reflections on unitunicate ascomycetes with apiospores. Sydowia 50, 21-80.

Hyde KD, Jeewon R, Chen YJ, Bhunjun CS et al. 2020a - The numbers of fungi: is the descriptive curve flattening?. Fungal Diversity 103, 219-271.

Hyde KD, Jones EG, Liu JK, Ariyawansa H et al. 2013 - Families of dothideomycetes. Fungal Diversity 63, 1-313.

Hyde KD, Nilsson RH, Alias SA, Ariyawansa HA et al. 2014 - One stop shop: backbones trees for important pytopathogenic genera: I. Fungal Diversity 67, 21-125.

Hyde KD, Norphanphoun C, Maharachchikumbura SSN, Bhat DJ et al. 2020b - Refined families of Sordariomycetes. Mycosphere 11, 305-1059.

Index Fungorum 2021 - http://www.indexfungorum.org/names/Names.asp (Accessed on February $5,2021)$

Ito S, Iwadare S. 1934 - Studies on the red blotch of rice grains. Hokkaido Agricultural Experiment Station 31, 1-84.

Jaklitsch WM, Gardiennet A, Voglmayr H. 2016 - Resolution of morphology-based taxonomic delusions: Acrocordiella, Basiseptospora, Blogiascospora, Clypeosphaeria, Hymenopleella, Lepteutypa, Pseudapiospora, Requienella, Seiridium and Strickeria. Persoonia 37, 82-105.

Jayasiri SC, Hyde KD, Ariyawansa HA, Bhat J et al. 2015 - The Faces of Fungi database: fungal names linked with morphology, phylogeny and human impacts. Fungal Diversity 74, 3-18. 
Jayasiri SC, Hyde KD, Jones EBG, Jeewon R et al. 2017 - Taxonomy and multigene phylogenetic evaluation of novel species in Boeremia and Epicoccum with new records of Ascochyta and Didymella (Didymellaceae). Mycosphere 8, 1080-1101.

Jayasiri SC, Hyde KD, Jones EBG, McKenzie EHC et al. 2019 - Diversity, morphology and molecular phylogeny of Dothideomycetes on decaying wild seed pods and fruits. Mycosphere $10,1-186$.

Jayawardena RS, Hyde KD, Damm U, Cai L et al. 2016 - Notes on currently accepted species of Colletotrichum. Mycosphere 7, 1192-1260.

Jayawardena RS, Hyde KD, McKenzie EH, Jeewon R et al. 2019 - One stop shop III: taxonomic update with molecular phylogeny for important phytopathogenic genera: 51-75 (2019) Fungal Diversity 98, 77-160.

Jayawardena RS, Hyde KD, Chen YJ, Papp V et al. 2020 - One stop shop IV: taxonomic update with molecular phylogeny for important phytopathogenic genera: 76-100 (2020). Fungal Diversity 103, 87-218.

Jeewon R, Hyde KD. 2007 - Diversity and detection of Fungi from environmental samples: Traditional versus Molecular approaches. In: Varma A., Oelmüller R. (eds) Advanced Techniques in Soil Microbiology. Soil Biology, vol 11. Springer, Berlin, Heidelberg.

Jeewon R, Wanasinghe DN, Rampadaruth S, Puchooa D et al. 2017 - Nomenclatural and identification pitfalls of endophytic mycota based on DNA sequence analyses of ribosomal and protein genes phylogenetic markers: A taxonomic dead end?. Mycosphere 8, 1802-1817.

Kazenel MR, Kivlin SN, Taylor DL, Lynn JS et al. 2019 - Altitudinal gradients fail to predict fungal symbiont responses to warming. Ecology 100, 2740.

Kindo AJ, Subramanian A, Suresh K. 2014 - Nigrospora sphaerica causing corneal ulcer in an immunocompetent woman: a case report. International Journal of Case Reports and Images (IJCRI) 5, 675-679.

Ko TWK, Stephenson SL, Bahkali AH, Hyde KD. 2011 - From morphology to molecular biology: can we use sequence data to identify fungal endophytes?. Fungal Diversity 50, 113-120.

Kumar S, Singh R. 2016 - Corynespora celastri sp. nov. on Celastraceae from India. Studies in Fungi 1(1), 125-129.

Lacap DC, Hyde KD, Liew ECY. 2003 - An evaluation of the fungal 'morphotype' concept based on ribosomal DNA sequences. Fungal Diversity 12, 53-66.

Lamprecht SC, Crous PW, Groenewald JZ, Tewoldemedhin YT et al. 2011 - Diaporthaceae associated with root and crown rot of maize. IMA Fungus 2, 13-24.

Larsson KH. 2007 - Re-thinking the classification of corticioid fungi. Mycological Research 111(9), 1040-1063.

Li WJ, McKenzie EH, Liu JKJ, Bhat DJ et al. 2020 - Taxonomy and phylogeny of hyaline-spored coelomycetes. Fungal Diversity 100, 279-801.

Link HF. 1815 - Mag. Neuesten Entdeck. Gesammten Naturk. Ges. Naturf. Freunde Berlin 7, 32.

Liu F, Bonthond G, Groenewald JZ, Cai L, et al. 2019 - Sporocadaceae, a family of coelomycetous fungi with appendage-bearing conidia. Studies in Mycology 92, 287-415.

Liu F, Hou L, Raza M, Cai L. 2017 - Pestalotiopsis and allied genera from Camellia, with description of 11 new species from China. Scientific Reports 7(1), 1-19.

Liu F, Weir BS, Damm U, Crous PW et al. 2015a-Unravelling Colletotrichum species associated with Camellia: employing ApMat and GS loci to resolve species in the C. gloeosporioides complex. Persoonia 35, 63-86.

Liu JK, Hyde KD, Jones EG, Ariyawansa HA et al. 2015c - Fungal diversity notes 1-110: taxonomic and phylogenetic contributions to fungal species.Fungal Diversity 72, 1-197.

Liu YJ, Tang Q, Fang L. 2015b - First report of Nigrospora sphaerica causing leaf blight on Camellia sinensis in China. Plant Disease 100, 221.

Liu YJ, Whelen S, Hall BD. 1999 - Phylogenetic relationships among ascomycetes: evidence from an RNA polymerse II subunit. Molecular Biology and Evolution 6, 1799-1808. 
Lopes AA, Pupo MT. 2011 - Biosynthesis of aphidicolin proceeds via the mevalonate pathway in the endophytic fungus Nigrospora sphaerica. Journal of the Brazilian Chemical Society 22, $80-85$.

López-González RC, Gómez-Cornelio S, Susana C, Garrido E et al. 2017 - The age of lima bean leaves influences the richness and diversity of the endophytic fungal community, but not the antagonistic effect of endophytes against Colletotrichum lindemuthianum. Fungal Ecology 26, $1-10$.

Lo Presti L, Lanver D, Schweizer G, Tanaka S et al. 2015 - Fungal effectors and plant susceptibility. Annual Review of Plant Biology 66, 513-545.

Ma X, Nontachaiyapoom S, Jayawardena RS, Hyde KD et al. 2018 - Endophytic Colletotrichum species from Dendrobium spp. in China and Northern Thailand. MycoKeys 43, 23-57.

Maharachchikumbura SSN, Guo LD, Chukeatirote E, Bahkali AH et al. 2011 - Pestalotiopsis morphology, phylogeny, biochemistry and diversity. Fungal Diversity 50, 167-187.

Maharachchikumbura SSN, Guo LD, Cai L, Chukeatirote E et al. 2012 - A multi-locus backbone tree for Pestalotiopsis, with a polyphasic characterization of 14 new species. Fungal Diversity $56,95-129$.

Maharachchikumbura SS, Chukeatirote E, Guo LD, Crous PW et al. 2013 - Pestalotiopsis species associated with Camellia sinensis (tea). Mycotaxon 123, 47-61.

Maharachchikumbura SS, Guo LD, Chukeatirote E, Hyde KD. 2014a - Improving the backbone tree for the genus Pestalotiopsis; addition of $P$. steyaertii and P. magna sp. nov. Mycological Progress 13, 617-624.

Maharachchikumbura SS, Hyde KD, Groenewald JZ, Xu J, Crous PW. 2014b - Pestalotiopsis revisited. Studies in Mycology 79, 121-186.

Maharachchikumbura SS, Hyde KD, Jones EBG, McKenzie EH et al. 2015 - Towards a natural classification and backbone tree for Sordariomycetes. Fungal Diversity 72, 199-301.

Maharachchikumbura SS, Guo LD, Liu ZY, Hyde KD. 2016a - Pseudopestalotiopsis ignota and Ps. camelliae spp. nov. associated with grey blight disease of tea in China. Mycological Progress 15, 22-29.

Maharachchikumbura SS, Hyde KD, Jones EG, McKenzie EHC et al. 2016b - Families of sordariomycetes. Fungal Diversity 79, 1-317.

Manawasinghe IS, Dissanayake A, Liu M, Wanasinghe D et al. 2019 - High genetic diversity and species complexity of Diaporthe associated with grapevine dieback in China. Frontiers in Microbiology 10, 1-28.

Marin-Felix Y, Hernández-Restrepo M, Wingfield MJ, Akulov A et al. 2019 - Genera of phytopathogenic fungi: GOPHY 2. Studies in Mycology 92, 47-133.

Mason EW. 1927 - On species of the genus Nigrospora Zimmermann recorded on monocotyledons. Transactions of the British Mycological Society 12, 152-165.

McAlpine D. 1902 - Fungus diseases of stone-fruit trees in Australia and their treatment: 1-165.

McLennan EI, Hoëtte S. 1933 - Nigrospora musae n. sp. and its connexion with "squirter" disease in bananas. Council for Scientific and Industrial Research 75, 1-36.

Metwaly AM, Kadry HA, Atef A, Mohammad AEI et al. 2014 - Nigrosphaerin A a new isochromene derivative from the endophytic fungus Nigrospora sphaerica. Phytochemistry Letters 7, 1-5.

Miettinen O, Spirin V, Vlasák J, Rivoire B et al. 2016 - Polypores and genus concepts in Phanerochaetaceae (Polyporales, Basidiomycota). MycoKeys 17, 1-46.

Myllys L, Stenroos S, Thell A. 2002 - New genes for phylogenetic studies of lichenized fungi: glyceraldehyde-3-phosphate dehydrogenase and beta-tubulin genes. Lichenologist 34, $237-$ 246.

Munk A. 1953 - The system of the pyrenomycetes. A contribution to avnatural classification of the group Sphaeriales sensu Lindau. vDansk Bot Ark 15, 1-163. 
Nagy LG, Vágvölgyi C, Papp T. 2013 - Morphological characterization of clades of the Psathyrellaceae (Agaricales) inferred from a multigene phylogeny. Mycological Progress 12, 505-517.

Nagy LG, Walther G, Hazi J, Vágvölgyi C et al. 2011 - Understanding the evolutionary processes of fungal fruiting bodies: correlated evolution and divergence times in the Psathyrellaceae. Systematic Biology 60, 303-317.

Nooteboom HP, Chalermglin P. 2009 - The Magnoliaceae of Thailand. Thai Forest Bulletin (Botany) 37, 111-138.

O’Donnell K, Cigelnik E. 1997 - Two divergent intragenomic rDNA ITS2 types within a monophyletic lineage of the fungus Fusarium are nonorthologous. Molecular Phylogenetics and Evolution 7, 103-116.

Petch T. 1938 - British Hypocreales. Transactions of the British Mycological Society, 21(3-4), 243-301.

Petrini O. 1991 - Fungal endophytes of tree leaves. In Microbial ecology of leaves 179-197, Springer, New York, NY.

Petrini O, Sieber TN, Toti L, Viret O. 1992 - Ecology, metabolite production, and substrate utilization in endophytic fungi. Natural Toxins 1, 185-196.

Philippe H, Bryant D. 2006 - A simple and robust statistical test for detecting the presence of recombination. Genetics 172, 2665-2681.

Phookamsak R, Liu JK, Chukeatirote E, McKenzie EH et al. 2013 - Phylogeny and morphology of Leptosphaerulina saccharicola sp. nov. and Pleosphaerulina oryzae and relationships with Pithomyces. Cryptogamie Mycologie 34, 303-319.

Porras-Alfaro A, Herrera J, Sinsabaugh RL, Odenbach KJ et al. 2008 - Novel root fungal consortium associated with a dominant desert grass. Applied and Environmental Microbiology 74, 2805-2813.

Posada D, Crandall KA. 1998 - Modeltest: testing the model of DNA substitution. Bioinformatics $14,817-818$.

Potshangbam M, Devi SI, Sahoo D, Strobel GA. 2017 - Functional Characterization of Endophytic Fungal Community Associated with Oryza sativa L. and Zea mays L. Frontiers in Microbiology 8, 325-330.

Prihastuti H, Cai L, Chen H, McKenzie EHC et al. 2009 - Characterization of Colletotrichum species associated with coffee berries in northern Thailand. Fungal Diversity 39, 89-109.

Promputtha I, Jeewon R, Lumyong S, McKenzie EHC et al. 2005 - Ribosomal DNA fingerprinting in the identification of non sporulating endophytes from Magnolia liliifera (Magnoliaceae). Fungal Diversity 20, 167-186.

Promputtha I, Lumyong S, Dhanasekaran V, McKenzie EHC et al. 2007 - A phylogenetic evaluation of whether endophytes become saprotrophs at host senescence. Microbial Ecology $53,579-590$.

Promputtha I, Hyde KD, McKenzie EH, Peberdy JF et al. 2010 - Can leaf degrading enzymes provide evidence that endophytic fungi becoming saprobes?. Fungal Diversity 41, 89-99.

Pujade-Renaud V, Déon M, Gazis R, Ribeiro S et al. 2019 - Endophytes from wild rubber trees as antagonists of the pathogen Corynespora cassiicola. Phytopathology 109(11), 1888-1899.

Quaedvlieg W, Binder M, Groenewald JZ, Summerell BA et al. 2014 - Introducing the consolidated species concept to resolve species in the Teratosphaeriaceae. Persoonia: Molecular Phylogeny and Evolution of Fungi 33, 1-40.

Rambaut A. 2012 - FigTree version 1.4.0. Available at, http://tree.bio.ed.ac.uk/software/figtree (Accessed on June 1, 2020).

Ramos-García B, Shagarodsky T, Sandoval-Denis M, Ortiz Y et al. 2016 - Morphology and phylogeny of Cladosporium subuliforme, causing yellow leaf spot of pepper in Cuba. Mycotaxon 131(3), 693-702.

Rashmi M, Kushveer JS, Sarma VV. 2019 - A worldwide list of endophytic fungi with notes on ecology and diversity. Mycosphere 10, 798-1079. 
Raza M, Zhang ZF, Hyde KD, Diao YZ et al. 2019 - Culturable plant pathogenic fungi associated with sugarcane in southern China. Fungal Diversity 99(1), 1-104.

Rehner SA. 2001 - Primers for elongation factor 1-alpha (EF1-alpha). http://ocid.nacse.org/ research/deephyphae/EF1primer.pdf.

Rodrigues KF. 1994 - The foliar fungal endophytes of the Amazonian palm Euterpe oleracea. Mycologia 86, 376-385.

Rodriguez RJ, White JF, Arnold AE, Redman RS. 2009 - Fungal endophytes: diversity and functional roles. New Phytologist 182, 314-330.

Rossman AY, Crous PW, Hyde KD, Hawksworth DL et al. 2015 - Recommended names for pleomorphic genera in Dothideomycetes. IMA Fungus 6, 507-523.

Rungjindamai N, Pinruan U, Choeyklin R, Hattori T et al. 2008 - Molecular characterization of basidiomycetous endophytes isolated from leaves, rachis and petioles of the oil palm, Elaeis guineensis Thailand. Fungal Diversity 33, 139-161.

Saccardo PA. 1880 - Fungi Gallici lecti a cl. viris P. Brunaud, Abb. Letendre, A. Malbranche, J. Therry, vel editi in Mycotheca Gallica C. Roumeguèri. Series II. Michelia 2(6), 39-135.

Saccardo PA. 1931 - Sylloge Fungorum XXV: 572.

Sandoval-Denis M, Gené J, Sutton DA, Wiederhold NP et al. 2016 - New species of Cladosporium associated with human and animal infections. Persoonia: Molecular Phylogeny and Evolution of Fungi 36, 281-298.

Santangelo JS, Turley NE, Johnson MT. 2015 - Fungal endophytes of Festuca rubra increase in frequency following longterm exclusion of rabbits. Botany 93(4), 233-241.

Schubert K, Groenewald JZ, Braun U, Dijksterhuis J et al. 2007 - Biodiversity in the Cladosporium herbarum complex (Davidiellaceae, Capnodiales), with standardisation of methods for Cladosporium taxonomy and diagnostics. Studies in Mycology 58, 105-156.

Schulz B, Haas S, Junker C, Andree N et al. 2015 - Fungal endophytes are involved in multiple balanced antagonisms. Current Science 109, 39-45.

Seifert K, Morgan-Jones G, Gams W, Kendrick B. 2011 - The genera of hyphomycetes. CBS Biodiversity Series no. 9: 1-997. CBS-KNAW Fungal Biodiversity Centre, Utrecht, Netherlands.

Senanayake IC, Crous PW, Groenewald JZ, Maharachchikumbura SS et al. 2017 - Families of diaporthales based on morphological and phylogenetic evidence. Studies in Mycology 86, 217-296.

Senanayake IC, Jeewon R, Chomnunti P, Wanasinghe DN et al. 2018 - Taxonomic circumscription of Diaporthales based on multigene phylogeny and morphology. Fungal Diversity 93, 241443.

Silvestro D, Michalak I. 2012 - raxmlGUI: a graphical front-end for RAxML. Organisms Diversity \& Evolution 12(4), 335-337.

Sivanesan A. 1996 - Corynesporasca caryotae gen. et sp. nov. with a Corynespora anamorph, and the family Corynesporascaceae. Mycological Research 100, 783-788.

Song Y, Maharachchikumbura SS, Jiang YL, Hyde KD et al. 2014a - Pestalotiopsis keteleeria sp. nov., isolated from Keteleeria pubescens in China. Chiang Mai Jornal of Science 41(4), 885893.

Song Y, Tangthirasunun N, Maharachchikumbura SS, Jiang Y et al. 2014b - Novel Pestalotiopsis species from Thailand point to the rich undiscovered diversity of this chemically creative genus. Cryptogamie Mycologie 35(2), 139-149.

Steyaert RL. 1949 - Contributions etude monographique de Pestalotia de Not. et Monochaetia Sacc. (Truncatella gen. nov. et Pestalotiopsis gen. nov.). Bull JardinBotanique de l'EtatBruxelles 19, 285-354.

Suryanarayanan TS, Rajulu G, Vidal S. 2016 - Biological Control through fungal endophytes: Gaps in knowledge hindering success. Current Biotechnology 5, 1-13.

Swofford DL. 2002 - PAUP: phylogenetic analysis using parsimony, version 4.0 b10. Sinauer Associates, Sunderland. 
Tao G, Liu ZY, Hyde KD, Lui XZ et al. 2008 - Whole rDNA analysis reveals novel and endophytic fungi in Bletilla ochracea Orchidaceae. Fungal Diversity 331, 101-112.

Templeton AR, Crandall KA, Sing CF. 1992 - A cladistic analysis of phenotypic associations with haplotypes inferred from restriction endonuclease mapping and DNA sequence data. III. Cladogram estimation. Genetics 132, 619-633.

Tennakoon DS, Thambugala KM, De Silva NI, Kuo CH et al. 2019 - Leaf litter saprobic Didymellaceae (Dothideomycetes): Leptosphaerulina longiflori sp., nov. and Didymella sinensis, a new record from Roystonea regia. Asian Journal of Mycology 2(1), 87-100.

Thambugala KM, Wanasinghe DN, Phillips AJL, Camporesi E et al. 2017 - Mycosphere notes 150: grass (Poaceae) inhabiting Dothideomycetes. Mycosphere 8(4), 697-796.

Tibpromma S, Hyde KD, Bhat JD, Mortimer PE et al. 2018a - Identification of endophytic fungi from leaves of Pandanaceae based on their morphotypes and DNA sequence data from southern Thailand. MycoKeys (33), 25-67.

Tibpromma S, Hyde KD, McKenzie EHC, Bhat DJ et al. 2018b - Fungal diversity notes 840-928: micro-fungi associated with Pandanaceae. Fungal Diversity 93, 1-160.

Tibpromma S, Mortimer PE, Karunarathna SC, Zhan F et al. 2019 - Morphology and multi-gene phylogeny reveal Pestalotiopsis pinicola sp. nov. and a new host record of Cladosporium anthropophilum from edible pine (Pinus armandii) seeds in Yunnan province, China. Pathogens 8(4), 285-303.

Tsai I, Maharachchikumbura SS, Hyde KD, Ariyawansa HA. 2018 - Molecular phylogeny, morphology and pathogenicity of Pseudopestalotiopsis species on Ixora in Taiwan. Mycological Progress 17, 941-952.

U'Ren JM, Lutzoni F, Miadlikowska J, Laetsch AD et al. 2012 - Host and geographic structure of endophytic and endolichenic fungi at a continental scale. American Journal of Botany 99(5), 898-914.

Udayanga D, Castlebury LA, Rossman AY, Chukeatirote E et al. 2014b - Insights into the genus Diaporthe: phylogenetic species delimitation in the D. eres species complex. Fungal Diversity 67, 203-229.

Udayanga D, Castlebury LA, Rossman AY, Chukeatirote E et al. 2015 - The Diaporthe sojae species complex: Phylogenetic re-assessment of pathogens associated with soybean, cucurbits and other field crops. Fungal Biology 119(5), 383-407.

Udayanga D, Castlebury LA, Rossman AY, Hyde KD. 2014a - Species limits in Diaporthe: molecular re-assessment of $D$. citri, D. cytosporella, D. foeniculina and D. rudis. Persoonia: Molecular Phylogeny and Evolution of Fungi 32, 83-101.

Udayanga D, Liu X, McKenzie EHC, Chukeatirote E, Bahkali AHA et al. 2011 - The genus Phomopsis: biology, applications, species concepts and names of common phytopathogens. Fungal Diversity 50, 189-225.

Uzor PF, Ebrahim W, Osadebe PO, Nwodo JN et al. 2015 - Metabolites from Combretum dolichopetalum and its associated endophytic fungus Nigrospora oryzae - evidence for a metabolic partnership. Fitoterapia 105, 147-150.

Vilgalys R, Hester M. 1990 - Rapid genetic identification and mapping of enzymatically amplified ribosomal DNA from several Cryptococcus species. Journal of Bacteriology 172, 4238-4246.

Voglmayr H, Jaklitsch WM. 2014 - Stilbosporaceae resurrected: generic reclassification and speciation. Persoonia 33, 61-82.

Voglmayr H, Jaklitsch WM. 2017 - Corynespora, Exosporium and Helminthosporium revisitednew species and generic reclassification. Studies in Mycology 87, 43-76.

Von Höhnel FXR. 1917 - Über die Benennung Stellung und Nebenfruchtformen von Sphaerella Fries. Berichte der Deutschen Botanischen Gesellschaft 35, 627-631.

Walker C, Muniz M, Martins RDO, Rabuske J et al. 2018 - Susceptibility of Pecan cultivars to Cladosporium cladosporioides species complex. Floresta e Ambiente 25(4), 2-7. 
Walther BA, Moore JL. 2005 - The concepts of bias, precision and accuracy, and their use in testing the performance of species richness estimators, with a literature review of estimator performance. Ecography 28, 815-829.

Wanasinghe DN, Jones EBG, Camporesi E, Dissanayake AJ et al. 2016 - Taxonomy and phylogeny of Laburnicola gen. nov. and Paramassariosphaeria gen. nov. (Didymosphaeriaceae, Massarineae, Pleosporales). Fungal Biology 120(11), 1354-1373.

Wang B, Chen G, Li C, Sun W. 2017a - Floral characteristics and pollination ecology of Manglietia ventii (Magnoliaceae), a plant species with extremely small populations (PSESP) endemic to South Yunnan of China. Plant Diversity 39(1), 52-59.

Wang M, Liu F, Crous PW, Cai L. 2017b - Phylogenetic reassessment of Nigrospora: ubiquitous endophytes, plant and human pathogens. Persoonia: Molecular Phylogeny and Evolution of Fungi 39, 118-142.

Wang Q, Liu X, Ma H, Shen X et al. 2019 - Colletotrichum yulongense sp. nov. and C. rhombiforme isolated as endophytes from Vaccinium dunalianum var. urophyllum in China. Phytotaxa 394(4), 285-298.

Wang YC, Hao XY, Wang L, Xiao B et al. 2016 - Diverse Colletotrichum species cause anthracnose of tea plants (Camellia sinensis (L.) O. Kuntze) in China. Scientific Reports 6, 113.

Wang YU, Guo LD, Hyde KD. 2005 - Taxonomic placement of sterile morphotypes of endophytic fungi from Pinus tabulaeformis (Pinaceae) in northeast China based on rDNA sequences. Fungal Diversity 20, 235-260.

Webster J. 1952 - Spore projection in the hyphomycete Nigrospora sphaerica. New Phytology 51, 229-235.

Wehmeyer LE. 1975 - The Pyrenomycetous Fungi. Mycologia Memoirs 6, 1-250.

Weir BS, Johnston PR, Damm U. 2012 - The Colletotrichum gloeosporioides species complex. Studies in Mycology 73, 115-180.

White TJ, Bruns T, Lee S, Taylor J. 1990 - Amplification and direct sequencing of fungal ribosomal RNA genes for phylogenetics. In: Innis MA, Gelfand DH, Sninsky JJ, White TJ (Eds) PCR protocols: a guide to methods and applications. Academic Press, San Diego, 18(1), 315-322.

Wright ER, Folgado M, Rivera MC, Crelier A et al. 2008 - Nigrospora sphaerica causing leaf spot and twig and shoot blight on blueberry: a new host of the pathogen. Plant Disease 92, 171181.

Wijayawardene NN, Hyde KD, Al-Ani LKT, Tedersoo L et al. 2020 - Outline of Fungi and fungus like taxa. Mycosphere 11, 1060-1456.

Yamada KD, Tomii K, Katoh K. 2016 - Application of the MAFFT sequence alignment program to large data-reexamination of the usefulness of chained guide trees. Bioinformatics 32, 3246-3251.

Yang Y, Cai L, Yu Z, Liu Z et al. 2011 - Colletotrichum species on Orchidaceae in southwest China. Cryptogamie Mycologie 32, 229-253.

Zhang Y, Crous PW, Schoch CL, Hyde KD. 2012 - Pleosporales. Fungal Diversity 52, 1-225.

Zhang Q, Gong M, Yuan J, Hou Y et al. 2017 - Dark septate endophyte improves drought tolerance in sorghum. International Journal of Agriculture \& Biology 19, 53-60.

Zheng YK, Qiao XG, Miao CP, Liu K et al. 2016 - Diversity, distribution and biotechnological potential of endophytic fungi. Annals of Microbiology 66(2), 529-542.

Zimmerman NB, Vitousek PM. 2012 - Fungal endophyte communities reflect environmental structuring across a Hawaiian landscape. Proceedings of the National Academy of Sciences 109, 13022-13027.

Zhu GS, Yu ZN, Gui Y, Liu ZY. 2008 - A novel technique for isolating orchid mycorrhizal fungi. Fungal Diversity 33, 123-137. 